\title{
Baseline household survey: Khanewal district
}

Pakistan Initiative for Mothers and Newborns (PAIMAN)

Follow this and additional works at: https://knowledgecommons.popcouncil.org/departments_sbsr-rh

Part of the Family, Life Course, and Society Commons, and the Maternal and Child Health Commons How does access to this work benefit you? Let us know!

\section{Recommended Citation}

Pakistan Initiative for Mothers and Newborns (PAIMAN). 2006. "Baseline household survey: Khanewal district." Islamabad: Population Council. 




\section{Baseline Household Survey Khanewal DISTRICT}





\section{Pakistan Initiative for Mothers and Newborns (PAIMAN)}

\section{Khanewal \\ Baseline Household Survey}




\section{(1) Population Council}

The Population Council, an international, non-profit, non-governmental organization established in 1952, seeks to improve the well-being and reproductive health of current and future generations around the world and to help achieve a humane, equitable, and sustainable balance between people and resources.

The Council analyzes population issues and trends; conducts research in the reproductive sciences; develops new contraceptives; works with public and private agencies to improve the quality and outreach of family planning and reproductive health services; helps governments design and implement effective population policies; communicates the results of research in the population field to diverse audiences; and helps strengthen professional resources in developing countries through collaborative research and programs, technical exchanges, awards, and fellowships.

\section{For inquiries, please contact:}

Population Council

\#7, Street 62, F-6/3, Islamabad, Pakistan

Tel: 92512277439

Fax: 92512821401

Email: info@pcpak.org

web: http://www.popcouncil.org

Layout \& Design : Ali Ammad

Printed by: Crystal Printers, Islamabad

Disclaimer:

"This study/report is made possible by the generous support of the American people through the United States Agency for International Development (USAID). The contents are the responsibility of JSI Research \& Training Institute, Inc. and do not necessarily reflect the views of USAID or the United States Government." 


\section{Contents}

Contents

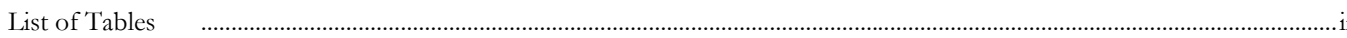

List of Figures

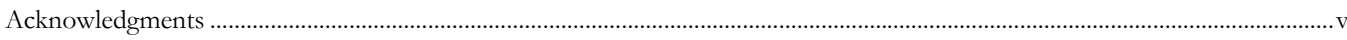

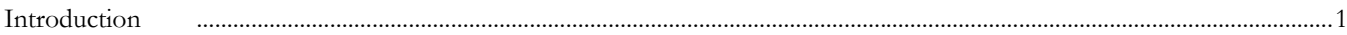

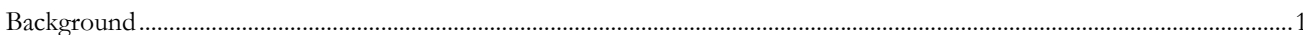

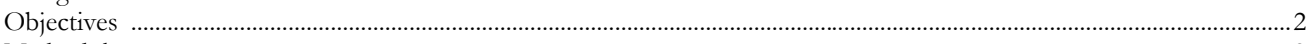

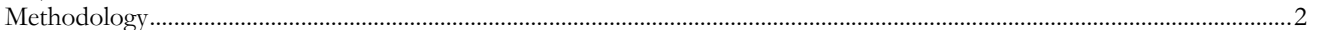

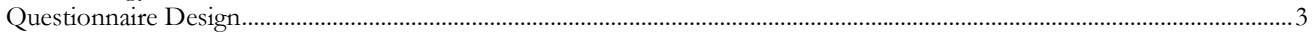

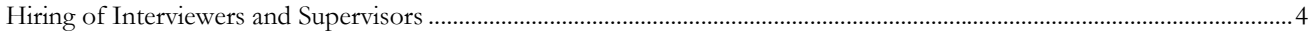

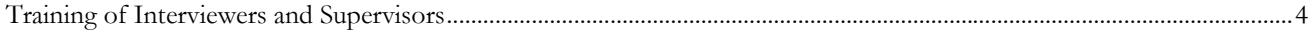

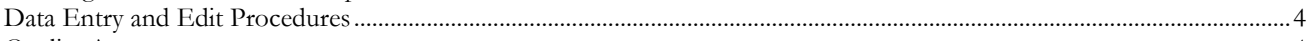

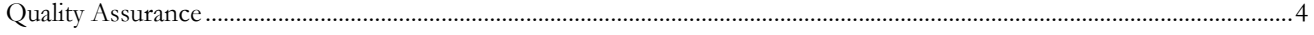

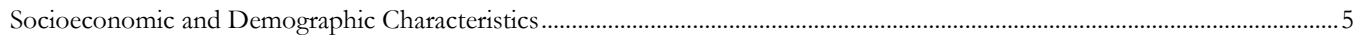

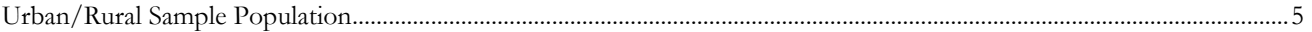

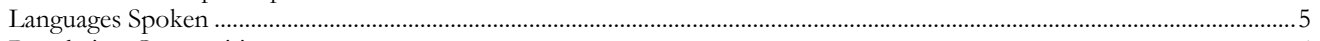

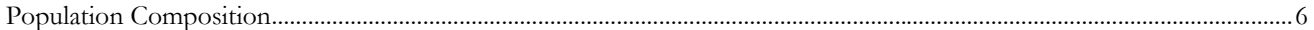







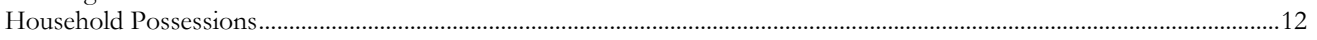



Background Characteristics of Married Women of Reproductive Age ….............................................................................15

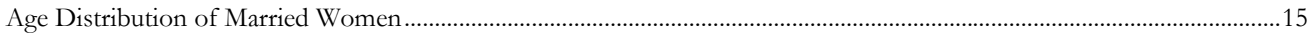

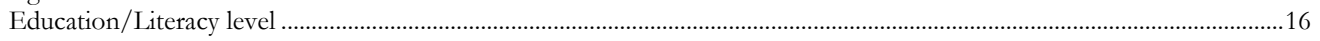

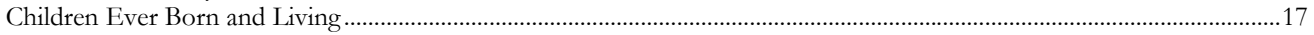







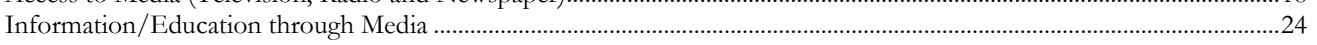

Knowledge of Safe Motherhood, Birth Preparedness and Community Resources ...............................................................25

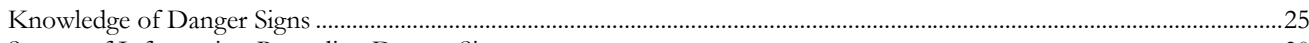



Attitudes Towards Pregnancy, Delivery and the Postpartum period ......................................................................................33



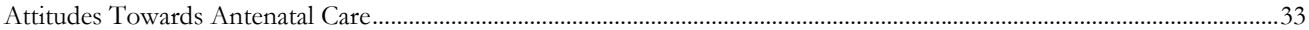





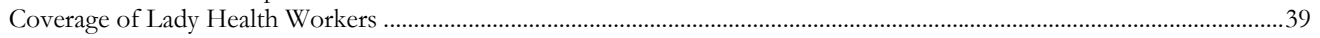

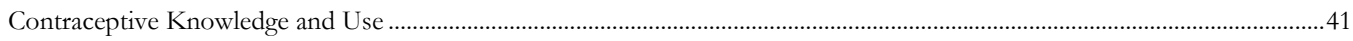





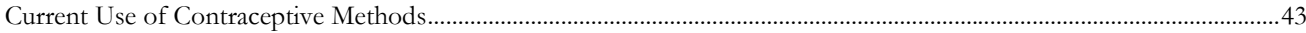

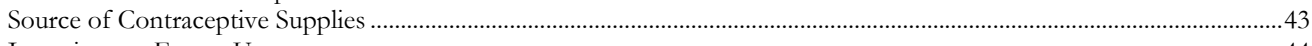

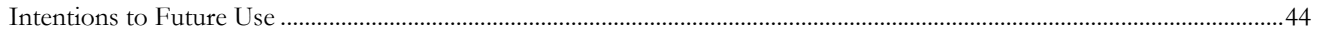



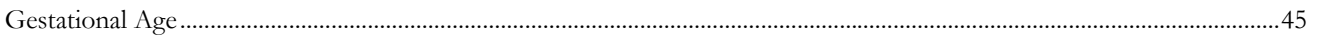

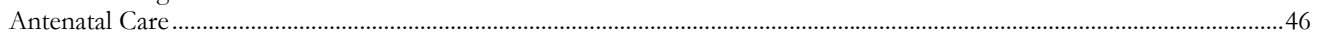

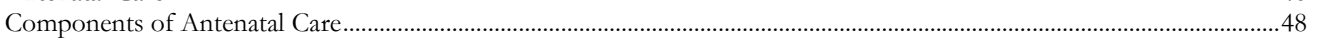

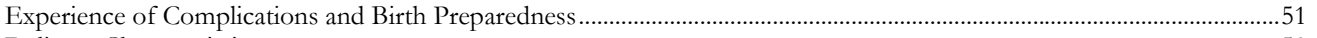



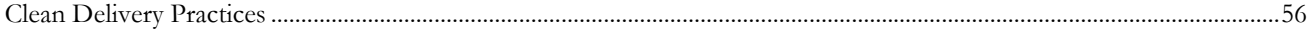

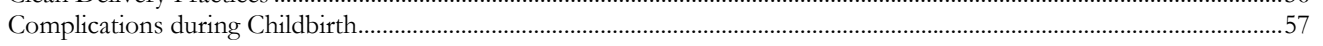

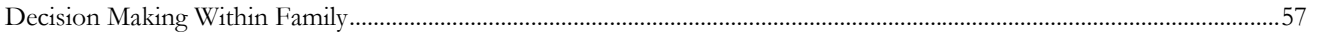

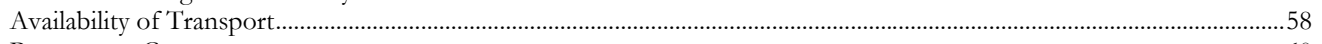



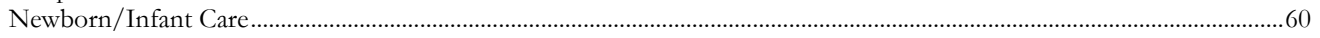

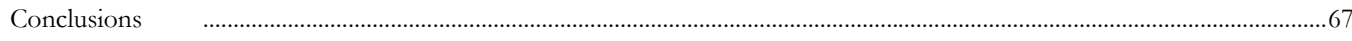

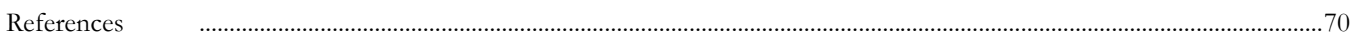




\section{List of Tables}

Table 1.1: Number of blocks/villages and households selected for the sample population.......... 2

Table 2.1: Language mostly spoken in the households by place of residence.................................. 5

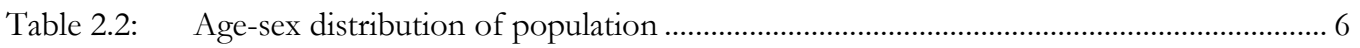

Table 2.3: $\quad$ Household population by age (15 years and above), sex and marital status................... 7

Table 2.4: Household population by age (10 years and above), sex and educational level............. 8

Table 2.5: $\quad$ Main source of drinking water by place of residence ....................................................... 9

Table 2.6: Type of toilet facility used by household members and place of residence................... 10

Table 2.7: $\quad$ Main type of fuel used in the HH for cooking by place of residence ........................... 10

Table 2.8: Number of rooms used for sleeping by place of residence .......................................... 11

Table 2.9: Ownership of household commodities/land by place of residence .............................. 12

Table 2.10: Status of house by place of residence ................................................................................ 13

Table 3.1: Current age and age at marriage by place of residence.................................................... 15

Table 3.2: $\quad$ Education and literacy level of respondents and their husbands ................................. 17

Table 3.3: Percentage distribution of married women by number of children ever born, mean number of children ever born, living children and age group compared to the 1998 Population Census.................................................................................................... 17

Table 3.4: Percentage distribution of married women by length of preceding birth interval....... 18

Table 3.5: $\quad$ Place where respondent usually watches television by place of residence.................... 20

Table 3.6: Frequency of watching television ................................................................................ 21

Table 3.7: Frequency of listening to the radio by place of residence............................................... 22

Table 3.8: Place where respondent listens to the radio by place of residence............................... 22

Table 4.1: Knowledge of existence and importance of transport, blood and finances by the community at the time of delivery by place of residence ................................................ 32

Table 5.1: Believe in necessity of antenatal check-up by place of residence.................................. 33

Table 5.2: $\quad$ Month of the pregnancy when women should go for antenatal care by place of

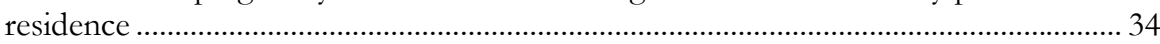

Table 5.3: $\quad$ Number of antenatal visits by place of residence............................................................ 35

Table 5.4: Believe that women should receive delivery services from health professional by

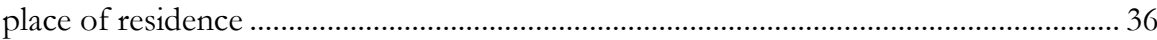

Table 5.5: Person women believe should take charge of the pregnant women by place of residence 37

Table 5.6: $\quad$ Belief in necessity of postnatal care by place of residence .............................................. 38

Table 5.7: $\quad$ Presence of lady health worker in the community by place of residence ..................... 39

Table 5.8: $\quad$ LHW ever visited home during last three months by place of residence .................... 39

Table 6.1: $\quad$ Ever used FP methods by contraceptive and place of residence................................... 42

Table 6.2: $\quad$ Current use of FP methods by contraceptive and place of residence ........................... 43

Table 6.3: $\quad$ Source of FP method by place of residence …............................................................ 44

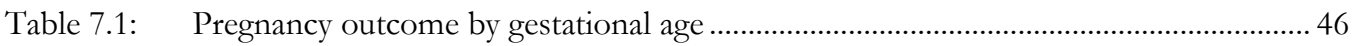

Table 7.3: Status of last delivery by place of residence ..................................................................... 53

Table 7.4: $\quad$ Experienced complications during last delivery by Place of Residence........................ 57

Table 7.5: $\quad$ Measures taken to address complications by place of residence.................................... 58 
Table 7.6: History of postpartum care by place of residence 60

Table 7.7: History of last child care by place of residence

\section{List of Figures}

Figure 2.1: $\quad$ Languages spoken by place of residence ....................................................................... 6

Figure 2.2: $\quad$ Material used for construction of roof by place of residence........................................ 11

Figure 3.1: Age distribution by place of residence......................................................................... 16

Figure 3.2: $\quad$ Exposure to mass media (Radio, television or Newspaper) .......................................... 19

Figure 3.3: $\quad$ Most trustworthy media by place of residence .................................................................. 19

Figure 3.4: Percentage of women who watch television or listen radio by place of residence ...... 20

Figure 3.5: Influence of television programs on health behaviors of people by place of

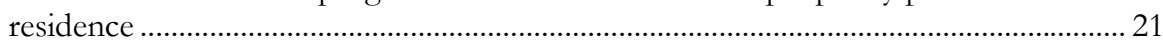

Figure 3.6: Influence of radio on health behaviors by place of residence ...................................... 23

Figure 3.7: Frequency of reading newspaper by place of residence.............................................. 23

Figure 3.8: Percentage of married women who had heard/read maternal and newborn messages during the last 3 months by place of residence ............................................. 24

Figure 4.1: Knowledge of danger signs during pregnancy, which require medical attention ........ 26

Figure 4.2: $\quad$ Percentage of married women by status of knowledge of danger signs during pregnancy by place of residence ...................................................................................... 26

Figure 4.3: Distribution of respondents who had knowledge about complications during

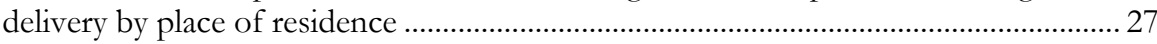

Figure 4.4: Percentage of married women by status of knowledge of danger signs during delivery and place of residence ..................................................................................... 28

Figure 4.5: Percentage of married women who had knowledge about danger signs during postpartum period.

Figure 4.6: Percentage of married women by status of knowledge of danger signs during postpartum period and place of residence.

Figure 4.7: Percentage of married women by status of knowledge of danger signs in newborn and place of residence

Figure 4.8: Distribution of respondents who had knowledge about danger signs in newborns by place of residence..... 30

Figure 4.9: Source of information about pregnancy by place of residence 31

Figure 5.1: Percentage of married women who received TT shots and took iron/folate during pregnancy by place of residence.

Figure 5.2: Percentage of women who thought the women in their community went for skilled birth attendance for their delivery by place of residence ................................................ 36

Figure 5.3: Percentage of women by their perception where should delivery take place............... 37

Figure 5.4: Percentage of married women by mode of transport they would use to reach ........... 38

Figure 5.5: Number of postnatal care visits women should have in the community by place of residence

Figure 6.1: Percentage of married women by knowledge of specific contraceptive method -

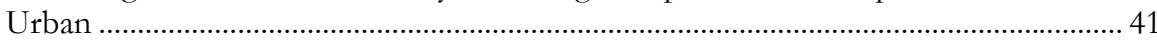

Figure 6.2: Percentage of married women by knowledge of specific contraceptive method -

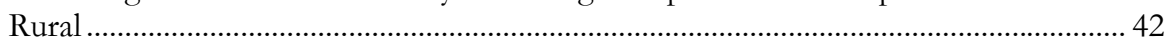

Figure 6.3: $\quad$ Percentage of married women by future intention to use contraceptives ................... 44 
Figure 7.1: Percentage of pregnant women by their antenatal care status for the pregnancy three years preceding the baseline survey

Figure 7.2: Percentage distribution of married women by persons who accompanied them to seek antenatal care

Figure 7.3: $\quad$ Services performed/asked during antenatal check-up by place of residence............. 49

Figure 7.4: Percentage of pregnant women by issues discussed during antenatal check-up and place of residence

Figure 7.5: Percentage of married women by status of TT Injections during the last pregnancy and place of residence

Figure 7.6: Percentage of married women by status of Iron/Folate tablets during the last pregnancy and place of residence.....

Figure 7.7: Percentage of married women who experienced complications during their last pregnancy .52

Figure 7.8: Percentage of married women who made arrangements for their last delivery by place of resident .53

Figure 7.9: $\quad$ Percentage of pregnancies by outcome and place of residence ................................... 54

Figure 7.10: Percentage of women by place of delivery ..................................................................... 54

Figure 7.11: Percentage of married women by delivery attendant................................................... 55

Figure 7.12: Main reason to choose a dai as delivery attendant ......................................................... 55

Figure 7.13: Percentage of delivery attendants who reported washed hands before conducting the delivery and type of thread used to tie the cord ........................................................ 56

Figure 7.14: Percentage of delivery attendants who reported instruments for cutting the cord ..... 56

Figure: 7.15: Time taken to reach the health facility for childbirth ....................................................5 59

Figure 7.16: Median time taken to find the transport, reach the hospital and obtain services ........ 59

Figure 7.17: Percentage of live births by their size (small, normal and big) at birth ........................ 61

Figure 7.18: Percentage of babies by time of given bath after birth................................................. 62

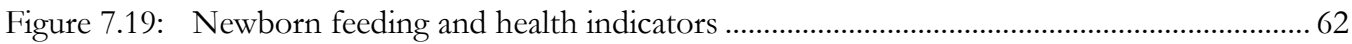

Figure 7.20: Percentage of newborns with appeared signs/symptoms soon after deliver by place of residence

Figure 7.21: Percentage of newborns with appeared signs/symptoms within 7-days after last delivery by place of residence

Figure 7.22: Percentage of newborn with measures taken to have complications treated by place of residence

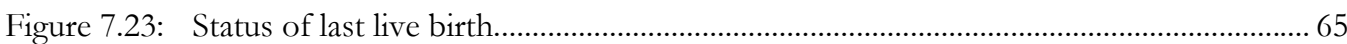




\section{Acknowledgments}

The PAIMAN Baseline Household Survey is a collaborative effort involving many partners, and will be the foundation of the PAIMAN project as a whole. Firstly, we would like to acknowledge our major partners. The United States Agency for International Development (USAID), in particular Mr. Chris McDermott, made funding available for this activity. Dr. Nabeela Ali, Chief of Party for PAIMAN, encouraged the study in general, and greatly facilitated the partnership between the Population Council and NIPS. The role of NIPS was supported under a separate agreement with PAIMAN. The comments, suggestions and feedback received from PAIMAN partners with regard to the design of this activity greatly contributed towards the success of the household survey.

The National Institute of Population Studies (NIPS) ably carried out the fieldwork for this study and was responsible for the completion of a clean dataset. We would like to appreciate the efforts of the Executive Director, Dr. Saeed Shafqat; and the Director Mr. Mahboob Sultan for the timely execution of the fieldwork; Computer Programmer, Mr. Fateh-ud-din, who managed the entry and cleaning of the data, and the numerous NIPS staff members who carried out the study.

The Population Council was primarily responsible for designing the study, overseeing the data collection, analysis of data, and writing the reports. Dr. Arshad Mahmood, Director of Monitoring and Evaluation for PAIMAN, used his capable technical and managerial skills to oversee the entire study with enthusiasm and energy. Mr. Peter Miller, Deputy Country Director, contributed substantially in the design phase, and Dr. Zeba Sathar and Mr. Miller contributed towards the report preparation.

The essential work of the study was carried out by several Council staff members at all phases. During the design and pre-testing phases, we would particularly like to acknowledge Shagufta Naheed, Bushra Bano, Tayyaba Gul, and Saima Pervaiz for monitoring fieldwork and ensuring quality data collection in the field. Muhammad Ashraf and Saman Naz assisted in preparing graphs and tables as well as with the writing process. Dr. Arshad Mahmood and Reem Khan jointly prepared the first draft of the baseline survey report, which served as the template for all ten district reports. Shafique Arif, Azeema Faizunisa and Nadia Abid also contributed to the report writing and reviewing process. Reem Khan completed the initial editing of the baseline reports, Mehdi Ali Khan designed the layout, Ali Ammad was responsible for the formatting, and Ms. Mary DeSouza carried out the final proofreading of the reports.

Finally, we must express our gratitude to the women of Khanewal, who gave their time freely and cooperated with us in order to make this study possible. We hope to repay them by using the information obtained from them to improve maternal and neonatal health services in the district of Khanewal. 



\section{Introduction}

\section{Background}

The Pakistan Initiative for Mothers and Newborns (PAIMAN) is a five-year project funded by the United States Agency for International Development (USAID). PAIMAN is committed to assisting the Government of Pakistan (GoP) in its attempt to implement the full spectrum of interventions necessary to address maternal and neonatal health $(\mathrm{MNH})$ issues.

The consortium is led by John Snow Incorporated (JSI), with partners from Pakistani and international organizations including Aga Khan University, Contech, Greenstar Social Marketing, Johns Hopkins University Center for Communication Program (JHU), PAVHNA, Population Council and Save the Children USA.

USAID has provided a grant to implement PAIMAN in 10 districts of Pakistan's four provinces. These districts are: Rawalpindi, Jhelum, Khanewal, and DG Khan in Punjab; Dadu and Sukkur in Sindh; Jafarabad and Lasbela in Balochistan; and Upper Dir and Buner in the North West Frontier Province. The goal of the project is to reduce maternal, newborn and child mortality in Pakistan. The project is based on the "Pathway to Care and Survival" framework. The five major strategic objectives are to:

1) Increase awareness and promote positive maternal and neonatal health behaviors

2) Increase access (including essential obstetric care) to and community involvement in maternal and child health services, while ensuring that services are successfully delivered through health and ancillary health services

3) Improve service quality in both the public and private sectors, particularly related to the management of obstetrical complications

4) Increase the capacity of Maternal and Newborn Health $(\mathrm{MNH})$ managers and care providers

5) Improve the management and integration of services at all levels

The PAIMAN Project will promote skilled attendants as the long-term goal for all deliveries in Pakistan while acknowledging that maternal and neonatal health outcomes are influenced by factors other than health care. The PAIMAN Project calls for a multi-pronged and integrated strategic approach combining individual health care with public health and community-based interventions. 
To ensure that the success of PAIMAN is properly attained and that the appropriate lessons are learned, PAIMAN has developed a Monitoring and Evaluation Plan. Included in this plan is the establishment of baseline measures for a set of indicators which will be used to evaluate the success of the project. This baseline report explores the level of knowledge of, as well as the attitudes and behaviors towards, maternal and newborn health in the Khanewal district. The specific objectives of the baseline survey were as follows:

\section{Objectives}

- To measure the Intermediate Result 7 indicators necessary as part of PAIMAN's obligation to USAID.

- To measure PAIMAN indicators for which household survey data are appropriate for measurement and for which sample sizes are feasible.

- To obtain information on maternal and neonatal health along with related issues, which may be of use to district Departments of Health for health management purposes.

- To obtain information needed for the detailed design of the PAIMAN project and, in particular, behavior change communication, public/private partnerships and health systems strengthening.

\section{Methodology}

\section{Study Population}

PAIMAN is primarily a district-level project, intended to improve the health of all pregnant women, women with neonatal children, as well as all neonates of the district over the course of the project. To this end, the study covers community residents - notably mothers and prospective mothers - in order to understand and measure general knowledge and practice in relation to pregnancy, delivery, obstetric and neonatal emergencies etc.

Hence, the study population for the baseline includes all currently married women of reproductive age (15-49 years) living in the selected districts. More specifically, it includes women who have experienced a pregnancy during the last three years.

\section{Sample Design}

The sampling design adopted for the survey is a stratified, systematic sample of households. The universe consists of all urban and rural areas of the district. The number of blocks selected in urban areas, along with the number of villages selected in rural areas, are presented in table 1.1. The selection procedure is described below:

Table 1.1: Number of blocks/villages and households selected for the sample population

\begin{tabular}{lcrc} 
& Area & $\begin{array}{c}\text { Number of Sample } \\
\text { Blocks/Villages }\end{array}$ & \multicolumn{2}{c}{$\begin{array}{c}\text { Number of Households } \\
\text { Selected }\end{array}$} \\
\hline Urban & & 7 & 168 \\
\hline Rural & & 38 & 792 \\
Total & 40 & 960
\end{tabular}




\section{Urban Sample}

The "Enumeration Circle" was the smallest unit available in the 1998 Population District Census Reports as demarcated by the Population Census organizations. The required numbers of enumeration blocks were selected with probability proportional to size. The maps of these circles were obtained from the Population Census Organization. The areas were already divided into blocks of approximately 250-300 households depending on the number of households in each circle. Later, blocks were randomly selected with probability proportional to size from the list of total blocks in that circle. The listing of each block was then updated by the enumeration teams before selecting the sampled households. A fixed number of 24 households has been drawn from each sample enumeration block by using systematic random technique.

\section{Rural Sample}

The 1998 Population Census list of villages was used as the sampling frame for the selection of the rural sample. Villages in rural areas have been treated as primary sampling units (PSU). Sample PSUs have been selected with probability proportional to size (number of households). Households within the sample PSUs were considered secondary sampling units. The enumeration teams then updated the listing of each village before selecting the sampled households. A fixed number of 24 households has been drawn from each sample enumeration village by the systematic random technique.

\section{Questionnaire Design}

The questionnaire has been developed by the Population Council based on a combination of current general Demographic and Health Survey methodologies and the questionnaire developed by the Population Council for the Safe Motherhood Applied Research and Training (SMART) Project. The questionnaires contain data sufficient to estimate all PAIMAN indicators.

Information on the following is included in the questionnaire:

- Households information

- Socio-economic status of women

- Fertility, pregnancy history and reproductive intentions

- Attitude towards, as well as knowledge and practice of, contraceptive methods

- Attitude towards pregnancy, delivery and the postpartum period

- Current birth preparedness/complications readiness (BP/CR) and knowledge of newborn care

- Current birth practices

- Health-seeking behaviors

- Future BP/CR intentions

- Personal beliefs regarding pregnancy, delivery and the postpartum period

- Common perceptions pertaining to women who are pregnant, delivering or in their postpartum period

- Facilities regarding BP/CR available in the community

- Factors that facilitate or hinder behaviors related to BP/CR

- Media habits 


\section{Pre-testing of Questionnaire}

The questionnaire was reviewed by the PAIMAN's M\&E thematic group and other interested stakeholders and was pre-tested in non-PAIMAN districts. The main objective of pre-testing was to examine the suitability and effectiveness of questions in eliciting adequate responses and to find out if there were any linguistic problems faced either by interviewers or by respondents.

Finally, the pre-testing also helped determine the approximate time required to complete a questionnaire. The pre-tests were carried out by the Population Council's female staff members who recorded their experiences with regard to each question. These records were then used to revise and finalize the questionnaire.

\section{Hiring of Interviewers and Supervisors}

Since the respondents in the baseline were to be MWRA and married men, it was decided that female interviewers would be used to interview women and male interviewers for men. Based on the constitution of each team, the required number of female interviewers were hired by the National Institute of Population Studies (NIPS) according to its own internal procedures.

\section{Training of Interviewers and Supervisors}

The quality of training received by interviewers is reflected in the quality of data they record. In order to ensure that interviews were of a high and uniform quality and that interviewers understood the definitions and concepts behind the language of the questions, training was conducted by the Population Council in collaboration with NIPS. The training took place in Islamabad over two weeks and interviewers were schooled in questionnaire and survey procedures. Interviewers visited 3-4 households to conduct practice interviews.

It was very important for the interviewers to thoroughly understand the methodology and statistical importance of the sampled households. Training regarding the importance of the criterion for the selection of primary sampling units, mapping and listing procedure, sample selection, field operation procedures, as well as the selection of the particular households and respondents was also provided by experts.

\section{Data Entry and Edit Procedures}

Data processing was started from the field level with the checking of the questionnaires. Each team leader completed on-the-spot checks and preliminary editing of questionnaires during the enumeration period. Editing instructions were provided to the team leaders and emphasis was laid on the importance of completing each questionnaire, correctly identifying each eligible respondent and the completeness of household composition.

\section{Quality Assurance}

To ensure the quality of the data, Population Council staff monitored the fieldwork accompanying the field teams. While supervising the fieldwork, the Population Council supervisory staff was also available to provide on-the-spot guidance to interviewers in the event that any part of the questionnaire was unclear to them. This ensured the completeness and accuracy of each questionnaire. 


\section{Socioeconomic and Demographic Characteristics}

This chapter presents the demographic and socioeconomic characteristics of the population in the survey households of Khanewal. Information was collected on some demographic and socioeconomic characteristics such as the condition of the households, including the source of drinking water, sanitation facilities, building materials, and possession of household durable goods. This information on the characteristics of the households is essential for the interpretation of survey findings. The definition of the household used for the baseline survey was "a person or a group of persons, related or unrelated, who live together in the same dwelling unit and share a common source of food".

\section{Urban/Rural Sample Population}

As mentioned in the previous section, a representative sample of 960 households was selected in Khanewal. This included 792 households from rural areas and 168 from urban areas. There was only one household which refused to provide information. Therefore the response rate was 99.9 percent for Khanewal.

\section{Languages Spoken}

An overall picture of the ethnic and linguistic makeup of the district becomes possible by determining the languages spoken in the households. About 63 percent of the population of Khanewal speaks Punjabi followed by 26 percent who are Saraiki speakers, the second most common language of the area. It is important to note that a majority of the women (62.5 percent) speak Punjabi in rural areas. Other languages spoken are Urdu (8.6 percent), Pushto (1.5 percent), Hindko (0.4 percent), as well as Balochi and Sindhi (0.1 percent).

Table 2.1:

Language mostly spoken in the households by place of residence

\begin{tabular}{lrrrrrr}
\multicolumn{1}{c}{ Language } & \multicolumn{2}{c}{ Rural } & \multicolumn{2}{c}{ Urban } & \multicolumn{2}{c}{ Total } \\
\cline { 2 - 7 } Urdu & Percent & Number & Percent & Number & Percent & Number \\
\hline Punjabi & 4.7 & 37 & 26.8 & 45 & 8.6 & 82 \\
\hline Sindhi & 62.5 & 494 & 66.7 & 112 & 63.2 & 606 \\
\hline Pushto & 0.1 & 1 & & & 0.1 & 1 \\
\hline Hindko & 1.6 & 13 & 0.6 & 1 & 1.5 & 14 \\
\hline Balochi & 0.3 & 2 & 1.2 & 2 & 0.4 & 4 \\
\hline Saraiki & 0.1 & 1 & & & 0.1 & 1 \\
\hline Others & 30.5 & 241 & 4.8 & 8 & 26.0 & 249 \\
\hline Total & 0.3 & 2 & & & 0.2 & 2 \\
\hline
\end{tabular}


Figure 2.1: $\quad$ Languages spoken by place of residence

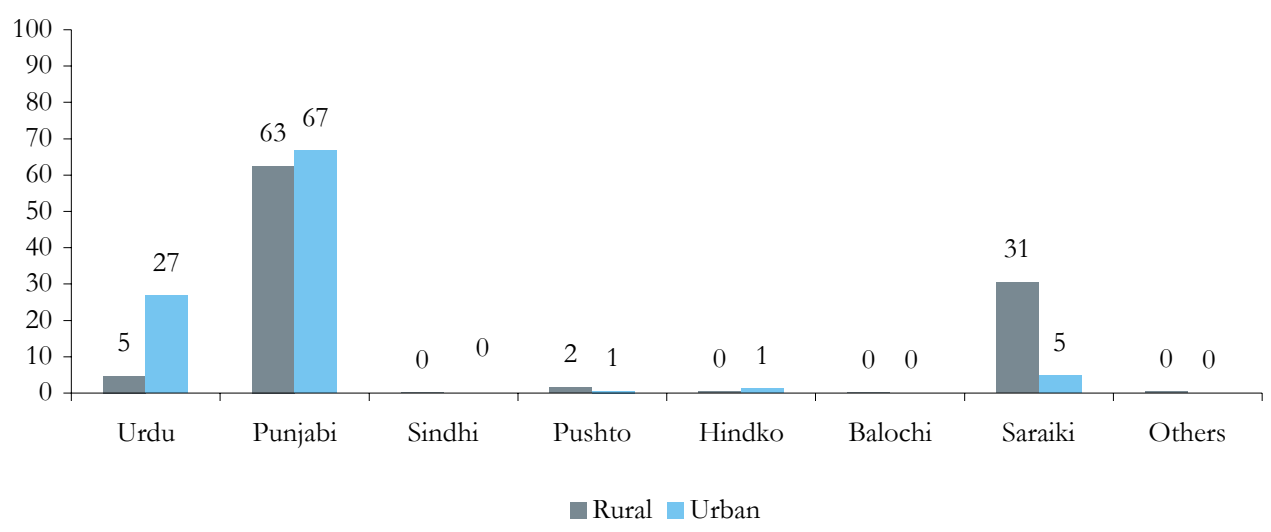

\section{Population Composition}

Age and sex are important demographic variables, and are the primary basis of demographic analysis. These are also important variables in the study of reproductive health, mortality and fertility.

More than half of the district population (51 percent) is comprised of males. According to the baseline survey, out of the total female population, about half of them ( 50.7 percent) fall within the reproductive health age group. The overall percentage of males and females in different age brackets, when seen in comparison, shows a very slight difference. Table 2.2 presents a comparative distribution of the population of Khanewal according to age and sex in selected age groups.

Table 2.2: $\quad$ Age-sex distribution of population

\begin{tabular}{lrrrrrr} 
& \multicolumn{2}{c}{ Males } & \multicolumn{2}{c}{ Females } & \multicolumn{2}{c}{ Both Sexes } \\
Age-group & Number & Percent & Number & Percent & Number & Percent \\
$<5$ & 477 & 13.0 & 432 & 12.6 & 909 & 12.8 \\
\hline $5-9$ & 473 & 12.9 & 459 & 13.4 & 932 & 13.1 \\
\hline $10-14$ & 477 & 13.0 & 454 & 13.2 & 931 & 13.1 \\
\hline $15-19$ & 453 & 12.3 & 443 & 12.9 & 896 & 12.6 \\
\hline $20-24$ & 367 & 10.0 & 346 & 10.1 & 713 & 10.0 \\
\hline $25-29$ & 289 & 7.9 & 291 & 8.5 & 580 & 8.2 \\
\hline $30-34$ & 216 & 5.9 & 220 & 6.4 & 436 & 6.1 \\
\hline $35-39$ & 211 & 5.8 & 198 & 5.8 & 409 & 5.8 \\
\hline $40-44$ & 165 & 4.5 & 141 & 4.1 & 306 & 4.3 \\
\hline $45-49$ & 142 & 3.9 & 99 & 2.9 & 241 & 3.4 \\
\hline $50-54$ & 97 & 2.6 & 105 & 3.1 & 202 & 2.8 \\
\hline $55-59$ & 77 & 2.1 & 74 & 2.2 & 151 & 2.1 \\
\hline $60-64$ & 94 & 2.6 & 67 & 2.0 & 161 & 2.3 \\
\hline 65 and older & 131 & 3.6 & 98 & 2.9 & 229 & 3.2 \\
\hline Total & 3669 & 100.0 & 3427 & 100.0 & 7096 & 100.0 \\
\hline
\end{tabular}




\section{Marital Status}

All individuals over the age of 15 years were asked about their marital status and the responses are presented in table 2.3. Sharp differences were noticed between the percentages of currently married males and females in the same age group. Only 2.4 percent of males in the 15-19-year age group are currently married, as compared to the 11.7 percent of females. Almost half of the females (49.1 percent) in the 20-24 year age group and three-fourths (75.9 percent) of the women in the 25-29 year age group were married at the time of survey. Though the figures, when compared against the 1998 Population Census, show a decline in the percentage of currently married women (from 15.9 percent to 11.7 percent) in the 15-19 year age cohort, they still highlight the fact that a high percentage of girls start reproducing at a very young age. As a result, they are in danger of encountering pre- and post natal complications. Table 2. 3 gives the percentage distribution of marital status by sex and age groups.

Table 2.3: $\quad$ Household population by age (15 years and above), sex and marital status

\begin{tabular}{|c|c|c|c|c|c|c|}
\hline \multirow[b]{2}{*}{ Age } & \multicolumn{3}{|c|}{ Males } & \multicolumn{3}{|c|}{ Females } \\
\hline & Never & Currently & Widow/ & Never & Currently & Widow/ \\
\hline Group & Married & Married & Divorced & Married & Married & Divorced \\
\hline \multicolumn{7}{|c|}{ PAIMAN Baseline 2005} \\
\hline $15-19$ & 97.6 & 2.4 & 0.0 & 87.8 & 11.7 & 0.5 \\
\hline $20-24$ & 79.3 & 20.4 & 0.0 & 50.3 & 49.1 & 0.6 \\
\hline $25-29$ & 45.3 & 52.6 & 1.0 & 19.9 & 75.9 & 3.4 \\
\hline $30-34$ & 12.5 & 85.2 & 0.9 & 3.2 & 90.5 & 5.5 \\
\hline $35-39$ & 6.6 & 92.9 & 0.5 & 3.5 & 92.4 & 4.0 \\
\hline $40-44$ & 1.8 & 95.8 & 1.2 & 2.1 & 89.4 & 8.5 \\
\hline $45-49$ & 1.4 & 95.8 & 2.1 & 1.0 & 83.8 & 14.1 \\
\hline $50-54$ & 0.0 & 93.8 & 5.2 & 0.0 & 86.7 & 13.3 \\
\hline $55-59$ & 0.0 & 96.1 & 2.6 & 1.4 & 75.7 & 21.6 \\
\hline $60-64$ & 0.0 & 87.2 & 12.8 & 1.5 & 53.7 & 43.3 \\
\hline 65 and older & 2.3 & 71.0 & 26.0 & 2.0 & 33.7 & 64.3 \\
\hline Total & 40.7 & 55.9 & 2.9 & 30.9 & 60.0 & 8.7 \\
\hline \multicolumn{7}{|c|}{ Population census 1998} \\
\hline $15-19$ & 95.5 & 4.3 & 0.2 & 83.8 & 15.9 & 0.4 \\
\hline $20-24$ & 73.4 & 26.0 & 0.6 & 42.6 & 56.4 & 1.0 \\
\hline $25-29$ & 41.3 & 57.4 & 1.3 & 15.4 & 82.7 & 1.9 \\
\hline $30-34$ & 18.4 & 79.8 & 1.9 & 7.0 & 90.2 & 2.8 \\
\hline $35-39$ & 9.0 & 88.5 & 2.5 & 4.0 & 91.2 & 4.8 \\
\hline $40-44$ & 5.5 & 91.1 & 3.4 & 3.0 & 89.8 & 7.2 \\
\hline $45-49$ & 3.9 & 91.4 & 4.7 & 2.1 & 87.2 & 10.7 \\
\hline $50-54$ & 4.0 & 89.2 & 6.8 & 2.5 & 80.0 & 17.5 \\
\hline $55-59$ & 2.8 & 88.0 & 9.3 & 2.1 & 74.7 & 23.2 \\
\hline $60-64$ & 3.5 & 83.4 & 13.1 & 3.5 & 61.8 & 34.7 \\
\hline 65 and older & 3.8 & 71.6 & 24.6 & 5.0 & 41.5 & 53.5 \\
\hline Total & 37.1 & 58.5 & 4.4 & 25.9 & 65.1 & 9.0 \\
\hline
\end{tabular}




\section{Education Attainment}

The productivity and economic growth of any country depends upon the educational status of its people. More than half of the women of Khanewal (54.5 percent) have never attended school, compared to 27.4 percent of the men. Furthermore, the findings indicate a very low percentage of males (10.2 percent) and females (4.9 percent) who have completed at least 11 years of schooling or more. The disparity between the percentage of males and females who have completed at least 6 to 10 years of schooling is very evident, sitting at 38.3 percent for males versus 18.7 percent for females.

A comparison of both the sexes shows women over the age of 45 years have very little to no education compared to the men in the same age group. An overall picture of Khanewal presents a higher educational status of men as compared to women. Details are presented in table 2.4.

Table 2.4: $\quad$ Household population by age (10 years and above), sex and educational level

\begin{tabular}{|c|c|c|c|c|c|}
\hline $\begin{array}{c}\text { Age } \\
\text { Group }\end{array}$ & $\begin{array}{c}\text { No } \\
\text { Schooling }\end{array}$ & $\begin{array}{c}1-5 \\
\text { Years }\end{array}$ & $\begin{array}{l}6-10 \\
\text { Years }\end{array}$ & $\begin{array}{c}11 \text { and } \\
\text { More years }\end{array}$ & Total \\
\hline \multicolumn{6}{|l|}{ Males } \\
\hline $10-14$ & 17.4 & 56.8 & 25.8 & 0.0 & 477 \\
\hline $15-19$ & 17.0 & 21.4 & 54.5 & 7.1 & 453 \\
\hline $20-24$ & 19.1 & 17.4 & 45.2 & 18.3 & 367 \\
\hline $25-29$ & 19.0 & 17.3 & 43.3 & 20.4 & 289 \\
\hline $30-34$ & 24.5 & 15.3 & 46.8 & 13.4 & 216 \\
\hline $35-39$ & 37.9 & 14.2 & 36.5 & 11.4 & 211 \\
\hline $40-44$ & 33.9 & 20.0 & 37.6 & 8.5 & 165 \\
\hline $45-49$ & 40.1 & 12.7 & 36.6 & 10.6 & 142 \\
\hline $50-54$ & 44.3 & 14.4 & 27.8 & 13.4 & 97 \\
\hline $55-59$ & 44.2 & 11.7 & 24.7 & 19.5 & 77 \\
\hline $60-64$ & 54.3 & 13.8 & 23.4 & 8.5 & 94 \\
\hline 65 and older & 66.4 & 17.6 & 16.0 & 0.0 & 131 \\
\hline Total & 27.4 & 24.1 & 38.3 & 10.2 & 2719 \\
\hline \multicolumn{6}{|c|}{ Females } \\
\hline $10-14$ & 30.4 & 50.2 & 19.4 & 0.0 & 454 \\
\hline $15-19$ & 36.1 & 21.0 & 36.8 & 6.1 & 443 \\
\hline $20-24$ & 43.1 & 17.3 & 25.7 & 13.9 & 346 \\
\hline $25-29$ & 51.9 & 17.2 & 23.4 & 7.6 & 291 \\
\hline $30-34$ & 61.4 & 17.3 & 15.9 & 5.5 & 220 \\
\hline $35-39$ & 76.3 & 12.6 & 7.1 & 4.0 & 198 \\
\hline $40-44$ & 80.1 & 12.8 & 4.3 & 2.8 & 141 \\
\hline $45-49$ & 77.8 & 18.2 & 3.0 & 1.0 & 99 \\
\hline $50-54$ & 82.9 & 11.4 & 5.7 & 0.0 & 105 \\
\hline $55-59$ & 87.8 & 8.1 & 4.1 & 0.0 & 74 \\
\hline $60-64$ & 95.5 & 4.5 & 0.0 & 0.0 & 67 \\
\hline 65 and older & 93.9 & 5.1 & 0.0 & 1.0 & 98 \\
\hline Total & 54.5 & 21.9 & 18.7 & 4.9 & 2536 \\
\hline
\end{tabular}




\section{Housing Characteristics}

\section{Source of Drinking Water}

In order to obtain a clear understanding of the living conditions of the population, it was necessary to record the source of drinking water available to respondents and their families. The source of drinking water has a close bearing on the household's socio-economic status and hygiene levels. A quantitative analysis of the information in table 2.5 below indicates that a majority of the population in Khanewal (86 percent), i.e. urban (61 percent) and rural (91 percent) reported access to a motorized system or hand pump. Among those who had access to motorized/hand pump systems, 83.5 percent had the pump installed inside their homes. Approximately 14 percent of the sample population obtained its drinking water from government supply schemes i.e. tap water, while 0.1 percent cited tube wells as their main source of drinking water. Table 2.5 gives details of rural urban differentials with regards to sources of drinking water.

Table 2.5: $\quad$ Main source of drinking water by place of residence

\begin{tabular}{lrrrrrr}
\multirow{2}{*}{ Source } & \multicolumn{2}{c}{ Rural } & \multicolumn{2}{c}{ Urban } & \multicolumn{2}{c}{ Total } \\
\cline { 2 - 7 } & Percent & Number & Percent & Number & Percent & Number \\
\hline Govt. supply (tap water inside) & 8.6 & 68 & 35.1 & 59 & 13.2 & 127 \\
\hline Govt. supply (communal) & 0.1 & 1 & 3.0 & 5 & 0.6 & 6 \\
\hline Motorized/hand pump (inside) & 88.2 & 698 & 61.3 & 103 & 83.5 & 801 \\
\hline Motorized/hand pump (outside) & 2.9 & 23 & & & 2.4 & 23 \\
\hline Tube-well & 0.1 & 1 & & & 0.1 & 1 \\
\hline Others & & & 0.6 & 1 & 0.1 & 1 \\
Total & 100.0 & 791 & 100.0 & 168 & 100.0 & 959
\end{tabular}

\section{Toilet Facilities}

Along with the source of drinking water, toilet facilities are a major indicator of a household's socioeconomic status, and therefore the level of hygiene, sanitation and comfort available to an expectant or new mother and her newborn children. The type of toilet facility a household has access to directly reflects the quality of sanitation, which has a more direct effect on mortality than does socioeconomic status (Martin et al, 1983). Households lacking hygienic toilet facilities have a higher risk of disease and infection, which in turn endangers the health of newborn children and their mothers. 
In response to a question regarding the type of toilet facility used in the household, a majority of the rural (65 percent) as well as urban population (97 percent) reported using a flush system (table 2.6). A high proportion of the population uses a flush system connected to the septic tank. In rural parts of the district, 33 percent of the population had no access to any type of toilet facility and used the fields.

Table 2.6: $\quad$ Type of toilet facility used by household members and place of residence

\begin{tabular}{l|r|rrrrrr}
\multirow{2}{*}{\multicolumn{1}{c}{ Toilet facility }} & \multicolumn{2}{c}{ Rural } & \multicolumn{2}{c}{ Urban } & \multicolumn{2}{c}{ Total } \\
\cline { 2 - 7 } & Percent & Number & Percent & Number & Percent & Number \\
\hline Flush to sewerage & 5.1 & 40 & 16.1 & 27 & 7.0 & 67 \\
\hline Flush connected to septic tank & 55.8 & 441 & 77.4 & 130 & 59.5 & 571 \\
\hline Flush connected to open drain & 4.0 & 32 & 3.0 & 5 & 3.9 & 37 \\
\hline Raised latrine & 0.6 & 5 & & & 0.5 & 5 \\
\hline Pit latrine & 1.6 & 13 & 1.2 & 2 & 1.6 & 15 \\
\hline In fields & 32.9 & 260 & 2.4 & 4 & 27.5 & 264 \\
\hline Total & 100.0 & 791 & 100.0 & 168 & 100.0 & 959
\end{tabular}

\section{Fuel Used for Cooking}

Substantial differences have been noted in the type of fuel used for cooking in urban and rural areas of Khanewal. Firewood continues to be the most common type of fuel used in rural areas and is used by 95 percent of the population as opposed to 34 percent of the urban respondents (table 2.7). On the other hand, natural gas is used by a majority of the urban population (64 percent) as compared to only 3.4 percent of users in rural areas. Other types of fuel reported to be in use in the district are gas cylinders (1.6 percent), and dry dung (0.3 percent).

Table 2.7: $\quad$ Main type of fuel used in the HH for cooking by place of residence

\begin{tabular}{lrrrrrrr} 
& \multicolumn{2}{c}{ Rural } & \multicolumn{2}{c}{ Urban } & \multicolumn{2}{c}{ Total } \\
\cline { 2 - 7 } \multicolumn{1}{c}{ Type of fuel } & Percent & Number & Percent & Number & Percent & Number \\
\hline Fire wood & 94.7 & 749 & 33.9 & 57 & 84.0 & 806 \\
\hline Gas cylinder & 1.5 & 12 & 1.8 & 3 & 1.6 & 15 \\
\hline Natural gas (Sui gas) & 3.4 & 27 & 64.3 & 108 & 14.1 & 135 \\
\hline Dry dung & 0.4 & 3 & & & 0.3 & 3 \\
Total & 100.0 & 791 & 100.0 & 168 & 100.0 & 959 \\
\hline
\end{tabular}




\section{Material Used for the House Roof}

The materials used for the roof and walls of a household are major indicators of the socio-economic status of that household, as well as the living standards of the people residing there. The more secure the materials, the higher the level of comfort and living standard for residents, and the lower the risk of disease and infection. Figure 2.2 shows that the majority of rural and urban respondents (58 percent and 63 percent respectively) reported having their roofs made of girder and $\mathrm{T}$-iron, while the second most commonly used materials for roofs were wood/bamboo/mud, which were used by 34 percent and 18 percent of the respondents in rural and urban areas respectively. A very small proportion of the population used iron sheets and concrete.

Figure 2.2: $\quad$ Material used for construction of roof by place of residence

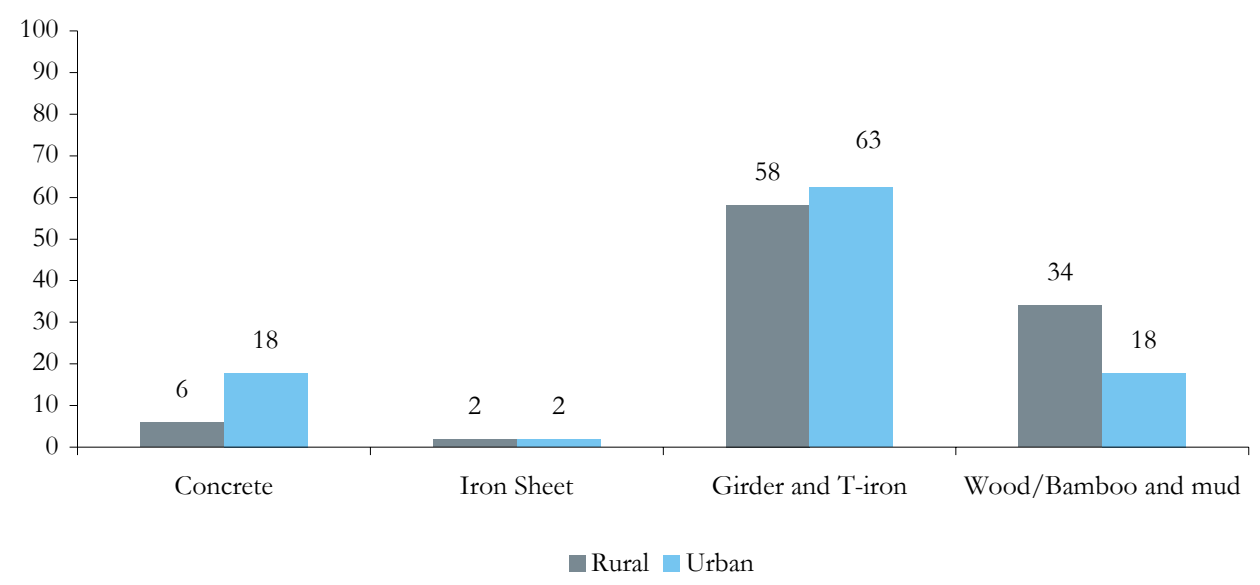

\section{Number of Rooms for Sleeping}

The number of separate rooms available for sleeping in each household is an important indicator of sanitation and hygiene levels. Overcrowding in households may lead to the spread of infection and diseases, which puts the lives of expectant/new mothers and their newborn children at risk.

According to table 2.8, a majority of the population ( 74 percent in rural areas and 78 percent in urban areas) has at least two rooms for sleeping. However, 25.4 percent of the respondents in Khanewal only have access to a single room for the purpose of sleeping. Findings show that in urban areas, there is an average of 3.7 persons per room compared to 3.8 persons per room in rural areas.

Table 2.8: $\quad$ Number of rooms used for sleeping by place of residence

\begin{tabular}{lrrrrrr}
\multirow{2}{*}{ Number of rooms } & \multicolumn{2}{c}{ Rural } & \multicolumn{2}{c}{ Urban } & \multicolumn{2}{c}{ Total } \\
& Percent & Number & Percent & Number & Percent & Number \\
\hline 1 & 26.2 & 207 & 22.0 & 37 & 25.4 & 244 \\
\hline 2 & 42.5 & 336 & 47.0 & 79 & 43.3 & 415 \\
\hline 3 & 18.7 & 148 & 15.5 & 26 & 18.1 & 174 \\
\hline 4 & 8.3 & 66 & 8.9 & 15 & 8.4 & 81 \\
\hline $5+$ & 4.3 & 34 & 6.5 & 11 & 4.7 & 45 \\
Total & 100.0 & 791 & 100.0 & 168 & 100.0 & 959
\end{tabular}




\section{Household Possessions}

Household possessions are perhaps one of the most effective ways of determining the socioeconomic status of a household. The presence of durable goods in the household, such as radio, television, telephone, refrigerator, motorcycle, and private car accurately reflects the household's socio-economic status. Moreover, particular goods have specific benefits, for example, ownership of a radio or television is a measure of access to mass media and exposure to innovative ideas; telephone ownership measures access to an efficient means of communication; refrigerator ownership means the life of wholesome food is prolonged and ownership of private transport allows greater access to many services away from the local area.

Table 2.9 presents information regarding household possessions as reported by the respondents in Khanewal. A majority of the respondents both in rural and urban areas own an electric iron, electric fan, sewing machine, radio or cassette player, furniture items including chairs and tables, bicycle, watch, clock and television. The percentages against each of the possession are given in the table.

Table 2.9:

Ownership of household commodities/land by place of residence

\begin{tabular}{lrrrr} 
& \multicolumn{1}{c}{ Household items } & Rural & Urban & \multicolumn{2}{c}{ Total } \\
& & & Percentage & Number \\
Electric iron & 68.4 & 92.9 & 72.7 & 697 \\
\hline Electric fan & 81.9 & 95.2 & 84.3 & 808 \\
\hline Sewing machine & 62.8 & 91.7 & 67.9 & 651 \\
\hline Radio or cassette player & 48.9 & 75.6 & 53.6 & 514 \\
\hline Chair/table & 59.2 & 85.7 & 63.8 & 612 \\
\hline Television & 39.2 & 69.0 & 44.4 & 426 \\
\hline Telephone & 25.4 & 51.2 & 29.9 & 287 \\
\hline Watch/clock & 64.2 & 91.1 & 68.9 & 661 \\
\hline VCR/VCP/VCD/CD player & 7.6 & 23.2 & 10.3 & 99 \\
\hline Refrigerator/deep freezer & 20.9 & 42.3 & 24.6 & 236 \\
\hline Air cooler & 9.9 & 24.4 & 12.4 & 119 \\
\hline Air conditioner & 1.5 & 7.1 & 2.5 & 24 \\
\hline Computer & 2.4 & 7.1 & 3.2 & 31 \\
\hline Bicycle & 62.1 & 50.6 & 60.1 & 576 \\
\hline Motorcycle & 17.4 & 24.4 & 18.7 & 179 \\
\hline Car/jeep & 1.6 & 2.4 & 1.8 & 17 \\
\hline Tractor/truck & 5.3 & 2.4 & 4.8 & 46 \\
\hline Ownership of any agriculture land by HH & 39.1 & 11.3 & 34.2 & 328 \\
\hline Agriculture major source of livelihood & 28.1 & 6.5 & 24.3 & 233 \\
\hline
\end{tabular}




\section{Ownership of the House}

A majority of respondents, in both urban and rural areas of Khanewal (93 percent and 91 percent respectively) claimed to own the house in which they live.

Table 2.10: $\quad$ Status of house by place of residence

\begin{tabular}{l|rrrrrr}
\multirow{2}{*}{ Status } & \multicolumn{2}{c}{ Rural } & \multicolumn{2}{c}{ Urban } & \multicolumn{2}{c}{ Total } \\
\cline { 2 - 7 } Owner occupied & Percent & Number & Percent & Number & Percent & Number \\
\hline Rented & 90.9 & 719 & 92.9 & 156 & 91.2 & 875 \\
\hline Rent free & 1.0 & 8 & 5.4 & 9 & 1.8 & 17 \\
\hline Others & 8.0 & 63 & 1.8 & 3 & 6.9 & 66 \\
\hline Total & 0.1 & 1 & & & 0.1 & 1 \\
& 100.0 & 791 & 100.0 & 168 & 100.0 & 959
\end{tabular}





\section{Chapter

\section{Background Characteristics of Married Women of Reproductive Age}

Information regarding the basic background characteristics of respondents is essential for the interpretation of survey findings. This chapter describes the basic background characteristics including age, education level, and place of residence of the respondents. It also describes detailed information on the educational status of respondents and their husbands, literacy levels, and exposure to mass media. Only currently married women aged 15-49 years were interviewed for this portion of the survey.

\section{Age Distribution of Married Women}

The age-distribution results of married women in Khanewal show a similar trend in both rural and urban areas with 20.6 percent of the respondents in rural areas and 19.7 percent in urban areas falling into the reproductive age group of 25- 29 years. Similarly, 20.3 percent and 22.6 percent of the respondents in rural and urban areas respectively are between the ages of 30-34 years. Overall, the mean age of married women of reproductive ages in Khanewal is approximately 33.7 years.

Table 3.1:

Current age and age at marriage by place of residence

\begin{tabular}{|c|c|c|c|c|c|c|c|}
\hline \multirow{2}{*}{\multicolumn{2}{|c|}{ Background profile }} & \multicolumn{2}{|c|}{ Rural } & \multicolumn{2}{|c|}{ Urban } & \multicolumn{2}{|c|}{ Total } \\
\hline & & Percent & Number & Percent & Number & Percent & Number \\
\hline \multirow{7}{*}{$\begin{array}{l}\text { Age of } \\
\text { respondent }\end{array}$} & $15-19$ & 4.1 & 29 & 5.1 & 7 & 4.2 & 36 \\
\hline & $20-24$ & 16.0 & 114 & 13.1 & 18 & 15.5 & 132 \\
\hline & $25-29$ & 20.6 & 147 & 19.7 & 27 & 20.4 & 174 \\
\hline & $30-34$ & 20.3 & 145 & 22.6 & 31 & 20.7 & 176 \\
\hline & $35-39$ & 17.9 & 128 & 16.1 & 22 & 17.6 & 150 \\
\hline & $40-44$ & 13.2 & 94 & 13.9 & 19 & 13.3 & 113 \\
\hline & $45-49$ & 8.0 & 57 & 9.5 & 13 & 8.2 & 70 \\
\hline \multirow{4}{*}{ Age at marriage } & $<15$ & 13.6 & 97 & 13.1 & 18 & 13.5 & 115 \\
\hline & $15-19$ & 57.8 & 413 & 47.4 & 65 & 56.2 & 478 \\
\hline & $20-24$ & 22.4 & 160 & 28.5 & 39 & 23.4 & 199 \\
\hline & $25+$ & 6.2 & 44 & 10.9 & 15 & 6.9 & 59 \\
\hline
\end{tabular}


The majority of rural (57.8 percent) and urban women (47.4 percent) reported getting married between the ages of 15-19 years. A very low percentage of women (6.9 percent) reported their age at marriage as 25 years and above. The mean age at marriage in district Khanewal is 17.5 years. Table 3.1 gives the details of age distribution and age at marriage.

Figure 3.1: $\quad$ Age distribution by place of residence

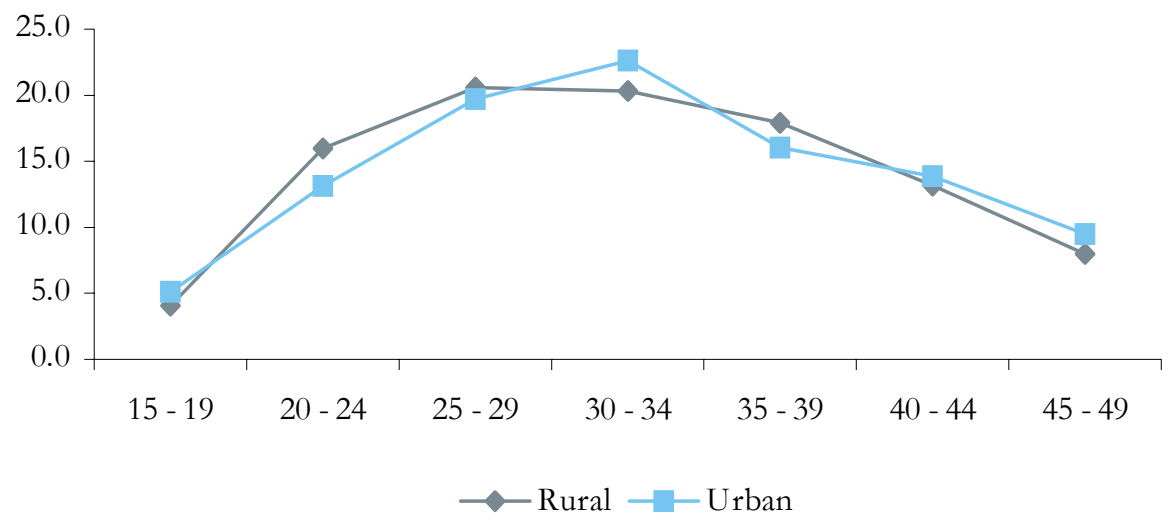

\section{Education/Literacy level}

The level of education obtained by a woman can be a good indicator of her status in society as well as the independent decision-making power available to her. It is presumed that the higher the level of education obtained by a woman, the more say she has in matters concerning her health and that of her children. With regards to maternal health, a higher literacy rate in women can result in an increased use of contraceptives, higher awareness of complications during and after pregnancy, a strong understanding of neonatal and newborn health, and finally, a more complete understanding of safe birth practices.

It has also been shown that the mortality rates among children with mothers who have six or more years of education are considerably lower than the mortality rates among children with uneducated mothers (Martin, 1983). Educated women are more likely to recognize signs of illness in their children, actively seek assistance from a doctor and administer the treatment in the manner required. Educated women are also more likely to return to a doctor in the event that the treatment administered failed to take effect. Therefore, the proactive nature of educated women with regard to the health of their children lowers the morbidity and mortality rates of infants and young children (Caldwell, 1986).

Out of the total woman interviewed, 66.5 percent were illiterate. The majority (70.2 percent) of the respondents who were reportedly illiterate were based in rural areas. The illiteracy rate for males was 33 percent.

Among the literate group of women, 17.5 percent had obtained a primary education, 6.2 percent had been educated to middle school level, and 5.6 percent had received a secondary education, while around 4.3 percent claimed to have attained post secondary education. Table 3.2 provides details with regards to the education and literacy levels of respondents and their husbands. 
Education and literacy level of respondents and their husbands

\begin{tabular}{llrrrrrrr}
\multirow{2}{*}{ Background profile } & \multicolumn{2}{c}{ Rural } & \multicolumn{2}{c}{ Urban } & \multicolumn{2}{c}{ Total } \\
\cline { 3 - 8 } & Percent & Number & Percent & Number & Percent & Number \\
& No education & 69.9 & 499 & 47.4 & 65 & 66.3 & 564 \\
\cline { 2 - 8 } $\begin{array}{l}\text { Level of } \\
\text { education }\end{array}$ & Up to primary & 17.1 & 122 & 19.7 & 27 & 17.5 & 149 \\
\cline { 2 - 8 } & Up to middle & 5.0 & 36 & 12.4 & 17 & 6.2 & 53 \\
\cline { 2 - 8 } & Up to secondary & 4.9 & 35 & 9.5 & 13 & 5.6 & 48 \\
\cline { 2 - 8 } & Secondary + & 3.1 & 22 & 10.9 & 15 & 4.3 & 37 \\
\hline $\begin{array}{l}\text { Respondent's } \\
\text { literacy }\end{array}$ & Literate & 29.8 & 213 & 52.6 & 72 & 33.5 & 285 \\
\cline { 2 - 8 } & Illiterate & 70.2 & 501 & 47.4 & 65 & 66.5 & 566 \\
\hline \multirow{3}{*}{$\begin{array}{l}\text { Husband's } \\
\begin{array}{l}\text { Level of } \\
\text { education }\end{array}\end{array}$} & No education & 34.7 & 248 & 24.1 & 33 & 33.0 & 281 \\
\cline { 2 - 8 } & Up to primary & 15.3 & 109 & 19.0 & 26 & 15.9 & 135 \\
\cline { 2 - 8 } & Up to middle & 16.0 & 114 & 10.2 & 14 & 15.0 & 128 \\
\hline & Up to secondary & 24.4 & 174 & 22.6 & 31 & 24.1 & 205 \\
\hline $\begin{array}{l}\text { Husband's } \\
\text { literacy }\end{array}$ & Secondary + & 9.7 & 69 & 24.1 & 33 & 12.0 & 102 \\
\hline
\end{tabular}

\section{Children Ever Born and Living}

According to the PAIMAN Baseline Survey, the mean number of children ever born in Khanewal is 4.2 which shows a decrease from 4.7 children ever born as determined in the 1998 Population Census. However, the mean number of living children is 3.7, which has increased from 3.5 since the Census in 1998. On average, 42.1 percent reported giving birth to five or more children. A high percentage of the respondents with five or more children belong to the 45 to 49 year age cohort. About 3 percent of the women in the 20 to 24 year age group were also among those who had 5 or more children. It is also important to note that approximately 58.3 percent of the women in the 15-19 year age group has one to two children, while about 2.8 percent in the same age group had three to four children.

Table 3.3: $\quad$ Percentage distribution of married women by number of children ever born, mean number of children ever born, living children and age group compared to the 1998 Population Census

\begin{tabular}{|c|c|c|c|c|c|c|c|c|c|c|}
\hline \multirow{3}{*}{$\begin{array}{l}\text { Age } \\
\text { Group }\end{array}$} & \multicolumn{5}{|c|}{ Number of Children Ever Born } & No. of & \multicolumn{4}{|c|}{ Mean Number of Children } \\
\hline & \multirow[t]{2}{*}{0} & \multirow[t]{2}{*}{$1-2$} & \multirow[t]{2}{*}{$3-4$} & \multirow{2}{*}{$\begin{array}{l}5 \text { or } \\
\text { more }\end{array}$} & \multirow[t]{2}{*}{ Total } & \multirow[t]{2}{*}{ Women } & \multicolumn{2}{|c|}{ PAIMAN Baseline } & \multicolumn{2}{|c|}{1998 Population Census } \\
\hline & & & & & & & Ever born & Living & Ever born & Living \\
\hline $15-19$ & 38.9 & 58.3 & 2.8 & 0.0 & 100 & 36 & 0.9 & 0.8 & 1.2 & 0.6 \\
\hline $20-24$ & 22.0 & 48.5 & 26.5 & 3.0 & 100 & 132 & 1.8 & 1.5 & 2.3 & 1.5 \\
\hline $25-29$ & 8.6 & 31.0 & 39.1 & 21.3 & 100 & 174 & 3.0 & 2.6 & 3.5 & 2.6 \\
\hline $30-34$ & 6.3 & 13.1 & 32.4 & 48.3 & 100 & 176 & 4.5 & 3.9 & 5.1 & 3.8 \\
\hline $35-39$ & 1.3 & 6.7 & 28.7 & 63.3 & 100 & 150 & 5.6 & 4.9 & 5.8 & 4.5 \\
\hline $40-44$ & 2.7 & 3.5 & 19.5 & 74.3 & 100 & 113 & 6.1 & 5.3 & 6.6 & 5.2 \\
\hline $45-49$ & 2.9 & 4.3 & 17.1 & 75.7 & 100 & 70 & 6.7 & 5.8 & 7.2 & 5.4 \\
\hline Total & 8.9 & 21.0 & 28.0 & 42.1 & 100 & 851 & 4.2 & 3.7 & 4.7 & 3.5 \\
\hline
\end{tabular}




\section{Preceding Birth Interval}

The length of the preceding birth interval is very important as it directly affects the health and mortality of both mother and child. A mother with repeated pregnancies, especially at short intervals, does not have sufficient time for recovery both physically and nutritionally and is therefore more likely to have pregnancy losses and babies of a lower birth weight. According to table 3.4, about 21.5 percent of the women surveyed indicated that they had a 19-24 month interval between their last two births, while about 25.4 percent of the respondents had a 25-36 month interval. Approximately 23.6 percent of the sample population cited an interval of more that 36 months between their last two births.

Table 3.4: Percentage distribution of married women by length of preceding birth interval

\begin{tabular}{lrr} 
Length of Preceding Birth Interval & Number & Percent \\
\hline Less than 12 months & 8 & 2.4 \\
\hline 13-18 months & 92 & 27.1 \\
\hline $19-24$ months & 73 & 21.5 \\
\hline $25-36$ months & 86 & 25.4 \\
\hline More than 36 months & 80 & 23.6 \\
Total & 339 & 100
\end{tabular}

\section{Access to Information}

In the baseline survey, respondents were asked several questions regarding access and exposure to television, radio and newspapers. One of the main objectives of the baseline was to determine the knowledge of married women on different maternal and newborn health issues and the source of that knowledge. This information is useful in determining which media channels should be employed in the dissemination of maternal and newborn health information to target audiences. Moreover it is important to measure the likelihood of reaching target audiences.

\section{Access to Media (Television, Radio and Newspaper)}

Mass media is regularly used to campaign on various issues, including those relating to the health of mothers and newborns. In the past, radio was the most popular form of communication (Syed, 1979). However, according to the survey findings, television has become a more popular source of information.

According to figure 3.2, 41.2 percent of the women interviewed reported having access to some sort of mass media (radio, TV or newspaper). The percentage of access to media was higher in urban areas (58.4 percent) than in rural parts of Khanewal (38 percent). 
Figure 3.2: $\quad$ Exposure to mass media (Radio, television or Newspaper)

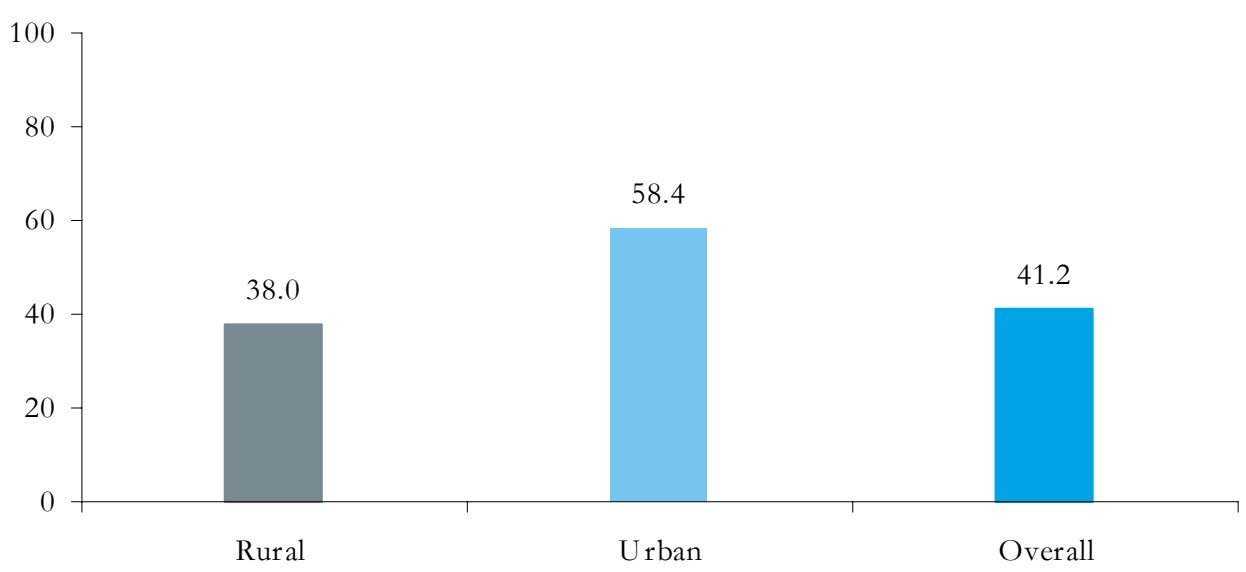

In Khanewal, approximately 65 percent of the women interviewed considered TV to be the most trustworthy source of media followed by radio ( 8.5 percent) and finally newspapers ( 3.1 percent). Figure 3.3 gives details of the trustworthiness of various sources of mass media according to urban and rural areas.

Figure 3.3: $\quad$ Most trustworthy media by place of residence

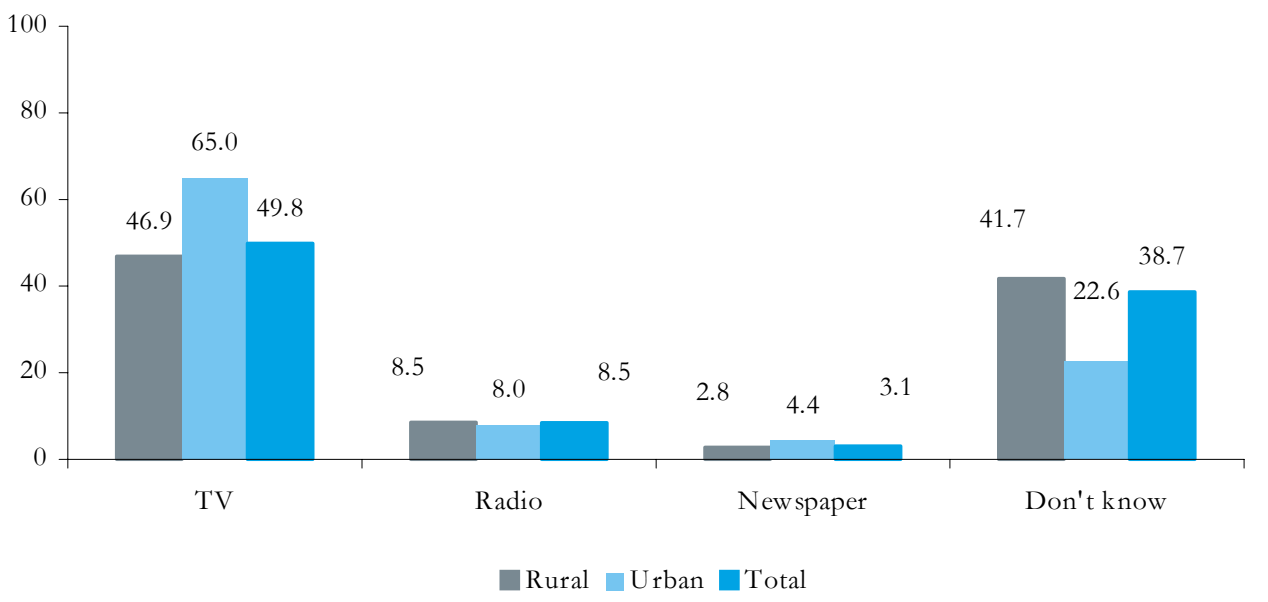




\section{Television}

Out of 41.2 percent of the respondents who had access to the mass media, 31.4 percent reported watching TV and 9 percent listened to the radio. The percentage of TV viewers was much higher in urban areas than in rural parts of the district (52.6 percent versus 27.3 percent).

Figure 3.4: $\quad$ Percentage of women who watch television or listen radio by place of residence

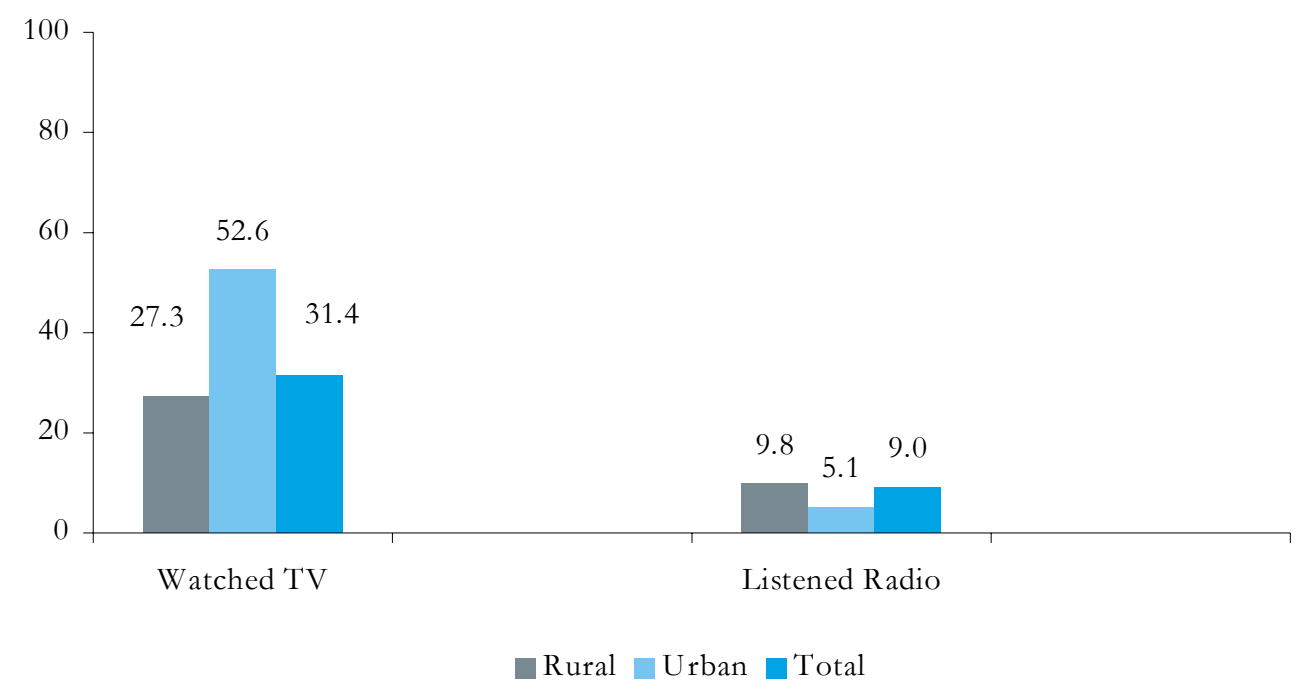

Out of the total TV viewers, 94.4 percent of the women in both urban and rural Khanewal reportedly watched TV at home. Only 4.1 percent watched television at a relative's house, 1.1 percent at a neighbor's house, and less than 1 percent ( 0.4 percent) at their place of work.

Table 3.5: $\quad$ Place where respondent usually watches television by place of residence

\begin{tabular}{lrrrrrrr}
\multirow{2}{*}{ Place } & \multicolumn{2}{c}{ Rural } & \multicolumn{2}{c}{ Urban } & \multicolumn{2}{c}{ Total } \\
\cline { 2 - 7 } & Percent & Number & Percent & Number & Percent & Number \\
\hline At home & 94.4 & 184 & 94.4 & 68 & 94.4 & 252 \\
\hline At work place & 0.5 & 1 & & & 0.4 & 1 \\
\hline At relative's house & 3.6 & 7 & 5.6 & 4 & 4.1 & 11 \\
\hline At neighbor's house & 1.5 & 3 & & & 1.1 & 3 \\
\hline Total & 100.0 & 195 & 100.0 & 72 & 100.0 & 267 \\
\hline
\end{tabular}

Half of the women in Khanewal (50.2 percent) who watched TV indicated that they did so on a daily basis. The percentage of daily viewers of TV in urban and rural areas was 56.9 percent and 47.7 percent respectively. 
Table 3.6:

Frequency of watching television

\begin{tabular}{lrrrr|r|r|r|} 
& \multicolumn{2}{c}{ Rural } & \multicolumn{2}{c|}{ Urban } & \multicolumn{2}{c}{ Total } \\
\cline { 2 - 8 } \multicolumn{1}{r}{ Frequency } & Percent & Number & Percent & Number & Percent & Number \\
\hline Almost daily & 47.7 & 93 & 56.9 & 41 & 50.2 & 134 \\
\hline Rarely & 52.3 & 102 & 43.1 & 31 & .49 .8 & 133 \\
\hline Total & 100.0 & 195 & 100.0 & 72 & 100.0 & 267 \\
\hline
\end{tabular}

About 32 percent of the respondents in urban areas and 22 percent in rural areas believed that TV had a great deal of influence on their daily lives. Meanwhile, only 9.7 percent of the respondents in both urban and rural areas believed television had only a small amount of influence on the behaviors of people. The highest percentage of women in both rural and urban areas (44.6 percent and 40.3percent respectively) indicated that television had a moderate influence on the behaviors of people.

Figure 3.5: $\quad$ Influence of television programs on health behaviors of people by place of residence

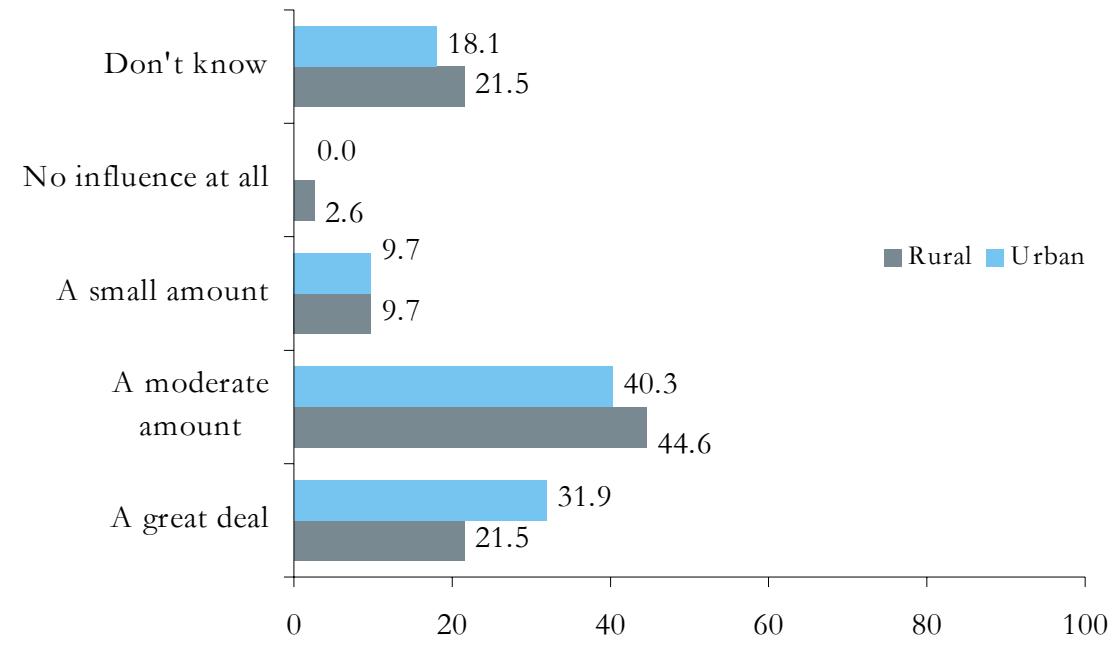




\section{Radio}

Out of a total of 9 percent who had access to radio (figure 3.2), table 3.7 shows that only 29 percent listened to it on daily basis (42.9 percent in urban areas and 27.1 percent in rural areas).

Table 3.7: $\quad$ Frequency of listening to the radio by place of residence

\begin{tabular}{lrrrrrrr}
\multirow{2}{*}{ Frequency } & \multicolumn{2}{c}{ Rural } & \multicolumn{2}{c}{ Urban } & \multicolumn{2}{c}{ Total } \\
\cline { 2 - 7 } & Percent & Number & Percent & Number & Percent & Number \\
\hline Almost daily & 27.1 & 19 & 42.9 & 3 & 28.6 & 22 \\
\hline Alt least once a week & 1.4 & 1 & & & 1.3 & 1 \\
\hline Rarely & 71.4 & 50 & 57.1 & 4 & 70.1 & 54 \\
\hline Total & 100.0 & 70 & 100.0 & 7 & 100.0 & 77 \\
\hline
\end{tabular}

Table 3.8 shows that the majority of radio listeners ( 93.5 percent) listened to the radio at their home. The findings indicate that radio is not a very popular media among the people of Khanewal, especially in the urban areas.

Table 3.8: $\quad$ Place where respondent listens to the radio by place of residence

\begin{tabular}{lrrrrrrr} 
& \multicolumn{2}{c}{ Rural } & \multicolumn{2}{c}{ Urban } & \multicolumn{2}{c}{ Total } \\
\cline { 2 - 7 } \multicolumn{1}{c}{ Place } & Percent & Number & Percent & Number & Percent & Number \\
\hline At home & 92.9 & 65 & 100.0 & 7 & 93.5 & 72 \\
\hline At work place & 5.7 & 4 & & 5.2 & 4 \\
\hline At relative's house & 1.4 & 1 & & 1.3 & 1 \\
\hline Total & 100.0 & 70 & 100.0 & 7 & 100.0 & 77 \\
\hline
\end{tabular}

Figure 3.6 shows that the majority of the radio listeners in rural (40 percent) and urban areas (57percent) believed radio had only a moderate influence on health behaviors. Only 12.9 percent in rural areas and 14.3 percent in urban areas believed that it had a great deal of influence. 
Figure 3.6: $\quad$ Influence of radio on health behaviors by place of residence

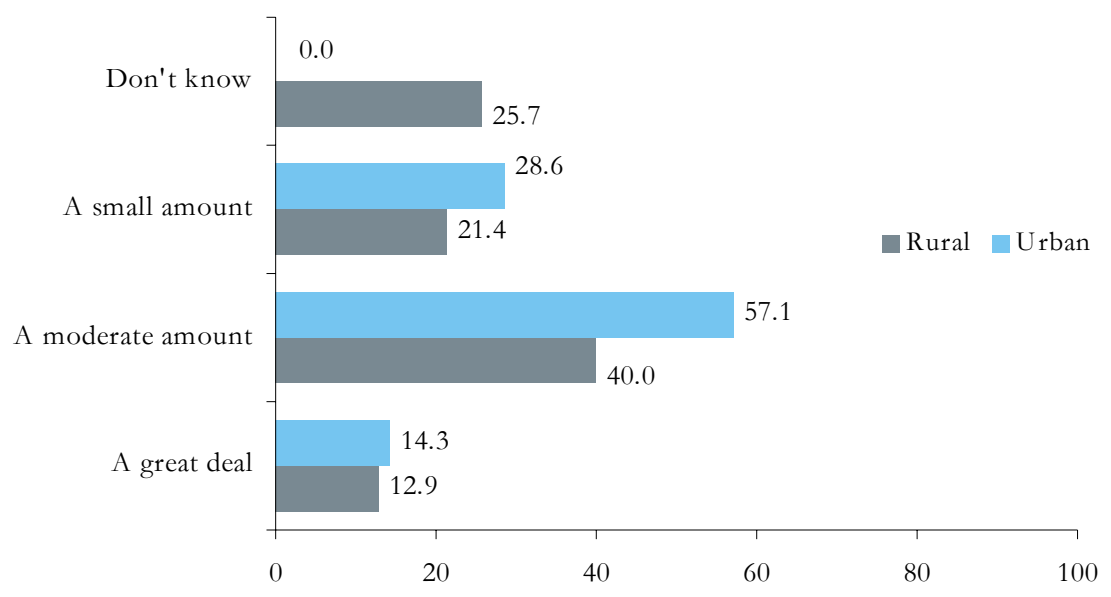

\section{Newspapers}

Figure 3.7 shows that only 0.8 percent of the respondents in rural areas and 4.4 percent in urban areas read the newspaper on a daily basis. This would suggest that a majority of the married women in Khanewal never read the newspaper, while those who do, do so very rarely. Therefore it can be concluded that newspapers are not a very efficient means of communication for the PAIMAN target population in Khanewal.

Figure 3.7: $\quad$ Frequency of reading newspaper by place of residence

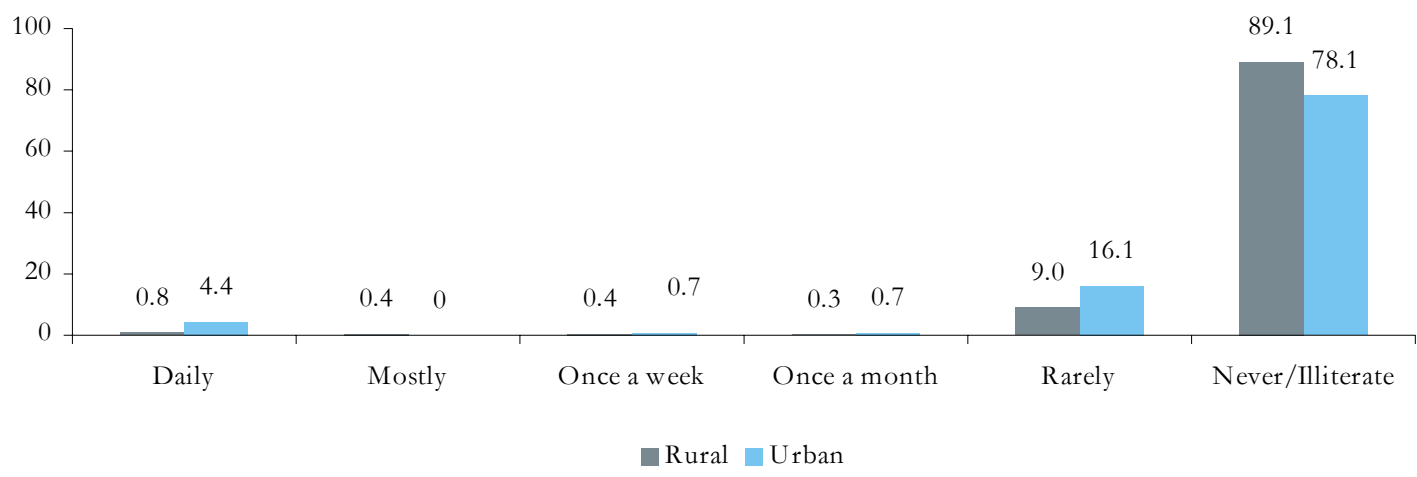




\section{Information/Education through Media}

Respondents were asked to comment on whether or not they had heard or read anything regarding maternal and newborn health within the past three months. Approximately 12 percent of the respondents in rural and 15 percent in urban Khanewal reported having heard or read about maternal and newborn health within the past three months.

Figure 3.8: $\quad$ Percentage of married women who had heard/ read maternal and newborn messages during the last 3 months by place of residence

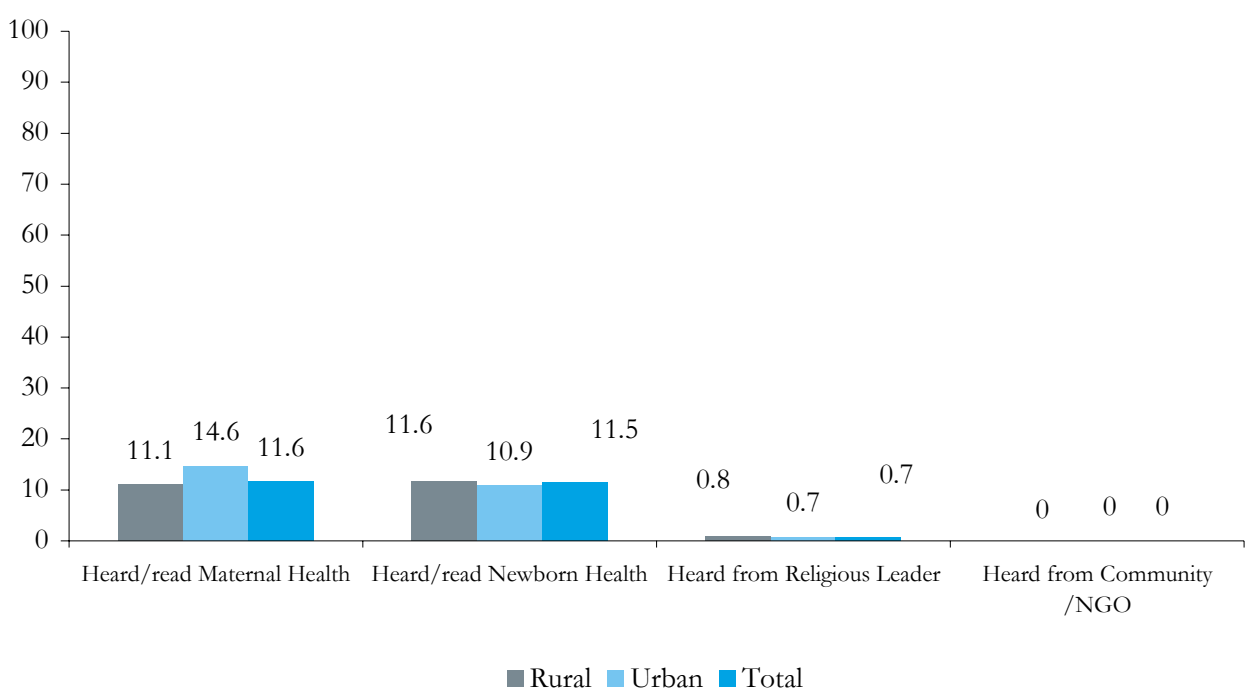

Similarly, just around 12 percent of the married women in Khanewal had heard/read anything regarding newborn health within the last three months. It appears a very large portion of the population is not exposed to any messages regarding maternal or newborn health on a frequent basis.

Furthermore, respondents were asked if they had heard religious leaders and community/NGO workers speak about health care in the last three months. In Khanewal, less than 1 percent of the population stated that they had heard a religious leader speak about maternal and newborn health. However, in both urban and rural Khanewal, none of the respondent reported that they had heard a community/NGO worker speak about maternal and newborn health.

It becomes evident from the data that the percentages of married women who had heard anything about maternal or newborn health are very low for both urban and rural areas, indicating the absence of proactive education and awareness in many areas of Khanewal. Hence, it would be a challenge for the PAIMAN team to reach these women in both urban and rural areas, and convey messages regarding maternal and newborn health. 


\section{Chapter 4}

\section{Knowledge of Safe Motherhood, Birth Preparedness and Community Resources}

This chapter explores the level of understanding women have of safe motherhood practices, birth preparedness and the use of community resources. It examines the level of health awareness women in the district possess and thus provides an explanation for the maternal and newborn mortality rates. Respondents were asked questions regarding knowledge of complications during pregnancy, delivery, the postpartum period and newborn health. They were also asked about the community resources available to them within the community. The findings of those responses are presented in this chapter.

\section{Knowledge of Danger Signs}

Danger signs include any vaginal bleeding, severe headache, dizziness or blurred vision, generalized edema, convulsions, breathlessness, tiredness, labor pains for more than 12 hours, excessive bleeding in labor or after delivery, ruptured membranes without labor for more than 12 hours and fever with or without vaginal discharge after delivery.

In this section of the survey, the respondents were asked about the various danger signs that could arise during pregnancy, delivery, postpartum soon after birth and within 7 days after birth for which medical advice/treatment was necessary.

\section{Knowledge of Danger Signs during Pregnancy}

Respondents were asked whether they knew about various danger signs during pregnancy. The responses are presented in figure 4.1. It shows that heavy vaginal bleeding, severe abdominal pain, high blood pressure, high fever and jaundice were some of the most commonly reported signs of danger during pregnancy in both urban and rural parts of Khanewal. The majority of the respondents in urban (60.6 percent) and rural areas (39.4 percent) recognized vaginal bleeding as being a danger sign during pregnancy for which immediate medical attention must be sought. Only 1.1 percent of the population in rural areas considered unconsciousness to be a danger sign. 
Figure 4.1: $\quad$ Knowledge of danger signs during pregnancy, which require medical attention

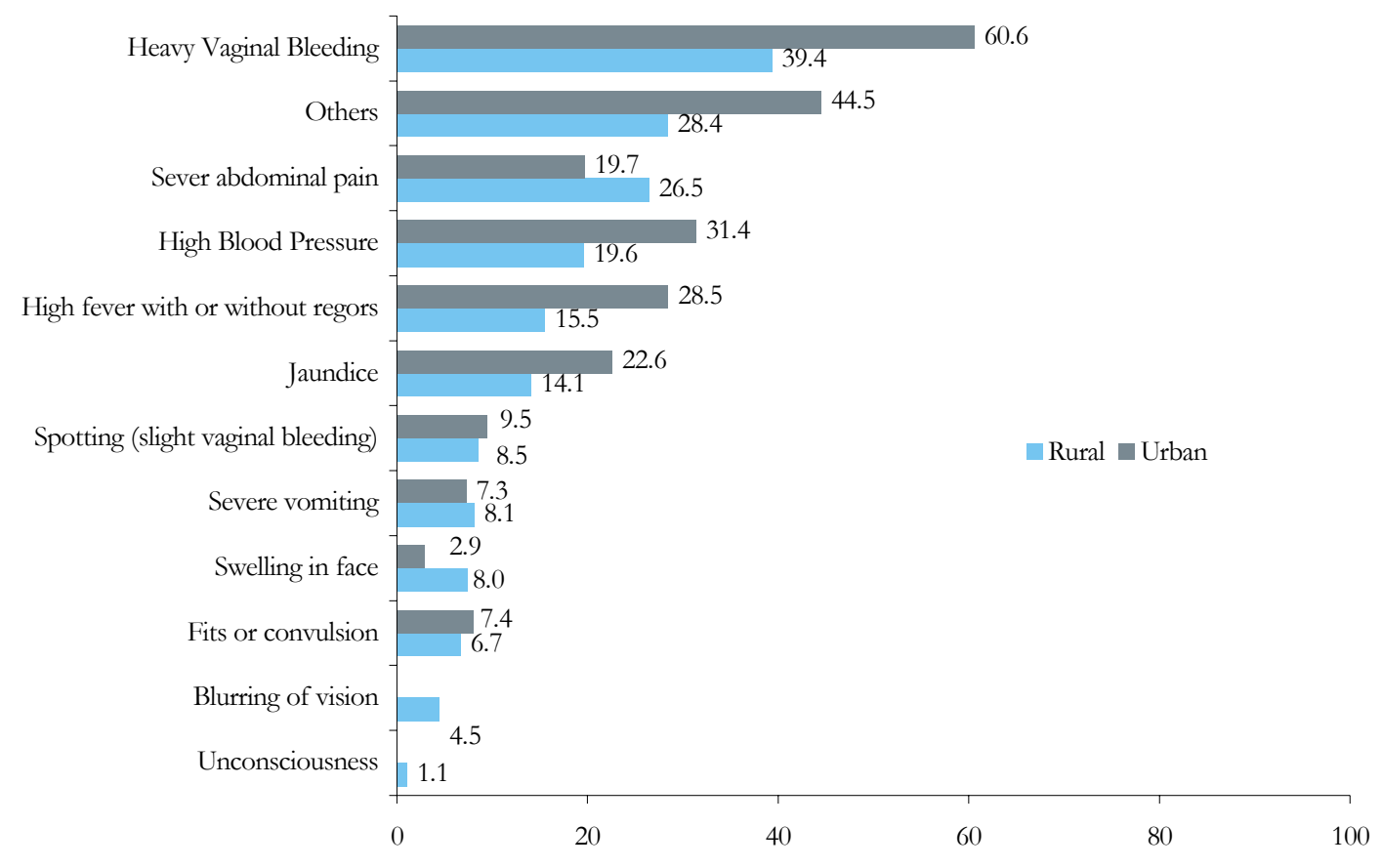

Figure 4.2 shows that only 27 percent of the respondents in urban areas and 16 percent in rural areas were aware of three or more danger signs during pregnancy. Figure 4.2 also shows that 6.6 percent married women in rural and 22 percent married women in urban Khanewal had no knowledge of danger signs during pregnancy.

Figure 4.2: $\quad$ Percentage of married women by status of knowledge of danger signs during pregnancy by place of residence

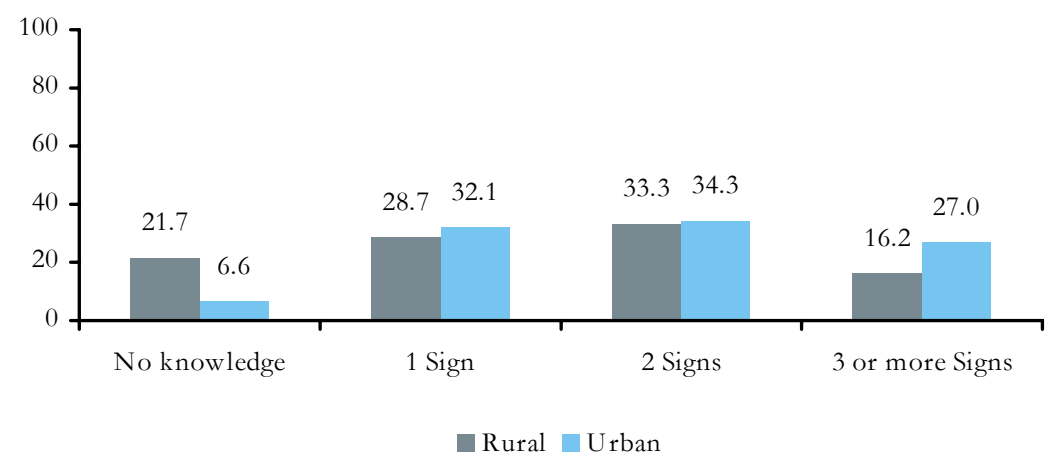




\section{Knowledge of Danger Signs during Childbirth/Delivery}

The fact is that most maternal deaths in developing countries occur during delivery. As in the case of pregnancy, many women are not aware of the complications that may arise during delivery. This lack of knowledge may eventually result in women not being taken to a hospital in the event that such a complication should occur. Figure 4.3 shows that the most widely reported complication during delivery was 'retained placenta/delay in the delivery of placenta', which was reported by 40.5 percent and 46.7 percent of the women in rural and urban Khanewal. 'Mal-positioning', 'excessive vaginal bleeding', and 'bleeding before labor began' were also commonly reported as some of the danger signs during delivery.

Figure 4.3: Distribution of respondents who had knowledge about complications during delivery by place of residence

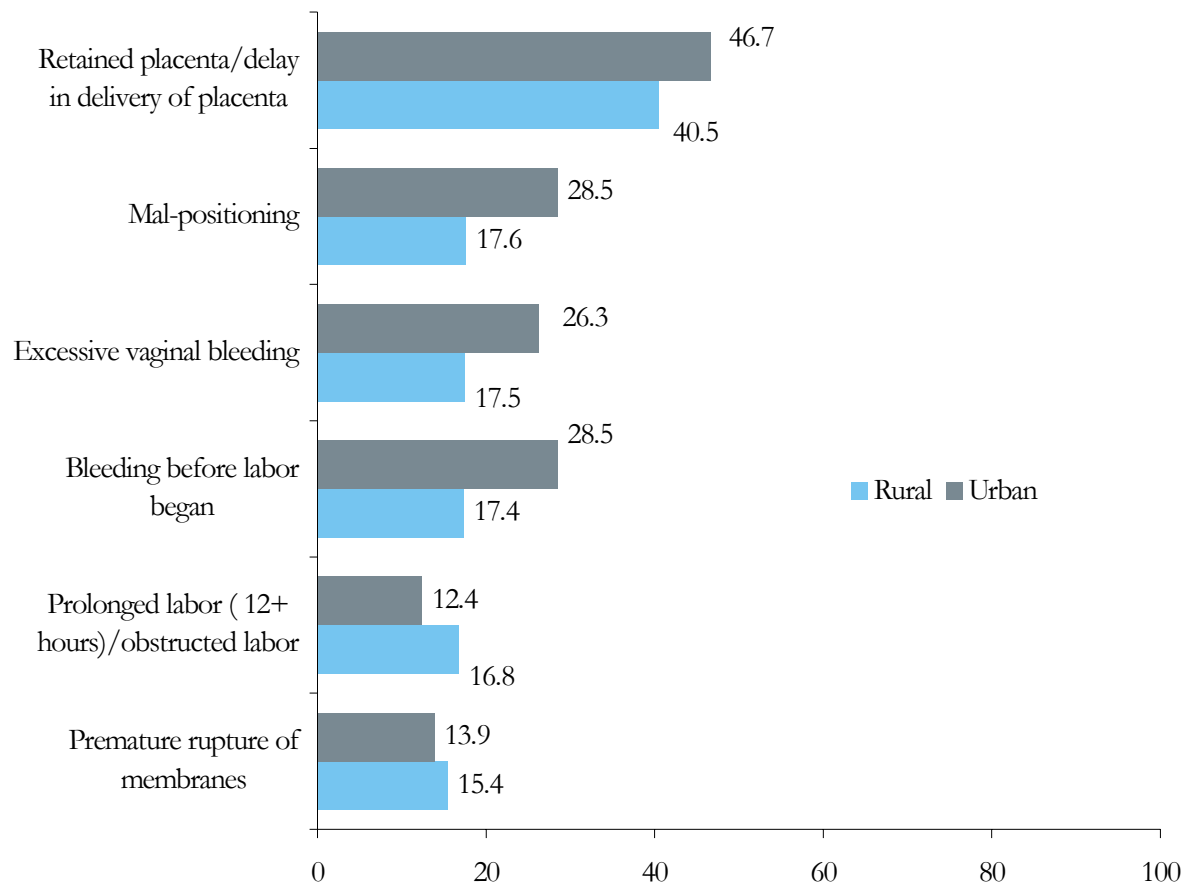

Figure 4.4 shows that only 7.8 percent in rural and 12.4 percent in urban, married women recognize three or more danger signs that lead to severe consequences. Deliveries can only be made safer if married women are educated regarding the danger signs that could arise during the delivery, in order for them to decide when to seek medical treatment. Even under normal circumstances, some 15 percent of pregnant women require emergency obstetric care to avoid maternal and newborn deaths.

A high percentage of respondents in both urban and rural Khanewal ( 8 and 22.3 percent respectively) were aware of only one danger sign during delivery. About 40 percent of the respondents in rural areas and 42 percent in urban areas reported knowledge of a single danger sign while 30 percent in rural and 37 percent in urban areas were able to name only two danger signs. 
Figure 4.4: $\quad$ Percentage of married women by status of knowledge of danger signs during delivery and place of residence

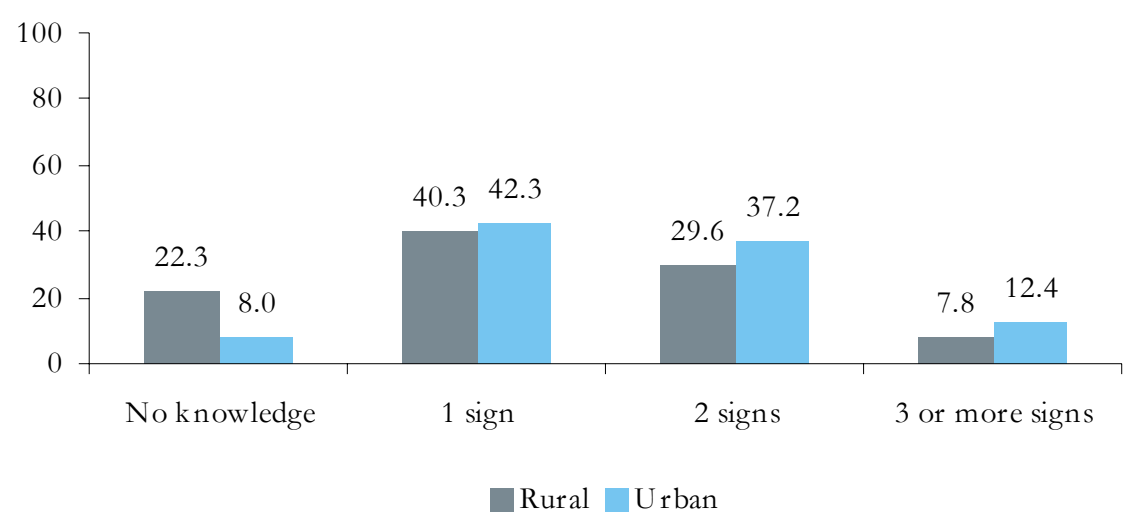

\section{Knowledge of Danger Signs during the Postpartum Period}

Postpartum hemorrhage is another significant cause of maternal mortality in developing countries including Pakistan. In the baseline survey, the postpartum period is defined as the 40 days after childbirth. Although baseline survey findings indicate that excessive vaginal bleeding is the most commonly known danger sign during the postpartum period, many women are still not aware of this fact. Again, this calls for some innovative approaches to make these communities knowledgeable regarding the danger signs during the postpartum period.

Figure 4.5: $\quad$ Percentage of married women who had knowledge about danger signs during postpartum period

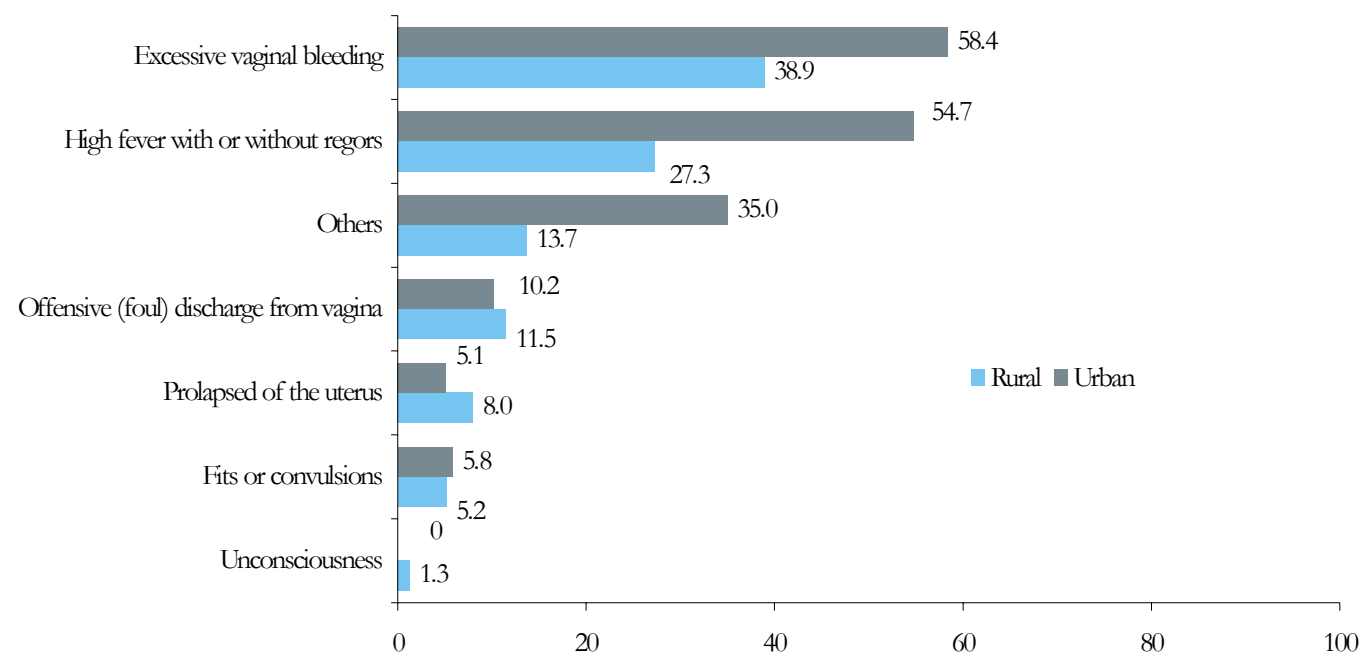

According to figure 4.5, heavy vaginal bleeding was the most highly reported danger sign during the postpartum period by both urban and rural women (58 percent and 39 percent respectively). High fever was also widely reported as being a danger sign. 
Figure 4.6 shows that about 35 percent of the women in rural areas were unable to name any danger signs whatsoever, while 12 percent of their urban counterparts were in the same predicament. About 49 percent of the respondents in urban areas along with 42 percent in rural areas only knew one danger sign during the postpartum period. A very low percentage was able to name three or more danger signs during the postpartum period for which medical treatment is necessary.

Figure 4.6: $\quad$ Percentage of married women by status of knowledge of danger signs during postpartum period and place of residence

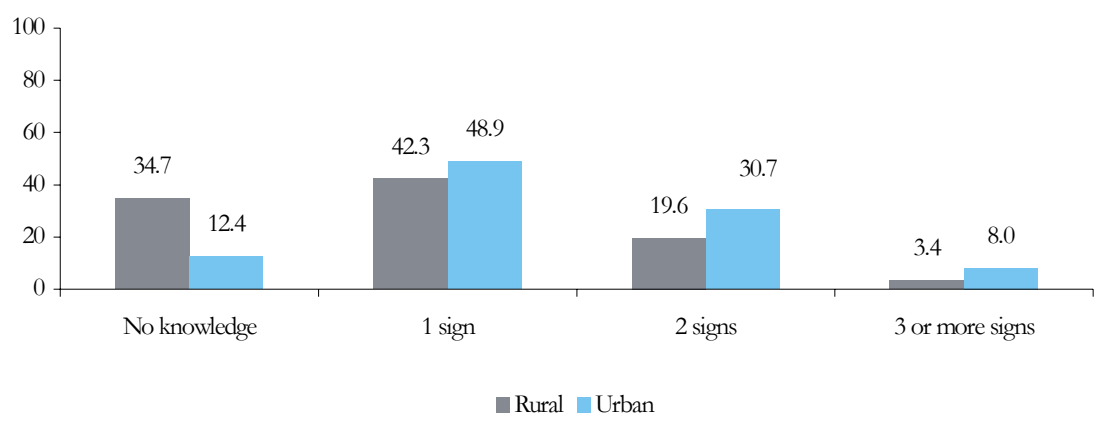

\section{Knowledge of Danger Signs in the Newborn}

Unfortunately, many women were also unaware of the danger signs that may appear in newborns, especially in the first seven days after the childbirth. The newborn period is defined as the first four weeks after birth. Two different questions were asked to assess the knowledge of currently married women regarding danger signs in newborns soon after the birth or within 7 days of birth. Half of the urban respondents (50.4 percent) and one fourth (26.6 percent) of rural respondents recognized 'fever/high fever with or without rigors' as a danger sign in newborns.

Figure 4.7: $\quad$ Percentage of married women by status of knowledge of danger signs in newborn and place of residence

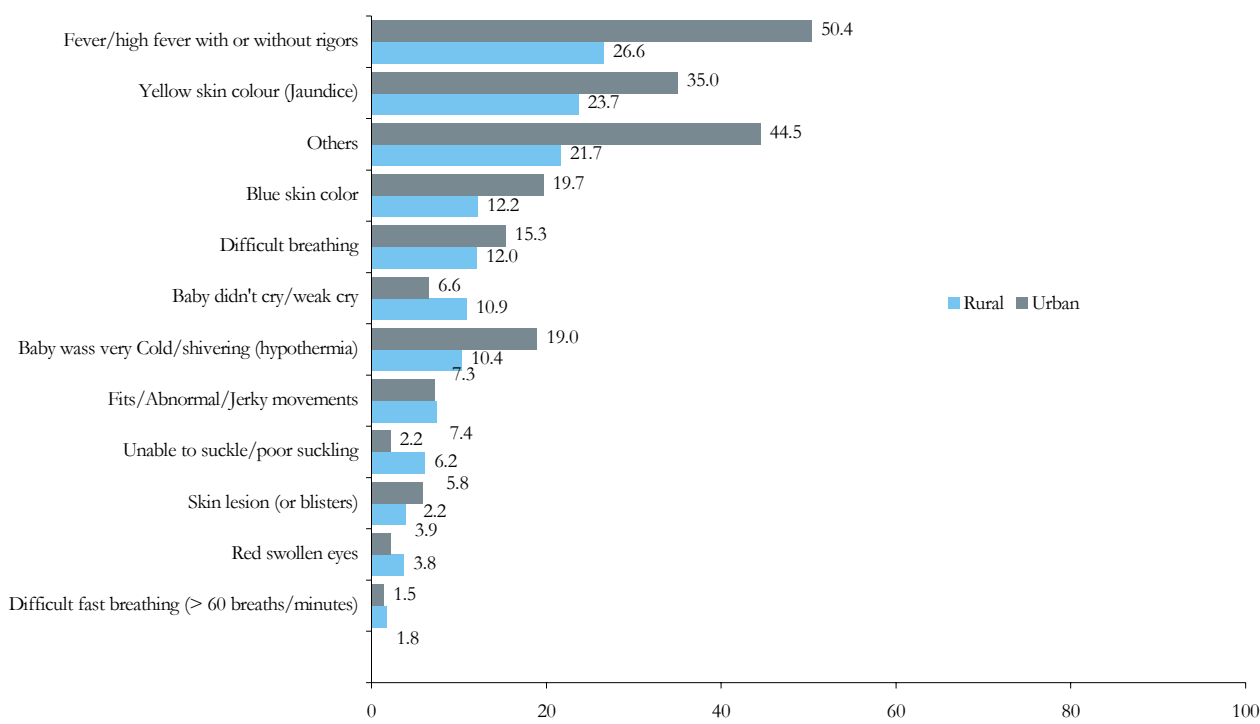


One third ( 33.3 percent) of the rural women were unable to name any of the danger signs that may appear in a newborn. Approximately 31 percent reported only one sign while about 25 percent reported two signs. In urban areas, 34 percent of the women were able to name one danger sign, followed by 35 percent who knew two, and finally 12 percent who were unable to name even a single complication or danger sign.

Figure 4.8: $\quad$ Distribution of respondents who had knowledge about danger signs in newborns by place of residence

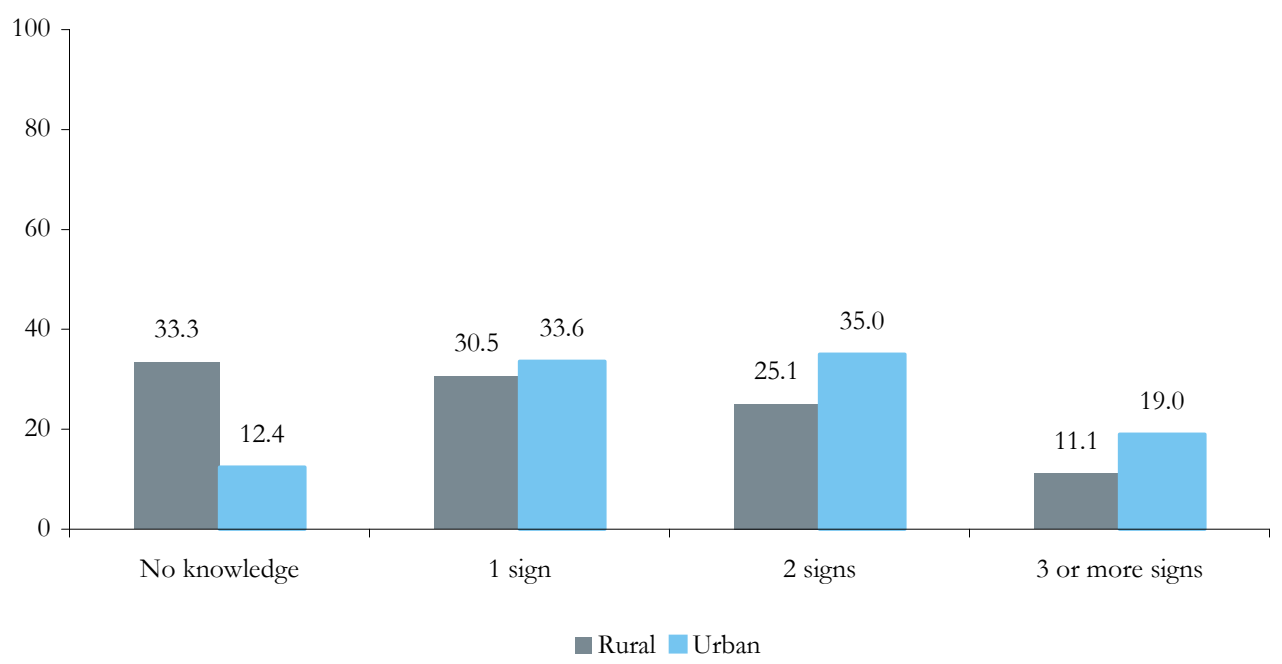

\section{Source of Information Regarding Danger Signs}

Finally, respondents were asked to state the source of their information regarding complications during pregnancy, delivery and the postpartum period. According to the findings, in-laws were the most common source of information for 40 percent of the rural women, while 33 percent of their urban counterparts reported the same source. Friends and neighbors were also important sources of information for many of the respondents (Figure 4.9).

Among the various health care providers, TBAs/Dais were the most common source of information for 28 percent and 10 percent of the rural and urban respondents respectively. Another important finding was that mass media was not cited as a source of knowledge by a very high percentage of women in both urban and rural Khanewal. For example, 16 percent of the urban respondents reported television as their source of information, while only 11 percent reported the same thing in rural Khanewal. 
Figure 4.9: $\quad$ Source of information about pregnancy by place of residence

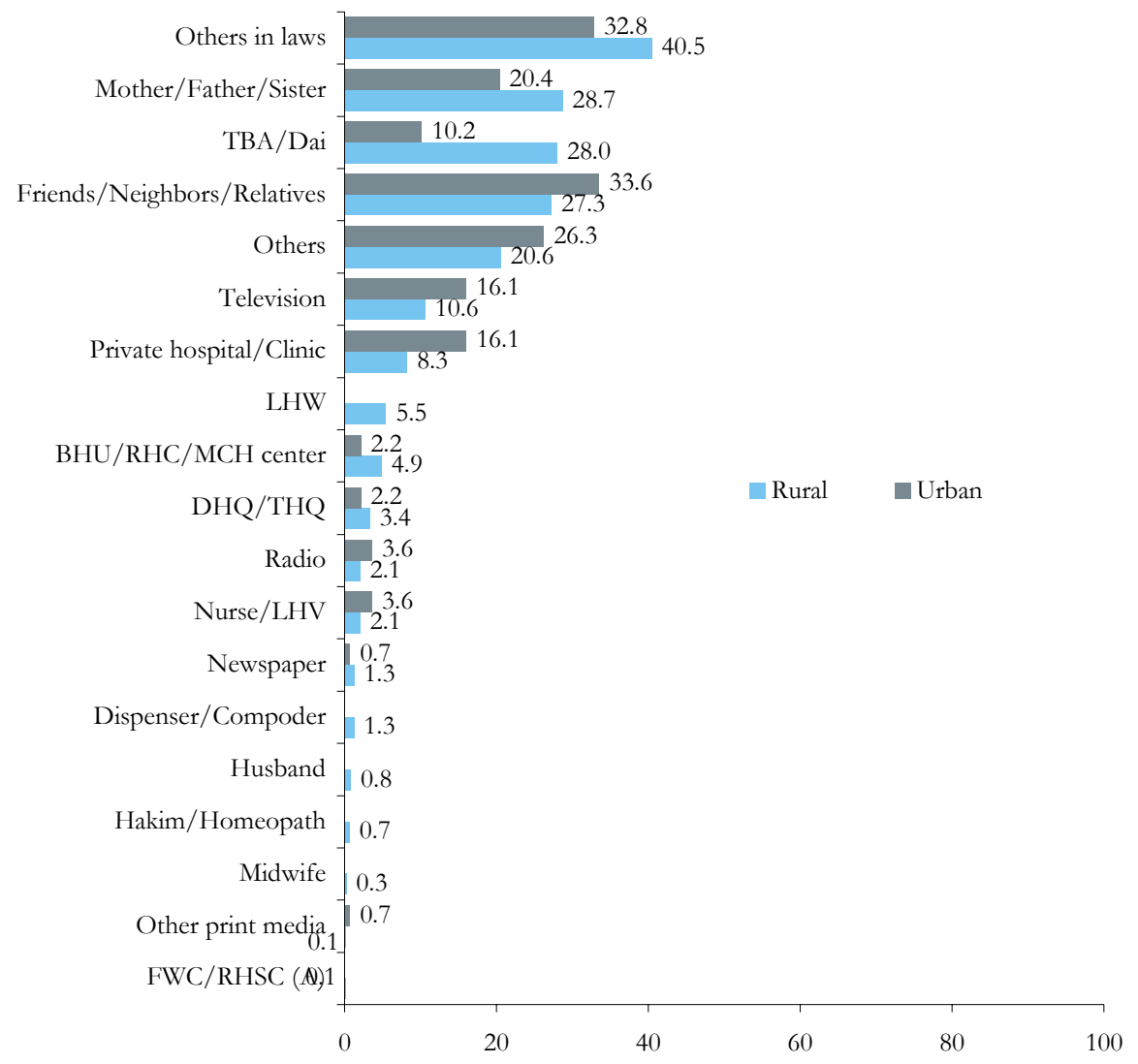




\section{Knowledge of Community Schemes for the Welfare of Women and Newborns}

The baseline also focused on community schemes pertaining to transportation and arrangements for blood and funding. These services help in ensuring that there are no delays at the time of delivery. Lack of arrangements for transport to a health facility can cause a major delay and can lead to maternal and newborn mortality. It is very important to arrange transport ahead of time in order to eliminate that delay. In order to assess the prevalence of such schemes in the rural and urban areas of Khanewal, the respondents were asked whether there was an arrangement in their community for transport, blood and money at the time of delivery.

Table 4.1: $\quad$ Knowledge of existence and importance of transport, blood and finances by the community at the time of delivery by place of residence

\begin{tabular}{lcccccc}
\hline \multirow{2}{*}{\begin{tabular}{l} 
Community Services \\
\cline { 2 - 6 }
\end{tabular}} & Percent & Number & Percent & Number & Percent & Number \\
\hline $\begin{array}{l}\text { Existence of transport by the } \\
\text { community at delivery }\end{array}$ & 0.3 & 2 & 0.7 & 1 & 0.4 & 3 \\
\hline $\begin{array}{l}\text { Important to have community } \\
\text { provided transport facility }\end{array}$ & 99.6 & 711 & 99.3 & 136 & 99.5 & 847 \\
\hline $\begin{array}{l}\text { Existence of blood by the } \\
\text { community at time of delivery }\end{array}$ & 0.0 & 0 & 0.0 & 0 & 0.0 & 0 \\
\hline $\begin{array}{l}\text { Important to have community } \\
\text { provided blood facility }\end{array}$ & 99.7 & 712 & 100.0 & 137 & 99.8 & 849 \\
\hline $\begin{array}{l}\text { Existence of money by community } \\
\text { at the time of delivery }\end{array}$ & 0.0 & 0 & 0.0 & 0 & 0.0 & 0 \\
\hline $\begin{array}{l}\text { Important to have community } \\
\text { provided money facility }\end{array}$ & 99.6 & 711 & 100.0 & 137 & 99.6 & 848 \\
\hline
\end{tabular}

Table 4.1 indicates that more than 99 percent of the married women of Khanewal believe in the importance of community based transport, money and blood facilities for pregnant women at the time of delivery. Unfortunately, less than one percent ( 0.3 percent) of the respondents knew of the existence of a transport facility in their respective communities, while none of the respondents knew of community based blood and money facilities to assist pregnant women at the time of delivery. 


\section{Chapter}

\section{Attitudes Towards Pregnancy, Delivery and the Postpartum period}

This chapter explores the attitudes of married women towards pregnancy, delivery and the postpartum period. Determining these attitudes and beliefs is important for designing strategies that bring about a change in traditional thinking.

\section{Attitudes Towards Age at Marriage}

In response to the question of whether or not women should get married soon after puberty, both urban and rural populations yielded similar results. More than half of the sample population (57 percent) in rural areas and half in the urban area (50 percent) were of the opinion that women should get married soon after puberty. On the other hand, almost an equal percentage of women in rural and urban areas (41 percent and 47 percent respectively), were of the opinion that women should not get married at an early age. A deeper look into this issue shows that many families do not value girls' education, and place greater emphasis on marriage. As a result, women are married at an early age and often do not have the opportunity to obtain any education whatsoever. There is also a link between the amount of education obtained by women and the fertility rate of a country (Sathar et al, 1988). The younger the age at marriage, the greater the exposure to childbearing.

\section{Attitudes Towards Antenatal Care}

Women in both urban and rural areas of Khanewal were then asked if they believed pregnant women needed to have antenatal check-ups. A very high percentage in both urban and rural areas (85 percent and 82 percent respectively) believed antenatal care was essential during pregnancy.

Table 5.1: $\quad$ Believe in necessity of antenatal check-up by place of residence

\begin{tabular}{l|rrrrrr} 
Have antenatal check- & \multicolumn{2}{c}{ Rural } & \multicolumn{2}{c}{ Urban } & \multicolumn{2}{c}{ Total } \\
\cline { 2 - 7 } & Percent & Number & Percent & Number & Percent & Number \\
\hline Yes & 82.4 & 588 & 85.4 & 117 & 82.8 & 705 \\
\hline No & 14.0 & 100 & 12.4 & 17 & 13.7 & 117 \\
\hline Don't know & 3.6 & 26 & 2.2 & 3 & 3.4 & 29 \\
Total & 100.0 & 714 & 100.0 & 137 & 100.0 & 851
\end{tabular}


Table 5.2: $\quad$ Month of the pregnancy when women should go for antenatal care by place of residence

\begin{tabular}{lrrrrrr}
\hline \multirow{2}{*}{ Month } & \multicolumn{2}{c}{ Rural } & \multicolumn{2}{c}{ Urban } & \multicolumn{2}{c}{ Total } \\
\hline 1 & Percent & Number & Percent & Number & Percent & Number \\
\hline 2 & 7.5 & 44 & 12.8 & 15 & 8.4 & 59 \\
\hline 3 & 10.1 & 59 & 9.4 & 11 & 9.9 & 70 \\
\hline 4 & 18.2 & 107 & 16.2 & 19 & 17.9 & 126 \\
\hline 5 & 8.0 & 47 & 5.1 & 6 & 7.5 & 53 \\
\hline 6 & 5.1 & 30 & 3.4 & 4 & 4.8 & 34 \\
\hline 7 & 1.9 & 11 & 1.7 & 2 & 1.8 & 13 \\
\hline 8 & 2.4 & 14 & 6.0 & 7 & 3.0 & 21 \\
\hline 9 & 0.9 & 5 & 1.7 & 2 & 1.0 & 7 \\
\hline $\begin{array}{l}\text { As soon as possible } \\
\text { after pregnancy }\end{array}$ & 1.0 & 6 & & & 0.9 & 6 \\
\hline $\begin{array}{l}\text { When check-up is } \\
\text { needed }\end{array}$ & 4.4 & 26 & 9.4 & 11 & 5.3 & 37 \\
\hline Don't know & 38.3 & 225 & 33.3 & 39 & 37.5 & 264 \\
\hline Total & 2.2 & 13 & 0.9 & 1 & 2.0 & 14 \\
\hline
\end{tabular}

From the 83 percent of the respondents who were in favor of antenatal care, 37.5 percent believed that antenatal care should be sought only when necessary. About 18 percent indicated that the first antenatal check-up should take place in the third month of pregnancy, while only 5.3 percent said that a woman should go for the first antenatal checkup as soon as she got pregnant. Furthermore, respondents were asked to indicate the number of antenatal visits that should take place over the course of a pregnancy. About 53 percent indicated that antenatal check-ups should be conducted only when needed while only 4 percent said that a woman should have 9 or more antenatal checkups. Surprisingly, a majority of these responses were received from rural Khanewal. Responses are presented in table 5.3. 
Table 5.3: $\quad$ Number of antenatal visits by place of residence

\begin{tabular}{lrrrrrr} 
& \multicolumn{2}{c}{ Rural } & \multicolumn{2}{c}{ Urban } & \multicolumn{2}{c}{ Total } \\
& Percent & Number & Percent & Number & Percent & Number \\
\cline { 2 - 7 } & 2.0 & 12 & 1.7 & 2 & 2.0 & 14 \\
\hline 2 & 8.5 & 50 & 3.4 & 4 & 7.7 & 54 \\
\hline 3 & 17.9 & 105 & 13.7 & 16 & 17.2 & 121 \\
\hline 4 & 7.0 & 41 & 6.8 & 8 & 7.0 & 49 \\
\hline 5 & 1.7 & 10 & 5.1 & 6 & 2.3 & 16 \\
\hline 6 & 0.7 & 4 & 3.4 & 4 & 1.1 & 8 \\
\hline 7 & 1.9 & 11 & 2.6 & 3 & 2.0 & 14 \\
\hline 8 & 1.4 & 8 & 1.7 & 2 & 1.4 & 10 \\
\hline 9 & 3.2 & 19 & 5.1 & 6 & 3.6 & 25 \\
\hline 10 & 0.2 & 1 & & & 0.1 & 1 \\
\hline 11 & 0.2 & 1 & & & 0.1 & 1 \\
\hline 21 & 0.2 & 1 & & & 0.1 & 1 \\
\hline When check-up is & 53.0 & 311 & 54.7 & 64 & 53.3 & 375 \\
needed & 2.2 & 13 & 1.7 & 2 & 2.1 & 15 \\
\hline Don't know & 100.0 & 587 & 100.0 & 117 & 100.0 & 704 \\
Total & & & & & & 17 \\
\hline
\end{tabular}

Almost three quarters of the women (74.3 percent) in Khanewal understood the importance of Tetanus Toxoid (TT) shots during pregnancy. A higher percentage of respondents (85 percent) knew the importance of taking iron/folate supplements during pregnancy.

Figure 5.1: $\quad$ Percentage of married women who received TT shots and took iron/folate during pregnancy by place of residence

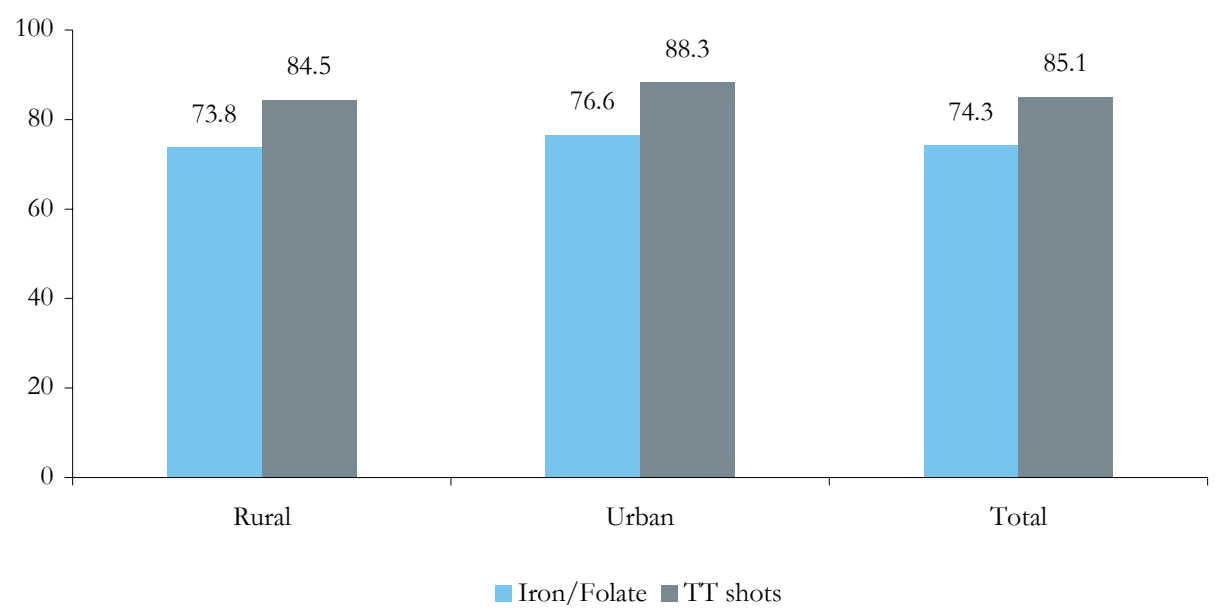




\section{Attitude Towards Delivery}

Many families prefer the traditional practice of employing Traditional Birth Attendants (TBAs) or Dais to assist with deliveries. These TBAs/Dais have vast experience but no formal training and therefore do not qualify as skilled birth attendants. However, many families do not realize the impact a lack of training can have on childbirth, and chose to opt for TBAs over health professionals. About 85 percent of the women surveyed in both rural and urban Khanewal believed that women should receive delivery services from health professionals.

Table 5.4: $\quad$ Believe that women should receive delivery services from health professional by place of residence

\begin{tabular}{lrrrrrrr} 
& \multicolumn{2}{c}{ Rural } & \multicolumn{2}{c}{ Urban } & \multicolumn{2}{c}{ Total } \\
\cline { 2 - 8 } & Nercent & Number & Percent & Number & Percent & Number \\
\hline Yes & 84.6 & 603 & 84.7 & 116 & 84.6 & 719 \\
\hline No & 7.6 & 54 & 13.1 & 18 & 8.5 & 72 \\
\hline Don't know & 7.9 & 56 & 2.2 & 3 & 6.9 & 59 \\
\hline Total & 100.0 & 713 & 100.0 & 137 & 100.0 & 850
\end{tabular}

The majority of the respondents of rural (58 percent) and urban (59 percent) areas said that only some of the women in their respective communities received delivery services from trained health providers.

Figure 5.2: $\quad$ Percentage of women who thought the women in their community went for skilled birth attendance for their delivery by place of residence

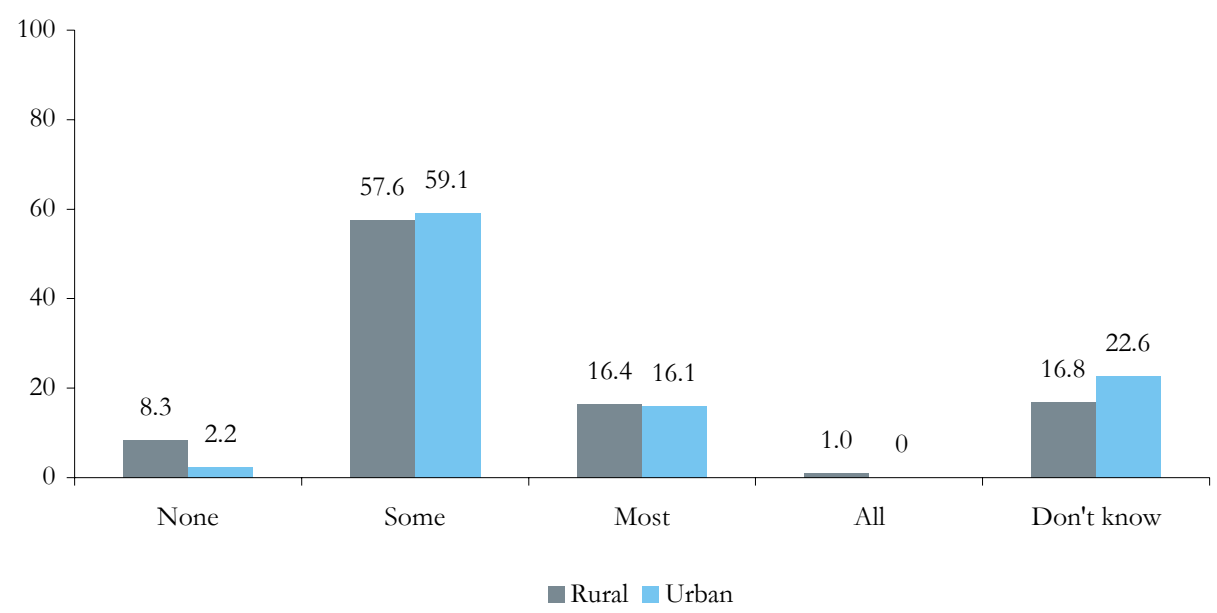

A majority of the respondents in both rural ( 66 percent) and urban (58 percent) Khanewal believed deliveries should be conducted at home. Approximately 41 percent and 34 percent of the respondents in urban and rural areas believed deliveries should take place at a hospital. 
Figure 5.3: $\quad$ Percentage of women by their perception where should delivery take place

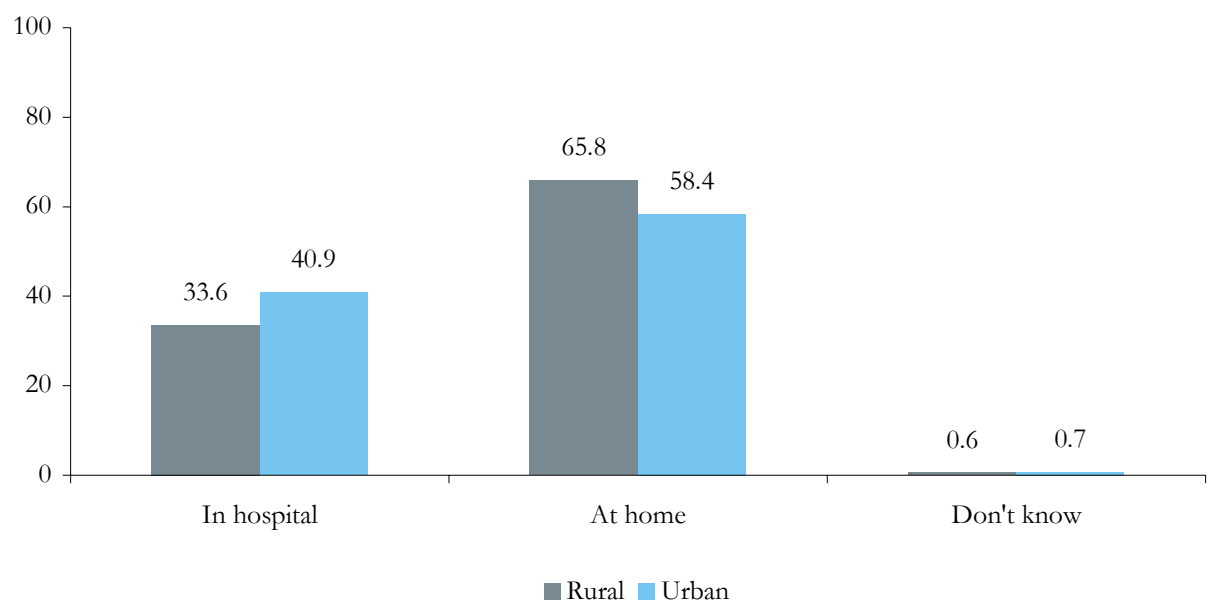

Only 3.6 percent respondents in rural and 2.2 percent in urban Khanewal believed that a pregnant woman should herself decide when to seek care and treatment in the event that a complication should arise. This would suggest that a majority of the women do not have the power to make decisions independently. A very high percentage of women (67 percent) believed that a woman's husband must make such important decisions.

Table 5.5: $\quad$ Person women believe should take charge of the pregnant women by place of residence

\begin{tabular}{lrrrrrr}
\multicolumn{1}{c}{ Person } & \multicolumn{2}{c}{ Rural } & \multicolumn{2}{c}{ Urban } & \multicolumn{2}{c}{ Total } \\
\cline { 2 - 7 } & Percent & Number & Percent & Number & Percent & Number \\
Pregnant woman & 3.6 & 26 & 2.2 & 3 & 3.4 & 29 \\
\hline Husband & 67.2 & 480 & 67.9 & 93 & 67.3 & 573 \\
\hline Other family members & 26.5 & 189 & 29.2 & 40 & 26.9 & 229 \\
\hline TBA/Dai & 2.1 & 15 & 0.7 & 1 & 1.9 & 16 \\
\hline Don't know & 0.6 & 4 & & & 0.5 & 4 \\
Total & 100.0 & 714 & 100.0 & 137 & 100.0 & 851
\end{tabular}

Finally, respondents were asked to indicate the mode of transportation they would use to reach a health facility. A very high percentage in rural and urban areas (81 percent and 83 percent respectively) indicated that they would hire private transport, while about 7 percent would use their own means of transport. 
Figure 5.4: $\quad$ Percentage of married women by mode of transport they would use to reach

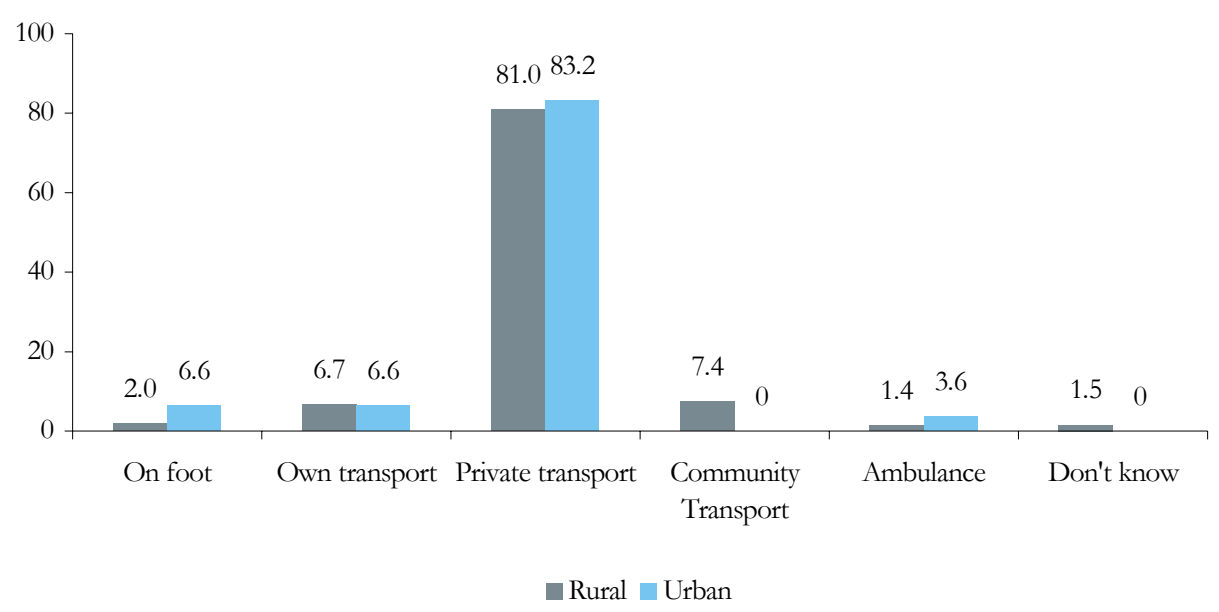

\section{Attitudes Towards Postpartum and Neonatal Care}

The importance of postnatal care is often undervalued. Postnatal care ensures that both mother and newborn are in good health, and monitors the recovery process of new mothers. When asked if women required postnatal check-ups, 43 percent of the respondents in both urban and rural areas said they did not consider it important. However, 50 percent of the women understood the necessity of postnatal care.

Table 5.6: $\quad$ Belief in necessity of postnatal care by place of residence

\begin{tabular}{lrrrrrrr} 
& \multicolumn{2}{c}{ Rural } & \multicolumn{2}{c}{ Urban } & \multicolumn{2}{c}{ Total } \\
\cline { 2 - 8 } Need postnatal & Percent & Number & Percent & Number & Percent & Number \\
\hline Yes & 49.2 & 351 & 51.1 & 70 & 49.5 & 421 \\
\hline No & 43.0 & 307 & 43.1 & 59 & 43.0 & 366 \\
\hline Don't know & 7.8 & 56 & 5.8 & 8 & 7.5 & 64 \\
Total & 100.0 & 714 & 100.0 & 137 & 100.0 & 851
\end{tabular}

In urban areas, the percentage of women who believed that only some of the women in their area received postnatal care was 41 percent, while 14 percent believed that no one was receiving postnatal care, and less than 1 percent believed that all women obtained such care. In rural areas, 23 percent indicated that no one in their community obtained postnatal care, while less than 1 percent indicated that all women obtained postnatal care. 
Figure 5.5: $\quad$ Number of postnatal care visits women should have in the community by place of residence

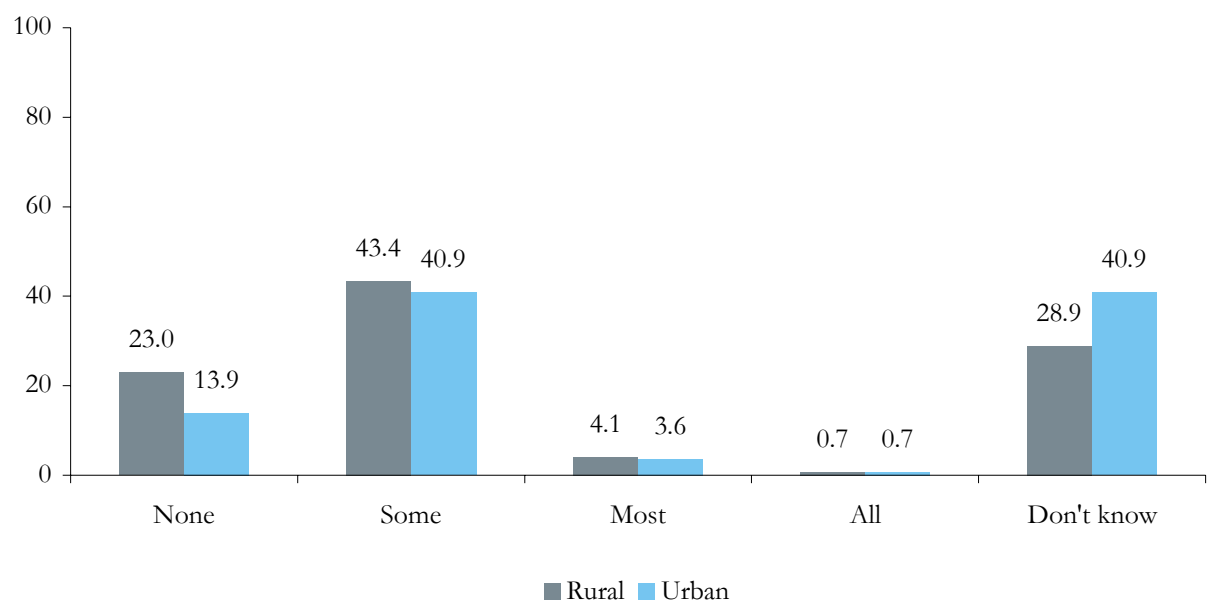

\section{Coverage of Lady Health Workers}

In assessing the coverage of Lady Health Workers (LHW) in the area, the respondents were asked if a LHW was present in their area. About 94 percent in urban areas and 91 percent in rural areas said that an LHW had visited their communities.

Table 5.7: $\quad$ Presence of lady bealth worker in the community by place of residence

\begin{tabular}{lrrrrrr} 
& \multicolumn{2}{c}{ Rural } & \multicolumn{2}{c}{ Urban } & \multicolumn{2}{c}{ Total } \\
\cline { 2 - 7 } Has LHW in the area & Percent & Number & Percent & Number & Percent & Number \\
Yes & 91.3 & 652 & 94.2 & 129 & 91.8 & 781 \\
\hline No & 7.1 & 51 & 2.2 & 3 & 6.3 & 54 \\
\hline $\begin{array}{l}\text { Respondent herself is } \\
\text { LHW }\end{array}$ & 0.8 & 6 & 1.5 & 2 & 0.9 & 8 \\
\hline Don't know & 0.7 & 5 & 2.2 & 3 & 0.9 & 8 \\
Total & 100.0 & 714 & 100.0 & 137 & 100.0 & 851
\end{tabular}

Among those who reported the presence of LHW in their areas, 35 percent of the women indicated that no LHW had visited their home in the three months prior to the survey. This proportion is almost the same in both urban and rural areas.

Table 5.8: $\quad$ LHW ever visited home during last three months by place of residence

\begin{tabular}{lrrrrrr}
\multirow{2}{*}{ Ever visited } & \multicolumn{2}{c}{ Rural } & \multicolumn{2}{c}{ Urban } & \multicolumn{2}{c}{ Total } \\
\cline { 2 - 7 } & Percent & Number & Percent & Number & Percent & Number \\
\hline Yes & 64.7 & 422 & 66.7 & 86 & 65.0 & 508 \\
\hline No & 35.3 & 230 & 33.3 & 43 & 35.0 & 273 \\
Total & 100.0 & 652 & 100.0 & 129 & 100.0 & 781
\end{tabular}





\section{Chapter}

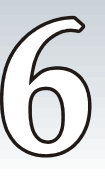

\section{Contraceptive Knowledge and Use}

Respondents were asked to name the ways in which a couple could delay or avoid a pregnancy. If the respondent did not spontaneously mention a particular method, the interviewer described different methods and asked the respondent to indicate if she recognized them. In the questionnaire, descriptions were included for six modern contraceptive methods and two traditional methods.

\section{Knowledge of Contraceptive Methods}

Respondents were asked to name the various family planning methods that they knew could be used to avoid a pregnancy. It was noted that more than three quarters of the urban women were aware of four modern family planning methods, namely pills ( 85 percent), injections ( 85 percent), IUD (82 percent) and female sterilization (75 percent). About 1.5 percent reported having no knowledge of any of these four methods. Nearly 71 percent of the women spontaneously reported condoms as a method of family planning they were aware of. Among the traditional family planning methods, rhythm was the least known method reported by only 6.6 percent of the women.

Figure 6.1: $\quad$ Percentage of married women by knowledge of specific contraceptive method - Urban

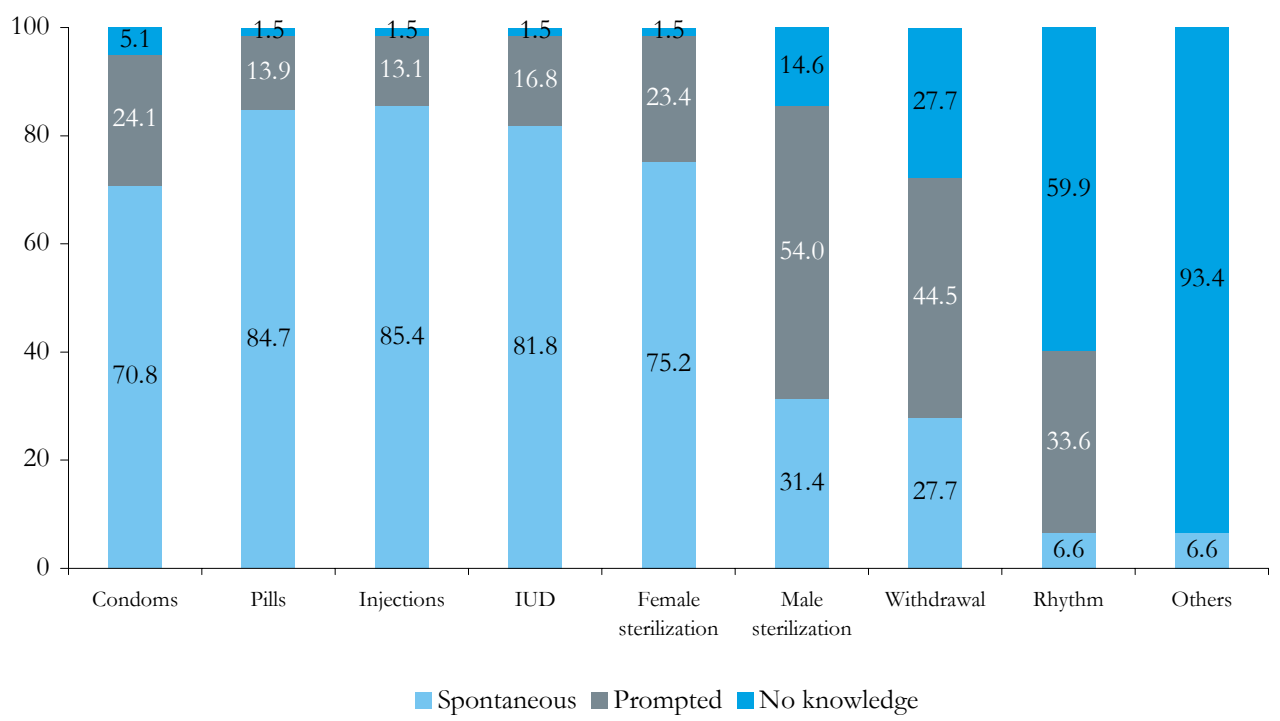


In rural areas, the most commonly known and reported methods were pills (79 percent), injections (82 percent), IUD (77 percent) and female sterilization (73 percent).

Figure 6.2: $\quad$ Percentage of married women by knowledge of specific contraceptive method - Rural

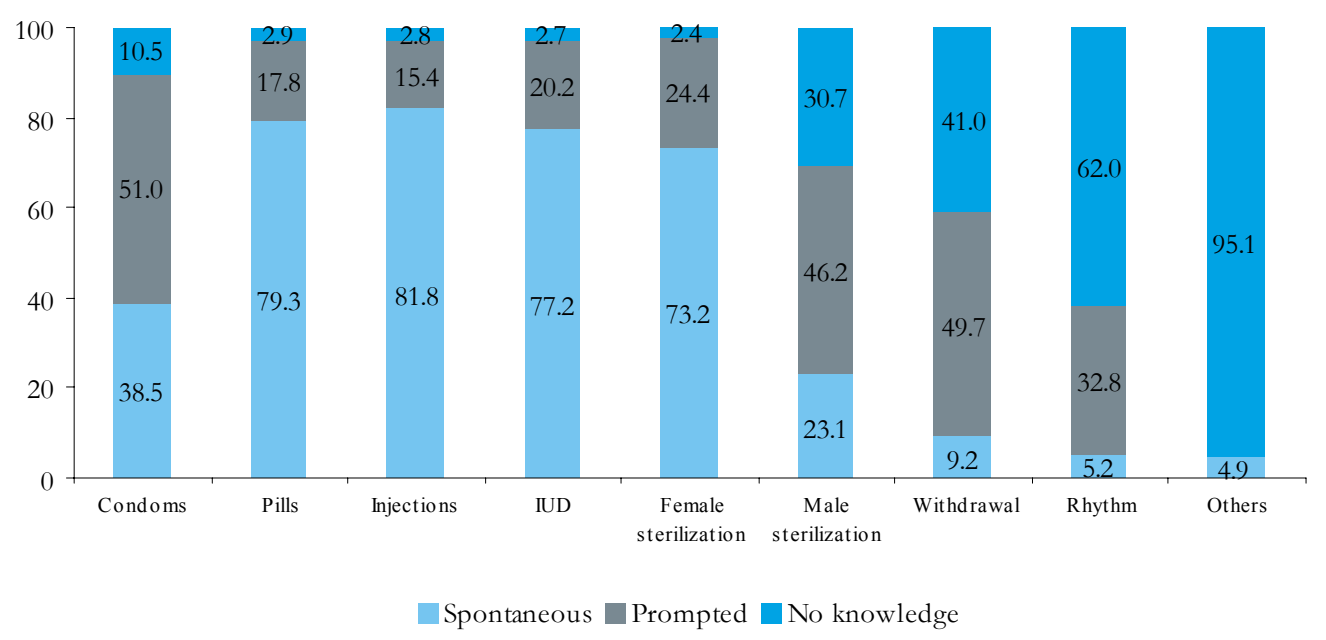

\section{Ever Use of Contraception}

When asked if they had ever used any form of contraception, 38 percent reported having used some type of contraceptive method ( 35 percent for rural and 50 percent for urban areas). About 12 percent of the respondents in rural areas and nearly 14 percent in urban areas reported using IUDs. The second most reported family planning method used by both rural and urban women was female sterilization (10 percent and 11 percent respectively). Less than 1 percent ( 0.6 percent) of the respondents in rural areas reported male sterilization as a form of birth control, while no urban cases of male sterilization were reported (Table 6.1).

Table 6.1: $\quad$ Ever used FP methods by contraceptive and place of residence

\begin{tabular}{lrrrr}
\multirow{2}{*}{$\begin{array}{l}\text { Contraceptive method } \\
\text { Any method }\end{array}$} & \multicolumn{2}{c}{ Place of residence } & \multicolumn{2}{c}{ Total } \\
\cline { 2 - 5 } Condoms & 35.4 & Urban & Percentage & Number \\
\hline Pills & 8.0 & 19.0 & 37.7 & 321 \\
\hline Injections & 6.7 & 7.3 & 9.8 & 83 \\
\hline IUD & 8.5 & 6.6 & 6.8 & 58 \\
\hline Female sterilization & 11.8 & 13.9 & 8.2 & 70 \\
\hline Male sterilization & 9.4 & 10.2 & 12.1 & 103 \\
\hline Withdrawal & 0.6 & & 9.5 & 88 \\
\hline Rhythm & 6.6 & 13.1 & 0.5 & 4 \\
\hline
\end{tabular}




\section{Current Use of Contraceptive Methods}

Contraceptive prevalence is defined as the proportion of currently married women aged 15-49 years using some method of family planning at the time of the survey. When asked about the type of family planning method used currently, more than half the urban respondents ( 65 percent) and 77 percent of the rural ones reported using no method. Out of 23 percent rural and 35 percent urban contraceptive users, 9.4 percent in rural area and 10.2 percent in urban are using female sterilization. Table 6.2 shows the percentage distribution of married women currently using specific family planning methods in Khanewal. It may be noted that a high number of urban women (10 percent) use traditional family planning methods which are not very reliable.

Table 6.2: $\quad$ Current use of FP methods by contraceptive and place of residence

\begin{tabular}{lcrr}
\multicolumn{1}{c}{ Contraceptive Method } & Rural & Urban & All \\
Any method & 23.1 & 35.0 & 25.0 \\
\hline Any modern method & 19.0 & 25.5 & 20.1 \\
\hline Any traditional method & 3.9 & 9.5 & 4.8 \\
\hline Condom & 3.1 & 7.3 & 3.8 \\
\hline Pill & 0.7 & 1.5 & 0.8 \\
\hline Injectables & 1.3 & 2.2 & 1.4 \\
\hline IUD & 4.5 & 4.4 & 4.5 \\
\hline Female sterilization & 9.4 & 10.2 & 9.5 \\
\hline Male sterilization & 0.6 & & 0.5 \\
\hline Withdrawal & 3.6 & 5.1 & 3.9 \\
\hline Rhythm & 0.3 & 4.4 & 0.9 \\
\hline Other & 0.1 & & 0.1 \\
\hline Not currently using & 76.9 & 65.0 & 75.0 \\
\hline Number & 714 & 137 & 851 \\
\hline
\end{tabular}

\section{Source of Contraceptive Supplies}

Respondents were then asked where they obtained their method of contraception. Table 6.3 outlines the distribution of current users by most recent source of contraception. About 35 percent and 29 percent of the women in rural and urban areas respectively indicated that Tehsil or District Headquarter Hospitals (THQ/DHQ) were their source of contraception. Table 6.3 also shows that more than 5 percent of the population was unsure of where they obtained contraceptives. This would indicate that many of the respondents were not able to obtain contraception themselves and were provided with family planning methods either by their husbands or by other family members and inlaws. LHWs were cited as a source of contraception by 3 percent and 6 percent of the population in urban and rural areas respectively. 
Table 6.3: $\quad$ Source of FP method by place of residence

\begin{tabular}{lrrrrrrr}
\multirow{2}{*}{ Source/Place } & \multicolumn{2}{c}{ Rural } & \multicolumn{2}{c}{ Urban } & \multicolumn{2}{c}{ Total } \\
\cline { 2 - 7 } LHW & Percent & Number & Percent & Number & Percent & Number \\
\hline TBA/dai & 5.9 & 8 & 2.9 & 1 & 5.3 & 9 \\
\hline BHU/RHC/dispensary/MCH center & 3.7 & 5 & & & 2.9 & 5 \\
\hline DHQ/THQ & 19.1 & 26 & 5.7 & 2 & 16.4 & 28 \\
\hline Private clinic/hospital & 35.3 & 48 & 28.6 & 10 & 33.9 & 58 \\
\hline Nurse/LHV & 19.9 & 27 & 25.7 & 9 & 21.1 & 36 \\
\hline Medical store & 2.2 & 3 & 2.9 & 1 & 2.3 & 4 \\
\hline General store/shop & 3.7 & 5 & 11.4 & 4 & 5.3 & 9 \\
\hline Don't know & 6.6 & 9 & 11.4 & 4 & 7.6 & 13 \\
\hline Total & 3.7 & 5 & 11.4 & 4 & 5.3 & 9
\end{tabular}

\section{Intentions to Future Use}

Non-users of family planning methods were then asked if they had any intentions of using family planning methods in the future. As outlined in figure 6.3, about 36 percent of the respondents in rural areas and nearly 30 percent in urban areas indicated that they had no intentions of using contraception in the future. A very high percentage in both urban (41 percent) and rural Khanewal (37 percent) was uncertain if they wanted to use contraceptives in the future.

Figure 6.3: $\quad$ Percentage of married women by future intention to use contraceptives

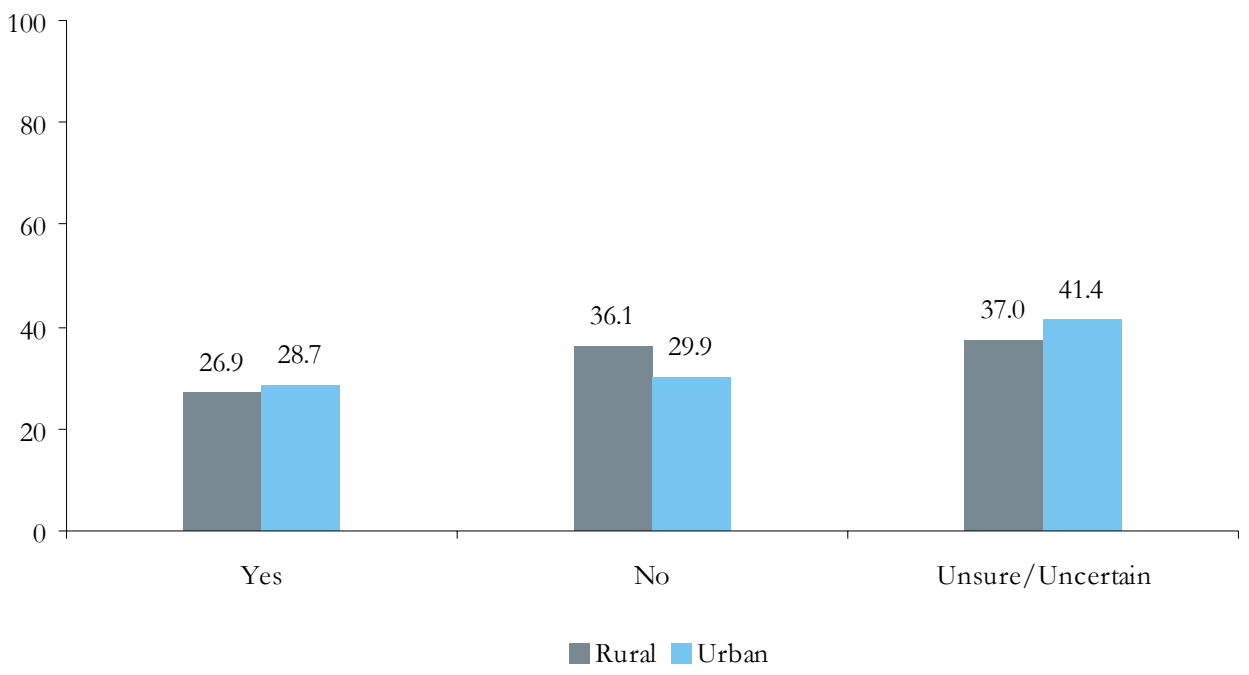




\title{
Chapter

\section{Behavior Regarding Maternal and Newborn Health}

\begin{abstract}
Many of the women who were interviewed were currently pregnant. However, some women, especially those in the early stages of pregnancy, had not yet experienced the full range of events that take place over the nine-month gestational period. Women who had recently given birth were able to provide a full range of information on these events and thus constitute an important part of the sample population in terms of understanding attitudes and behavior concerning maternal and newborn health. This chapter pertains to the respondents' last pregnancy, given that it was within the past three years. Respondents were asked several questions regarding their experience during their last pregnancy including antenatal and delivery care, complications during pregnancy and delivery, postnatal care and problems in accessing health care.

Information on antenatal care, delivery services and postnatal care is of great value in identifying segments of married women who do not utilize such services and is useful in planning for future improvements in services. Delivery services are described according to the person assisting the delivery and the rate of caesarean section. Information on postnatal care was collected for women who did not give birth in a health facility, and it describes the time since delivery when it was received, as well as the caregiver.
\end{abstract}

\section{Gestational Age}

The respondents were asked to indicate the gestational age at the time their pregnancy ended. According to the results obtained, out of the total pregnancies reported 88.2 percent resulted in live births, 3.5 percent in stillbirths, and 8.3 percent in abortions, which includes both spontaneous and induced (6.6 percent and 1.7 percent respectively). The majority of the live births (86 percent) were reported to have taken place after a gestational period of nine months. More than half of the reported stillbirths (53 percent) took place after completion of the gestational period which is a very significant finding. The majority of the spontaneous abortions ( 75 percent), along with all of the induced abortions, took place in the first trimester of pregnancy. 
Table 7.1: $\quad$ Pregnancy outcome by gestational age

\begin{tabular}{lrrrr}
$\begin{array}{l}\text { Gestational age when } \\
\text { Pregnancy ended }\end{array}$ & Live Birth & Still birth & $\begin{array}{c}\text { Spontaneous } \\
\text { Abortions }\end{array}$ & $\begin{array}{c}\text { Induced } \\
\text { Abortions }\end{array}$ \\
Less than 3 months & & & 75.0 & 100.0 \\
\hline 4 to 6 months & & & 25.0 & \\
\hline 7 & 0.5 & 33.4 & & \\
\hline 8 & 12.0 & 13.3 & & \\
\hline 9 & 85.8 & 53.3 & & 100.0 \\
\hline 10 & 1.6 & & 100.0 & 7 \\
\hline Total & 100.0 & 100.0 & 28 & \\
\hline Number of Pregnancies & 374 & 15 & & \\
\hline
\end{tabular}

\section{Antenatal Care}

In the PAIMAN baseline survey, antenatal care was defined by type of care provider, the number of visits made, the stage of pregnancy at the time of the first visit, including information regarding TT shots and iron supplements. The baseline survey also included questions regarding the antenatal care received by the respondent during the last pregnancy.

Over half the women interviewed in both urban and rural areas (50.8 percent and 53.7 percent respectively) indicated that they had received antenatal care after their last pregnancy.

Figure 7.1: $\quad$ Percentage of pregnant women by their antenatal care status for the pregnancy three years preceding the baseline survey

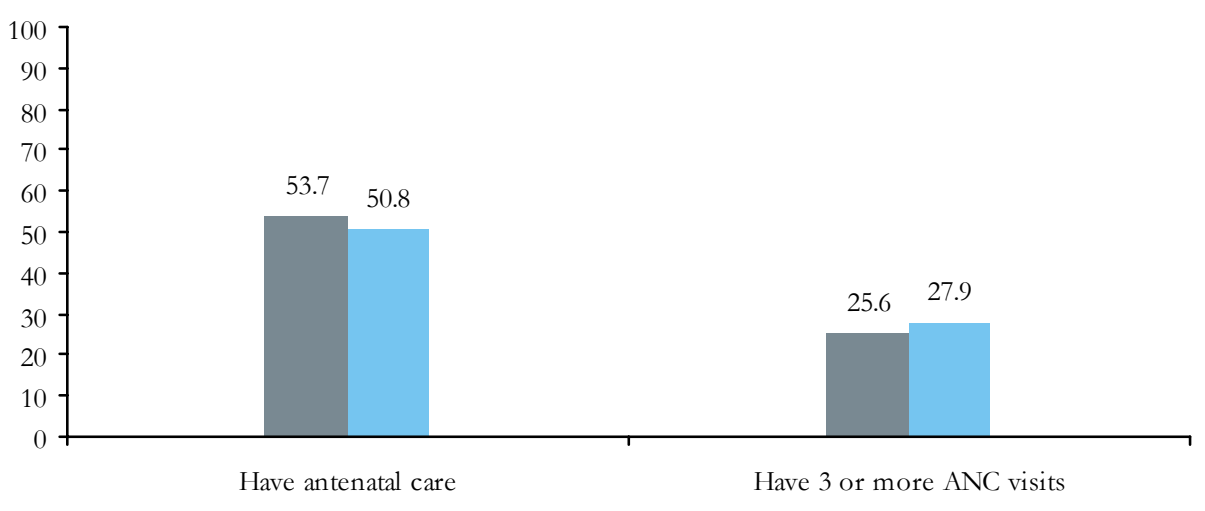

Rural $\square$ Urban

Furthermore, a high percentage of respondents (18.6 percent) who had received an antenatal check-up during their last pregnancy did so in their seventh month of pregnancy, followed by another 18.6 percent who obtained antenatal care in their third month of pregnancy. More than one-fourth of the women interviewed (28 percent) indicated that they received only one antenatal check-up during their pregnancy. Furthermore, 25.6 percent of pregnant women in rural Khanewal had 3 or more antenatal checkups during their last pregnancy, compared to 27.9 percent in urban areas. 
Table 7.2: $\quad$ Antenatal check-ups by place of residence

\begin{tabular}{|c|c|c|c|c|c|c|c|}
\hline \multirow{2}{*}{\multicolumn{2}{|c|}{ Check-ups }} & \multicolumn{2}{|c|}{ Rural } & \multicolumn{2}{|c|}{ Urban } & \multicolumn{2}{|c|}{ Total } \\
\hline & & Percent & Number & Percent & Number & Percent & Number \\
\hline \multirow{10}{*}{$\begin{array}{l}\text { Gestational age of } \\
\text { pregnancy at first } \\
\text { antenatal care }\end{array}$} & 1 & 8.7 & 17 & 12.9 & 4 & 9.3 & 21 \\
\hline & 2 & 9.7 & 19 & 16.1 & 5 & 10.6 & 24 \\
\hline & 3 & 18.5 & 36 & 19.4 & 6 & 18.6 & 42 \\
\hline & 4 & 7.7 & 15 & 3.2 & 1 & 7.1 & 16 \\
\hline & 5 & 7.7 & 15 & & & 6.6 & 15 \\
\hline & 6 & 8.7 & 17 & 9.7 & 3 & 8.8 & 20 \\
\hline & 7 & 19.0 & 37 & 16.1 & 5 & 18.6 & 42 \\
\hline & 8 & 12.3 & 24 & 16.1 & 5 & 12.8 & 29 \\
\hline & 9 & 4.1 & 8 & 6.5 & 2 & 4.4 & 10 \\
\hline & Don't know & 3.6 & 7 & & & 3.1 & 7 \\
\hline \multirow{11}{*}{$\begin{array}{l}\text { No. of antenatal } \\
\text { check-ups during } \\
\text { pregnancy }\end{array}$} & 1 & 29.7 & 58 & 19.4 & 6 & 28.3 & 64 \\
\hline & 2 & 21.5 & 42 & 25.8 & 8 & 22.1 & 50 \\
\hline & 3 & 16.4 & 32 & 22.6 & 7 & 17.3 & 39 \\
\hline & 4 & 9.7 & 19 & 9.7 & 3 & 9.7 & 22 \\
\hline & 5 & 7.2 & 14 & 3.2 & 1 & 6.6 & 15 \\
\hline & 6 & 2.6 & 5 & 3.2 & 1 & 2.7 & 6 \\
\hline & 7 & 3.6 & 7 & 3.2 & 1 & 3.5 & 8 \\
\hline & 8 & 1.5 & 3 & 6.5 & 2 & 2.2 & 5 \\
\hline & 9 & 3.6 & 7 & 6.5 & 2 & 4.0 & 9 \\
\hline & 10 & 2.1 & 4 & & & 1.8 & 4 \\
\hline & $\begin{array}{l}\text { Don't } \\
\text { know }\end{array}$ & 1.5 & 3 & & & 1.3 & 3 \\
\hline Total & & 100.0 & 195 & 100.0 & 31 & 100.0 & 226 \\
\hline
\end{tabular}

Figure 7.2: $\quad$ Percentage distribution of married women by persons who accompanied them to seek antenatal care

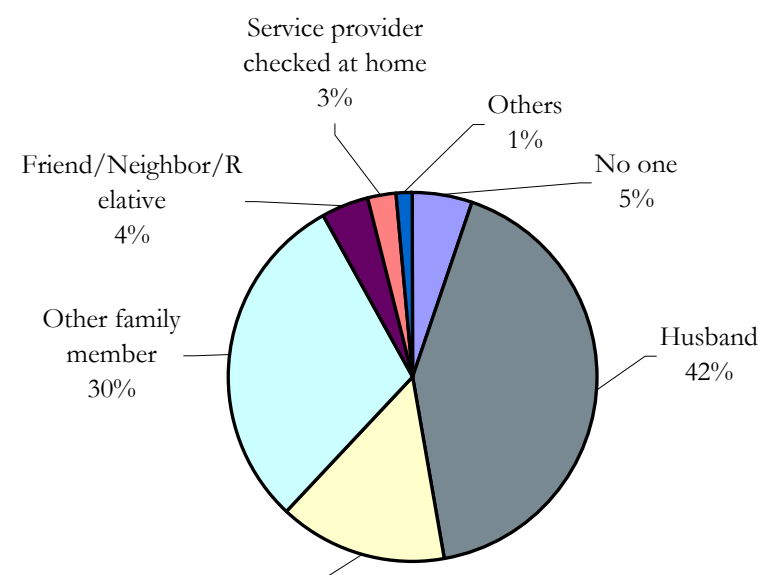

Mother in law

$15 \%$ 
According to figure 7.2, about 42 percent of the women interviewed indicated that they were accompanied by their husbands when they sought antenatal care, while 30 percent were accompanied by other family members. About 15 percent indicated that they were accompanied by their mothers in law.

\section{Components of Antenatal Care}

In Pakistan, it is recommended for every pregnant woman to receive the following antenatal care services; weight measurements, blood pressure measurement, iron tablets, tetanus toxoid immunization, and abdominal examination. It is said that during an antenatal care visit, a woman should have her weight measured, provide blood and urine samples for testing and should be informed of the danger signs of pregnancy. Antenatal care can improve certain outcomes of pregnancy and childbirth through the detection and management of possible complications. Antenatal care can improve birth weight of newborns, as well as identify and treat deficiencies in pregnant mothers.

Respondents were asked to report the various questions that the health providers asked them during their antenatal visits. This was to determine the level of care being provided by various district health care facilities in both urban and rural Khanewal.

Figure 7.3 illustrates the various services received by women in Khanewal during their antenatal visits. An ultrasound was performed during the antenatal check-up for 68 percent of the women in urban Khanewal and 63 percent in rural Khanewal. More than half of the women in Khanewal also reported receiving blood pressure checks and anemia tests. Finally, women indicated that their past obstetric history was also enquired about by their health providers. 
Figure 7.3: $\quad$ Services performed/asked during antenatal check-up by place of residence

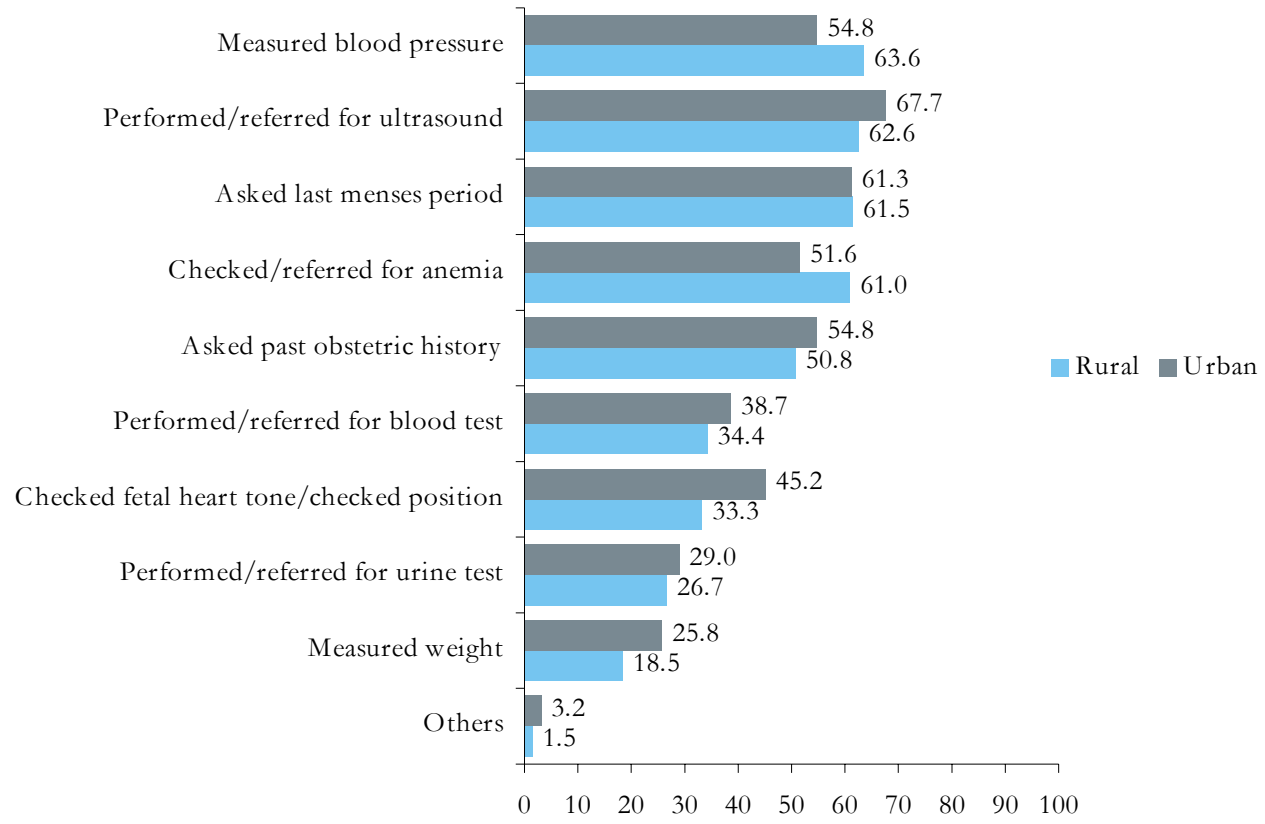

Respondents were also asked to indicate the issues discussed with them by health care providers during their antenatal visits.

Figure 7.4: $\quad$ Percentage of pregnant women by issues discussed during antenatal check-up and place of residence

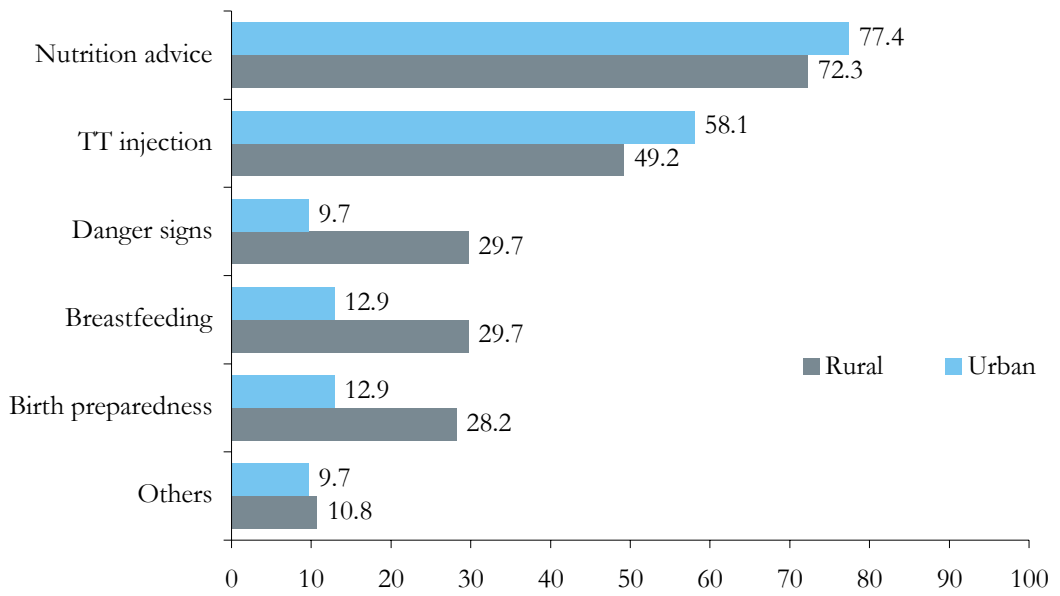

The most commonly discussed issue during antenatal visits was nutrition, as reported by 77 percent and 72 percent of the respondents in urban and rural areas. About 58 percent in urban areas and 49 percent in rural areas reported having received advice on TT injections. An important finding to be 
noted is that only 30 percent of women in rural Khanewal and 10 percent in urban Khanewal, were informed about danger signs during pregnancy. Again, this calls for some innovative approaches to make these communities knowledgeable regarding the danger signs arising during pregnancy.

\section{T'T Injections and Iron/Folate Tablets}

Respondents were also asked to state whether they took iron and folate supplements and received TT shots during their last pregnancy. Tetanus is one of the main causes of neonatal death in Pakistan and can be prevented by immunization of the mother during pregnancy. The immunization is transferred to the baby through the placenta, and protects the newborn against diseases. The immunization of pregnant women is enforced by a program coordinated by the Expanded Program on Immunization (EPI) and the Maternal and Child Health Care $(\mathrm{MCH})$ departments at the district level. The program recommends that women receive two tetanus toxoid (TT) injections during their first pregnancy. Booster injections are given once during each subsequent pregnancy to maintain full protection. In recent years, TT immunization has also been given to women before marriage, so that any pregnancy occurring within three years of their marriage would be protected against tetanus.

Only 44.3 percent of respondents in urban areas and 39 percent in rural Khanewal had received TT vaccinations in the last three years preceding the baseline survey. It has been noted that immunization coverage was slightly lower in rural areas as compared to urban areas.

Figure 7.5: $\quad$ Percentage of married women by status of TT Injections during the last pregnancy and place of residence

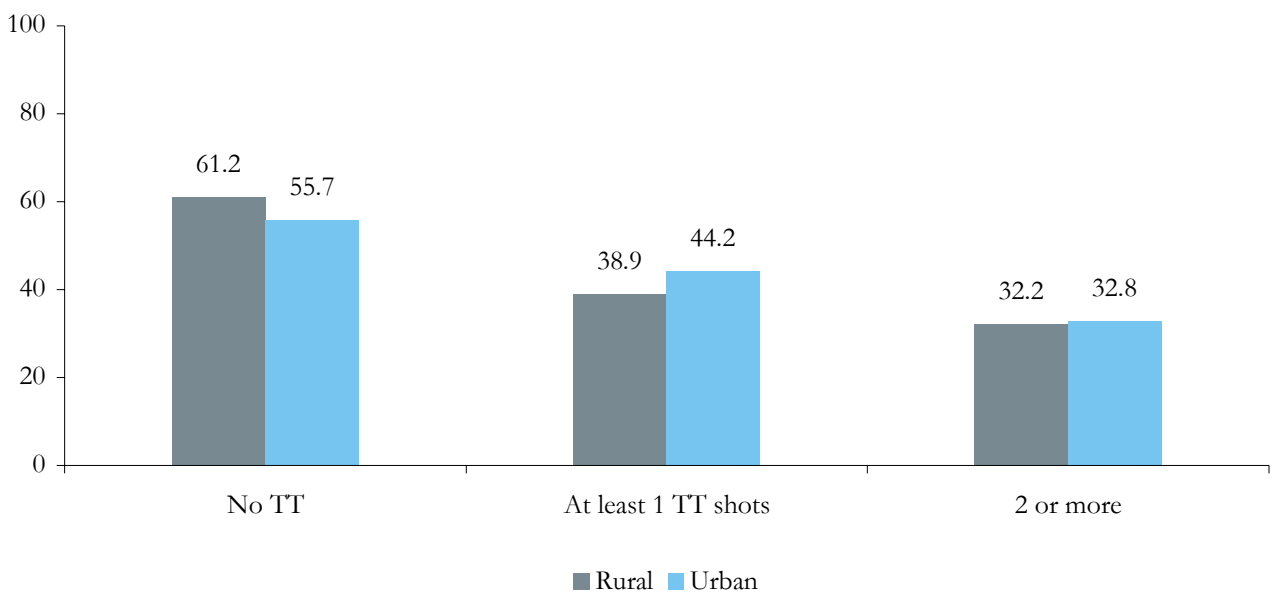

The respondents were also asked if they had taken iron/folate supplements during their last pregnancy. Nearly 69 percent of the women in Khanewal indicated that they had not taken iron/folate supplements during their last pregnancy, as seen in figure 7.6. 
Figure 7.6: $\quad$ Percentage of married women by status of Iron/Folate tablets during the last pregnancy and place of residence

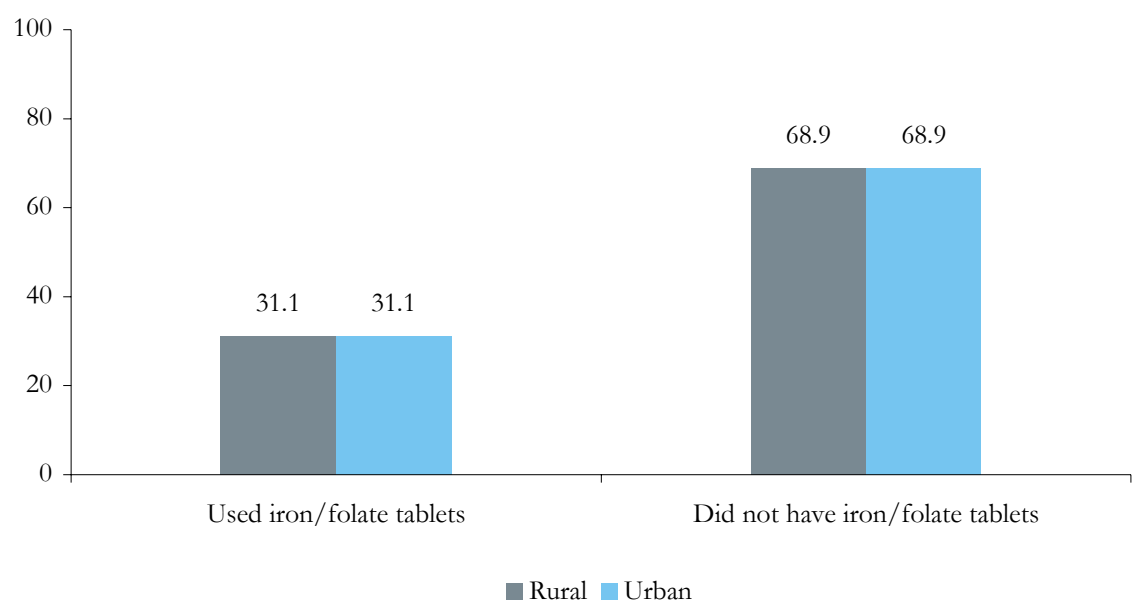

\section{Experience of Complications and Birth Preparedness}

\section{Complications During Pregnancy}

To identify complications associated with pregnancy, women were asked about certain signs and symptoms that they had experienced during their last pregnancy. More than half of the women in rural Khanewal (53.6 percent) and nearly half in urban Khanewal (44.3 percent) had experienced some type of complication during their last pregnancy. The majority of those had experienced severe lower abdominal pain, followed by those who had severe headaches, prolonged vomiting, blurring of vision, shortness of breath etc. 
Figure 7.7: $\quad$ Percentage of married women who experienced complications during their last pregnancy

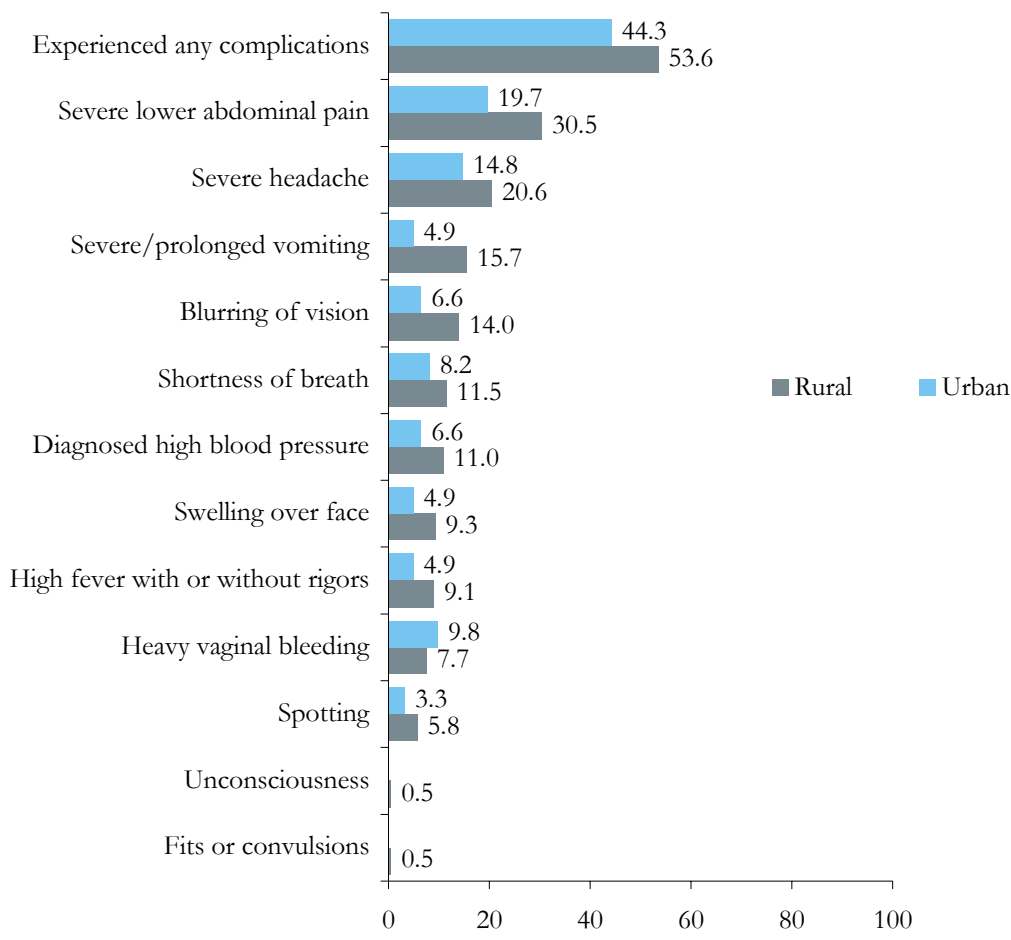

\section{Preparedness for Childbirth}

To ensure the safety of the mother and newborn at the time of delivery, certain preparations need to be made. These include deciding who is going to assist the delivery, where the delivery is going to take place, how the expectant mother will reach the place of delivery, and how much the delivery is going to cost. Delivery services, especially emergency obstetric care, are critical for pregnant women. Emergency care is important in case of obstructed labor, pregnancy-induced hypertension, eclampsia or severe untreated anemia. Obstructed or prolonged labor is one of the most serious complications that can cause maternal death. Obstetric care can also prevent or treat complications that affect the neonate, such as birth asphyxia.

In the baseline survey, women were asked about the arrangements that were made by them for the delivery, and the removal of various delays which may affect the health of both mother and baby. Respondents were also asked if they had made necessary arrangements regarding transport, money, blood, location and hours of operation of the nearest hospital, as well as clothes for the newborn baby. According to the baseline results three quarters ( 73 percent) of the respondents had prepared clothes for the baby, more than half (60 percent) reported having arranged money for a normal delivery and nearly half (49 percent) had made money arrangements for an emergency as well. 
Figure 7.8: $\quad$ Percentage of married women who made arrangements for their last delivery by place of resident

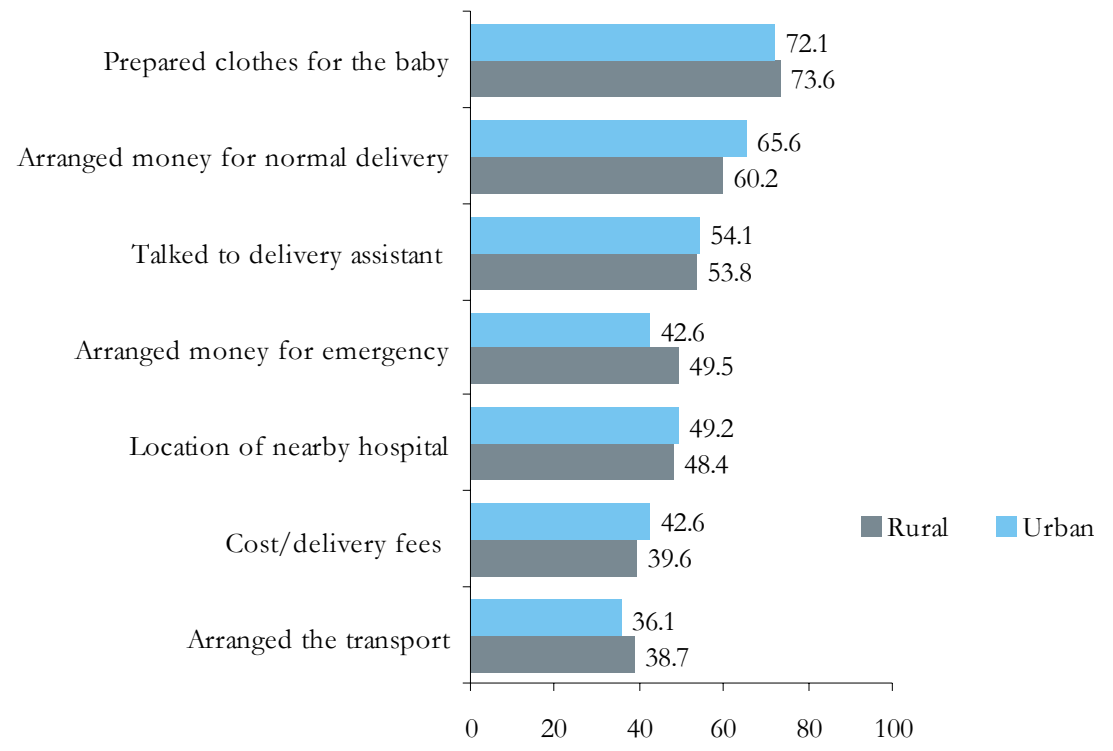

\section{Delivery Characteristics}

Nearly 80 percent of the respondents in rural areas reported having a normal vaginal delivery, whereas 70.5 percent of their counterparts in urban areas reported the same thing. Caesarean section deliveries appear to make up 7.4 percent of the deliveries in rural areas and 8.2 percent in urban areas.

Table 7.3: $\quad$ Status of last delivery by place of residence

\begin{tabular}{lrrrrrr}
\multicolumn{1}{c}{ Status } & \multicolumn{2}{c}{ Rural } & \multicolumn{2}{c}{ Urban } & \multicolumn{2}{c}{ Total } \\
\cline { 2 - 7 } & Percent & Number & Percent & Number & Percent & Number \\
\hline Normal vaginal delivery & 79.9 & 290 & 70.5 & 43 & 78.5 & 333 \\
\hline Assisted vaginal delivery & 4.4 & 16 & 11.5 & 7 & 5.4 & 23 \\
\hline Caesarean Section & 7.4 & 27 & 8.2 & 5 & 7.5 & 32 \\
\hline Spontaneous abortion & 6.3 & 23 & 9.8 & 6 & 6.8 & 29 \\
\hline Induced abortion & 1.9 & 7 & & & 1.7 & 7 \\
\hline Total & 100.0 & 363 & 100.0 & 61 & 100.0 & 424
\end{tabular}

Approximately 88 percent and 87 percent of the pregnancies in rural and urban Khanewal respectively resulted in live births. Spontaneous abortions amounted to 6 percent in rural areas and almost 10 percent in urban areas. 
Figure 7.9: $\quad$ Percentage of pregnancies by outcome and place of residence

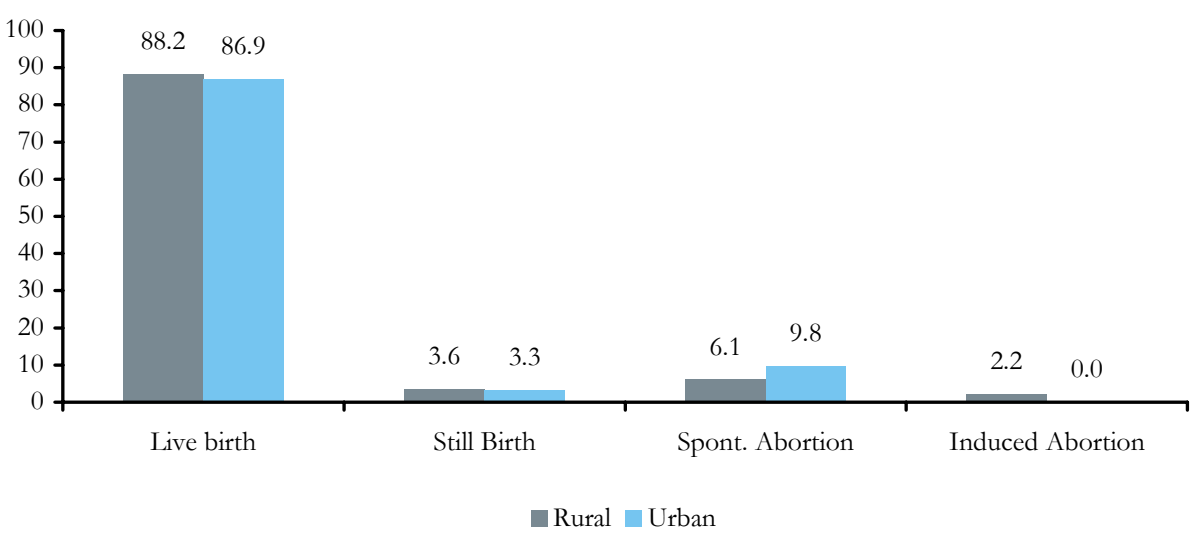

\section{Place of Delivery}

About 74 percent of the births in rural areas and nearly 62 percent in urban Khanewal took place at home. About 38 percent of the urban women used the public/private hospitals for their delivery compared to 25 percent in rural areas. In urban areas more than 27 percent of the deliveries were conducted at private hospitals/clinics compared to 18 percent in rural areas.

Figure 7.10: $\quad$ Percentage of women by place of delivery

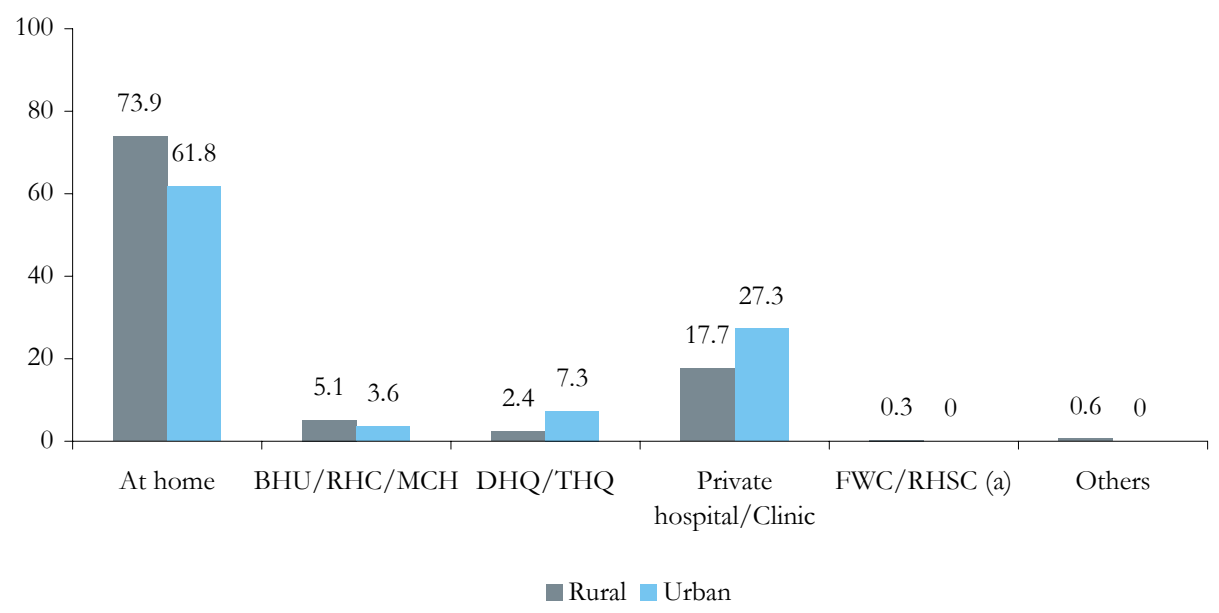




\section{Assistance during Delivery}

TBAs assisted approximately 90 percent of all deliveries which took place at home in the district of Khanewal, while about 5.7 percent were assisted by a nurse or lady health visitor (LHV). The percentage of births attended by a doctor were minimal, sitting at around 1.1 percent.

Figure 7.11: $\quad$ Percentage of married women by delivery attendant

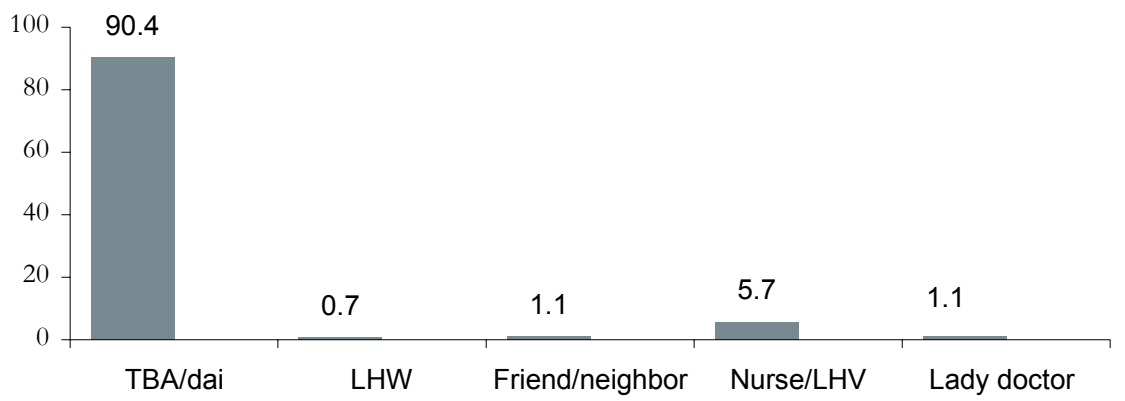

About 61 percent of the women indicated that earlier use of the TBA was the main reason for choosing a TBA to assist with the most recent delivery. Just over 20 percent cited family choice as being the main reason, followed by 8.7 percent who claimed geographical proximity was the deciding factor. Finally, 7.5 percent of the respondents who opted for TBAs/Dai did so as they believed TBAs/Dais were more knowledgeable than health professionals.

Figure 7.12: $\quad$ Main reason to choose a dai as delivery attendant

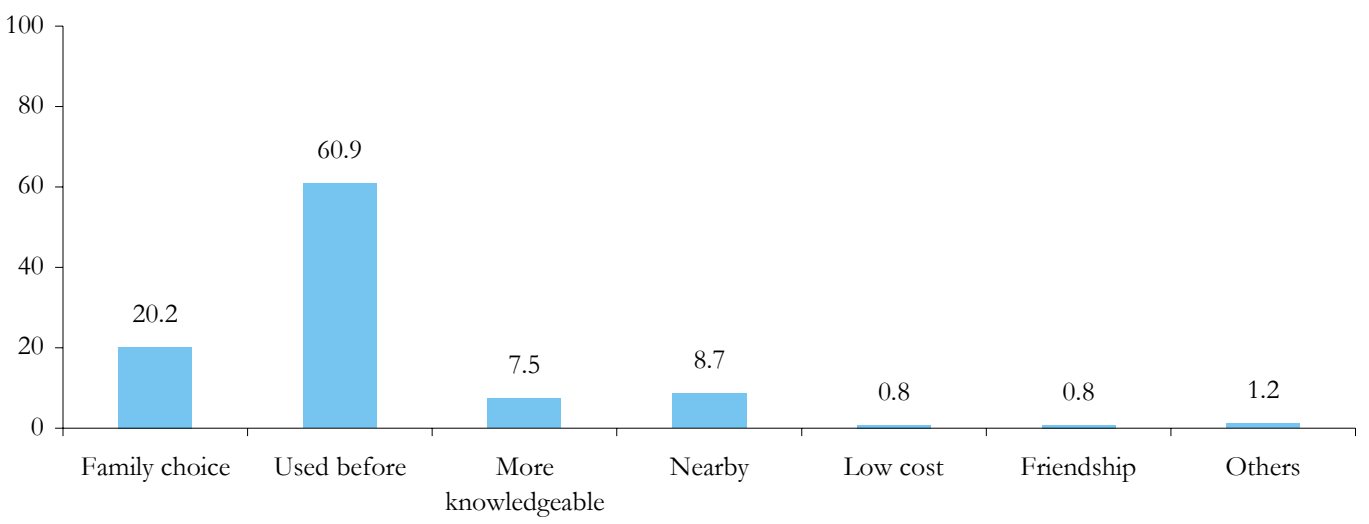




\section{Clean Delivery Practices}

Respondents were asked if the TBA followed safe health practices such as washing her hands with soap prior to the delivery and using clean delivery kits. About 93 percent of the respondents in rural areas and 91 percent in urban areas indicated that the TBAs who assisted with the delivery washed their hands. Similarly 86 percent in rural and 85 percent respondents in urban Khanewal indicated that their birth attendant used new thread to tie the cord.

Figure 7.13: $\quad$ Percentage of delivery attendants who reported washed hands before conducting the delivery and type of thread used to tie the cord

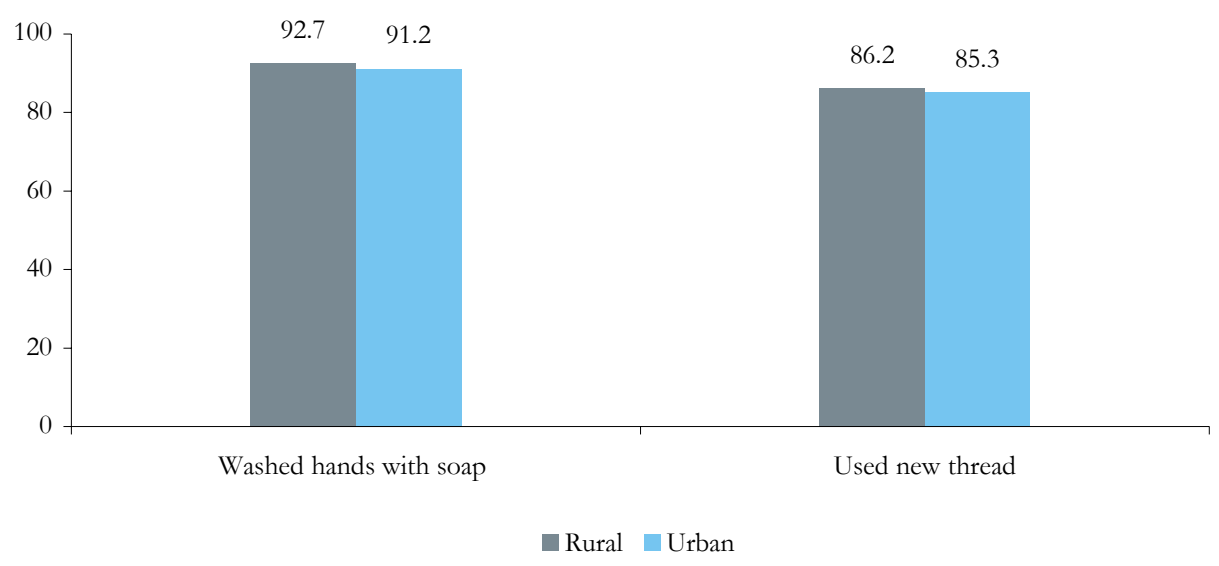

Approximately 44 percent of the respondents in both urban and rural areas indicated that a new blade was used to cut the cord after delivery. Scissors/knives were the next most widely used instruments as cited by 40 percent and 44 percent of the rural and urban respondents respectively.

Figure 7.14: $\quad$ Percentage of delivery attendants who reported instruments for cutting the cord

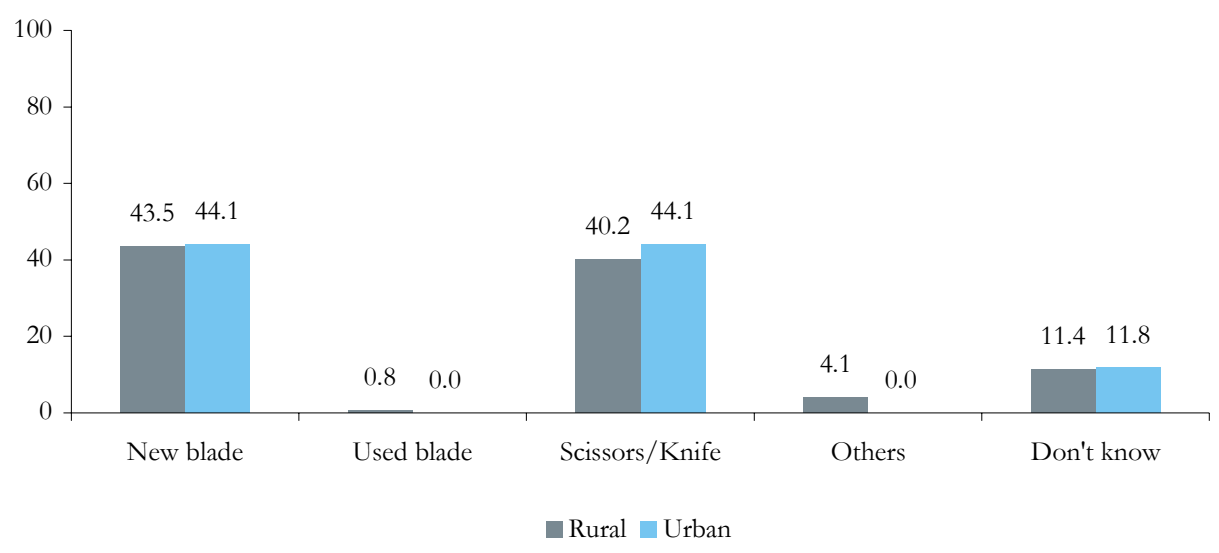




\section{Complications during Childbirth}

Common complications arising during childbirth were also discussed with the respondents. When asked about the complications they had experienced during their last delivery, 10.4 percent mentioned going through excruciating abnormal pain, followed by 8.9 percent who suffered from prolonged/obstructed labor, and 8 percent who had premature rupture of membranes.

Table 7.4: $\quad$ Experienced complications during last delivery by Place of Residence

\begin{tabular}{lcccc}
\multicolumn{1}{c}{ Complications } & Rural & Urban & \multicolumn{2}{c}{ Total } \\
\hline Prolonged/obstructed labor & 9.3 & 6.6 & 8.9 & 38 \\
\hline Bleeding before labor began & 3.0 & & 2.6 & 11 \\
\hline Excruciating abnormal pain & 10.7 & 8.2 & 10.4 & 44 \\
\hline Premature rupture of membranes & 8.8 & 3.3 & 8.0 & 34 \\
\hline Delay in delivery of placenta/retained placenta & 2.5 & 1.6 & 2.4 & 10 \\
\hline $\begin{array}{l}\text { Excessively postpartum bleeding on day of } \\
\text { delivery/abortion }\end{array}$ & 1.9 & 3.3 & 2.1 & 9 \\
\hline Tear in vagina, cervix or uterus & 1.4 & 1.6 & 1.4 & 6 \\
\hline Prolapsed of the uterus & 1.4 & 1.6 & 1.4 & 6 \\
\hline Fever & 2.5 & & 2.1 & 9 \\
\hline Abnormal position fetus & 5.5 & 6.6 & 5.6 & 24
\end{tabular}

\section{Decision Making Within Family}

Delays in seeking care, in reaching adequate health facilities, and in receiving appropriate care at health facilities are recognized barriers to care for pregnant women. These factors may be especially pronounced for young and older pregnant mothers. Timely and appropriate care provides an opportunity to prevent or manage the direct causes of maternal mortality such as, hemorrhage, obstructed labor, infection and hypertensive disorders. It also reduces fetal and neonatal deaths related to obstetric complications. 
Table 7.5:

Measures taken to address complications by place of residence

\begin{tabular}{|c|c|c|c|c|c|c|c|}
\hline \multirow{2}{*}{\multicolumn{2}{|c|}{ Measures taken }} & \multicolumn{2}{|c|}{ Rural } & \multicolumn{2}{|c|}{ Urban } & \multicolumn{2}{|c|}{ Total } \\
\hline & & Percent & Number & Percent & Number & Percent & Number \\
\hline \multirow{6}{*}{$\begin{array}{l}\text { Person who } \\
\text { made decision } \\
\text { to seek health } \\
\text { care }\end{array}$} & Self & 3.8 & 3 & 8.3 & 1 & 4.4 & 4 \\
\hline & Husband & 32.1 & 25 & 16.7 & 2 & 30.0 & 27 \\
\hline & Mother in law & 14.1 & 11 & 8.3 & 1 & 13.3 & 12 \\
\hline & Other family member & 24.4 & 19 & 16.7 & 2 & 23.3 & 21 \\
\hline & TBA/Dai & 23.1 & 18 & 50.0 & 6 & 26.7 & 24 \\
\hline & Others & 2.6 & 2 & 0.0 & 0 & 2.2 & 2 \\
\hline \multirow{6}{*}{$\begin{array}{l}\text { Mode of } \\
\text { transport to } \\
\text { reach health } \\
\text { care service }\end{array}$} & $\begin{array}{l}\text { Service provider visited at } \\
\text { home }\end{array}$ & 28.2 & 22 & 50.0 & 6 & 31.1 & 28 \\
\hline & On foot & 0.0 & 0 & 16.7 & 2 & 2.2 & 2 \\
\hline & Own transport & 17.9 & 14 & 16.7 & 2 & 17.8 & 16 \\
\hline & Private transport & 47.4 & 37 & 16.7 & 2 & 43.3 & 39 \\
\hline & Community transport & 2.6 & 2 & 0.0 & 0 & 2.2 & 2 \\
\hline & Others & 3.8 & 3 & 0.0 & 0 & 3.3 & 3 \\
\hline
\end{tabular}

According to table 7.5, About 30 percent indicated that the husband was the one who made important decisions regarding complications during delivery, followed by 13.3 percent who cited mothers in law as being the main decision maker regarding pregnancy- related health care. A comparison of the rural and urban parts of the district shows that the family is more dominant in making decisions in rural areas. Similarly more urban women ( 8.3 percent) had a say in deciding when to seek health care compared to women in rural areas (3.8 percent).

\section{Availability of Transport}

Timely access to health services is as important as the quality of health service itself. Out of the 69 percent of respondents in Khanewal who went to a hospital, a clinic or any other health service for delivery, 18 percent indicated using their own transport, 43 percent used a private transport facility and only 2.2 percent used community transport.

Whatever the mode of transport pregnant women used, 20 percent of the pregnant women were able to reach a health facility within 15 minutes. Another 49 percent reached a facility between 16-30 minutes, while 22 percent of the pregnant women reached a health facility within 31-60 minutes. A further 2 percent took more than two hours to reach a facility at the time of delivery. Figure 7.15 shows the distribution of respondents by the time they took to reach the facility. 
Figure: 7.15: $\quad$ Time taken to reach the health facility for childbirth

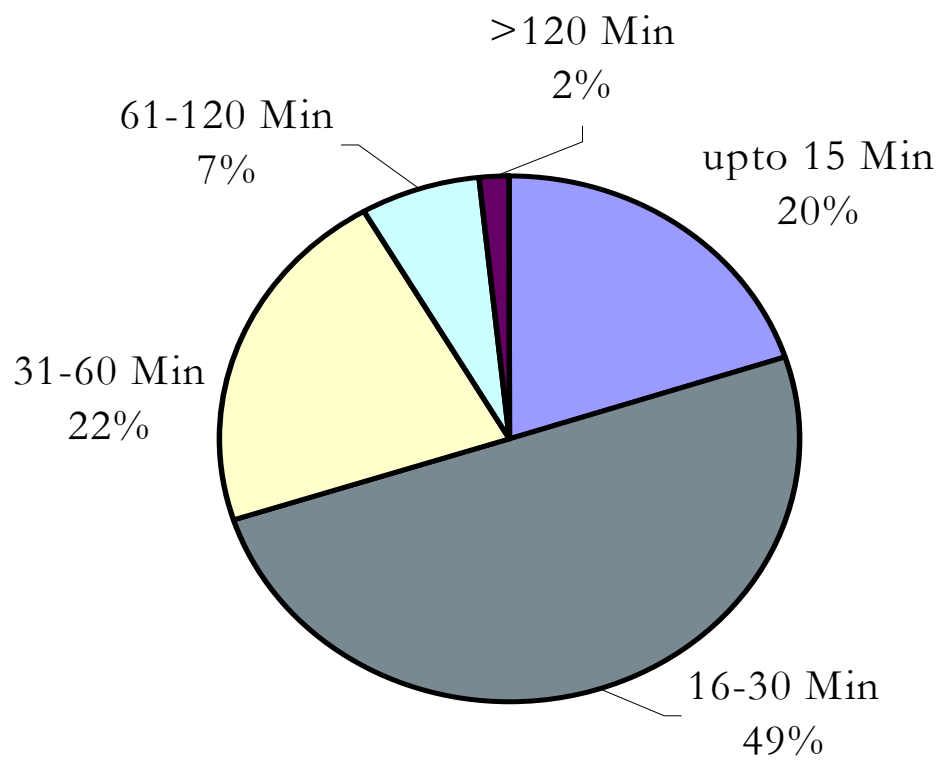

Figure 7.16: $\quad$ Median time taken to find the transport, reach the hospital and obtain services

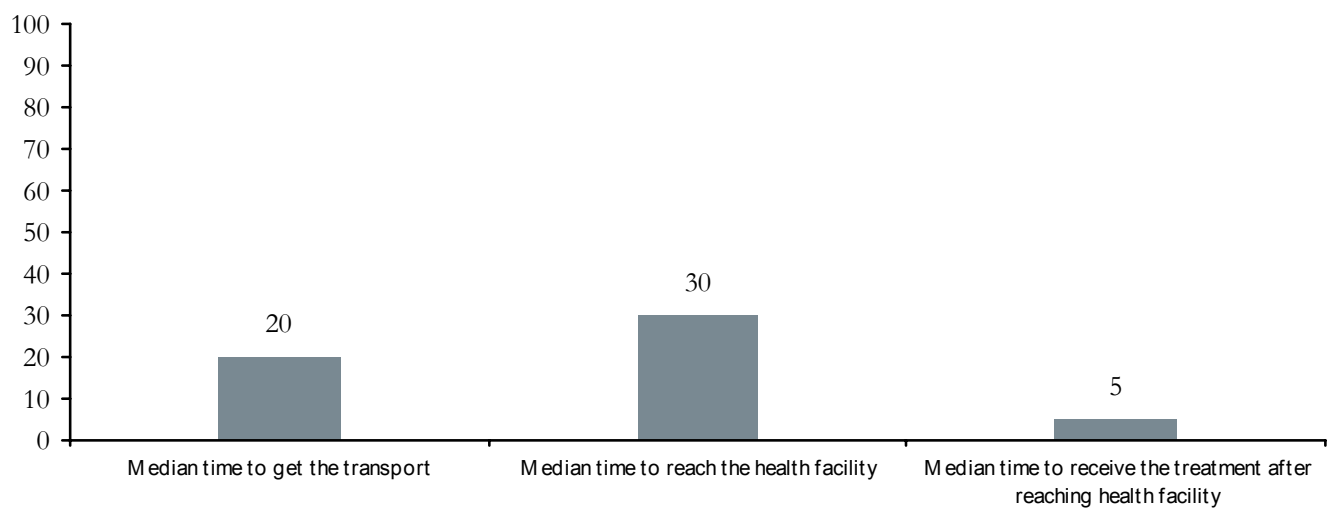

Figure 7.16 depicts the median time taken to find transport, reach a health facility, and obtain services upon arrival at the facility. Overall, it took approximately 20 minutes to find transport, and almost 30 minutes of traveling to reach a health facility at the time of delivery. Upon arrival at the health facility, it took an average of 5 minutes to obtain delivery services. The overall median time taken from getting transport to obtaining delivery services at a health facility was one hour (time indicated by respondents ranged from 45 minutes to 3.5 hours). 


\section{Postpartum Care}

The postpartum period is the period immediately following delivery, and is a critical time for both the mother and the newborn. Some health professionals refer to the postpartum period as the "fourth trimester".

Table 7.6: $\quad$ History of postpartum care by place of residence

\begin{tabular}{|c|c|c|c|c|c|c|c|}
\hline \multirow{2}{*}{ History } & & \multicolumn{2}{|c|}{ Rural } & \multicolumn{2}{|c|}{ Urban } & \multicolumn{2}{|c|}{ Total } \\
\hline & & Percent & Number & Percent & Number & Percent & Number \\
\hline \multirow{3}{*}{ Have a postnatal check-up } & Yes & 9.6 & 32 & 16.7 & 9 & 10.6 & 41 \\
\hline & No & 76.9 & 256 & 68.5 & 37 & 75.7 & 293 \\
\hline & $\begin{array}{l}\text { Delivered } \\
\text { in hospital }\end{array}$ & 13.5 & 45 & 14.8 & 8 & 13.7 & 53 \\
\hline $\begin{array}{l}\text { No. of days after delivery, } \\
\text { have first check-up }\end{array}$ & Same day & 6.3 & 2 & 44.4 & 4 & 14.6 & 6 \\
\hline \multirow{2}{*}{$\begin{array}{l}\text { Experienced complications } \\
\text { during postpartum period }\end{array}$} & Yes & 20.7 & 75 & 21.3 & 13 & 20.8 & 88 \\
\hline & No & 79.3 & 288 & 78.7 & 48 & 79.2 & 336 \\
\hline Total & & 100.0 & 363 & 100.0 & 61 & 100.0 & 424 \\
\hline
\end{tabular}

Respondents were asked if they had received a postnatal check-up after their last delivery. Among the 85 percent of the respondents who had delivered at home, three quarters ( 76 percent) did not receive any postnatal checkup in both rural and urban parts of Khanewal. Out of those who delivered at home and had a postnatal check-up, only 14.6 percent had it on the same day as the delivery. Furthermore, 21 percent in both rural and urban parts of Khanewal had experienced complications during the postpartum period.

\section{Newborn/Infant Care}

The care provided to a newborn upon birth is crucial to the baby's health. Survey questions regarding initial infant and child care help determine the cause of newborn morbidity and mortality.

\section{Child Care During Birth}

Respondents were asked where the newborn was placed immediately after delivery. The majority (45 percent) reported putting the baby next to the mother, followed by those who put the baby on a piece of cloth (34.3 percent), while others put the baby on a mattress (11.5 percent). When asked whether the child was dried up/cleaned before being given a bath, 93 percent responded in the affirmative. 
Table 7.7:

History of last child care by place of residence

\begin{tabular}{llrrrrrrr} 
& & \multicolumn{2}{c}{ Rural } & \multicolumn{2}{c}{ Urban } & \multicolumn{2}{c}{ Total } \\
\cline { 3 - 8 } & History & Percent & Number & Percent & Number & Percent & Number \\
& On floor & 3.1 & 10 & & & 2.7 & 10 \\
\cline { 2 - 8 } & On mattress & 11.9 & 38 & 9.4 & 5 & 11.5 & 43 \\
\cline { 2 - 8 } $\begin{array}{l}\text { Placed child } \\
\begin{array}{l}\text { immediately } \\
\text { after delivery }\end{array}\end{array}$ & $\begin{array}{l}\text { On a piece of } \\
\text { cloth }\end{array}$ & 33.8 & 108 & 37.7 & 20 & 34.3 & 128 \\
\cline { 2 - 8 } & $\begin{array}{l}\text { Put with the } \\
\text { mother }\end{array}$ & 44.7 & 143 & 45.3 & 24 & 44.8 & 167 \\
\cline { 2 - 8 } & Others & 3.4 & 11 & 1.9 & 1 & 3.2 & 12 \\
\cline { 2 - 8 } & Don't know & 3.1 & 10 & 5.7 & 3 & 3.5 & 13 \\
\hline $\begin{array}{l}\text { Child dried } \\
\text { up/cleaned } \\
\text { before giving } \\
\text { bath }\end{array}$ & Yes & 93.8 & 300 & 88.7 & 47 & 93.0 & 347 \\
\cline { 2 - 8 } & No & 0.9 & 3 & & & 0.8 & 3 \\
\hline
\end{tabular}

Figure 7.17 shows the distribution of size of the babies at birth. It shows that 76 percent of the newborns were of normal size whereas 15 percent were smaller and 8 percent were bigger than average. Respondents were also asked to indicate when they first bathed their newborn. Figure 7.18 shows that only 11 percent of the babies were given a bath after the recommended period of 6 hours following birth. It also shows that 84 percent of the babies were given a bath within the first hour of birth. Figure 7.18 shows the distribution of babies by their bath time after the delivery.

Figure 7.17: $\quad$ Percentage of live births by their size (small, normal and big) at birth

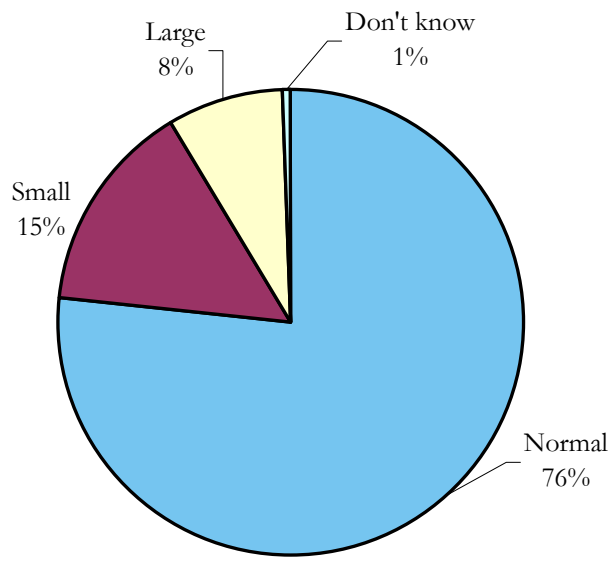


Figure 7.18: Percentage of babies by time of given bath after birth

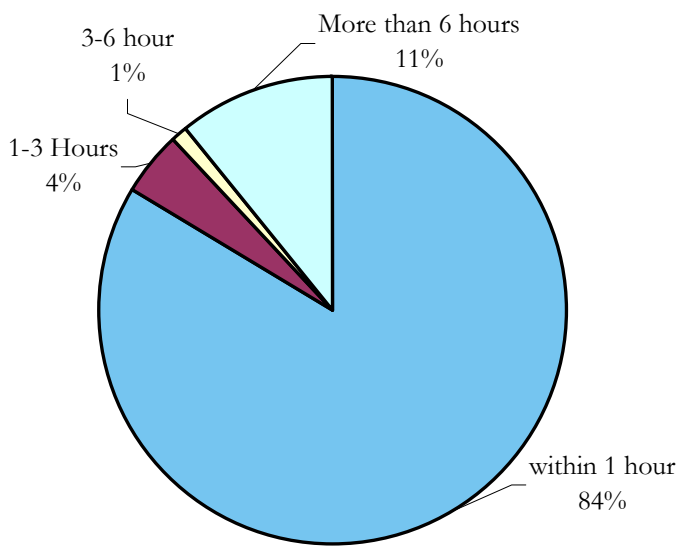

\section{Colostrum and Breastfeeding}

Respondents were asked whether they had given colostrums to their newborns soon after the birth and if they had given anything else other than breast milk during the first three days following birth and if anyone had medically/physically examined the child after birth.

About 76 percent of the respondents in urban areas and 57 percent in rural parts of Khanewal had fed their newborns colostrums. Approximately 81 percent of the newborns in urban areas and 71 percent in rural areas were exclusively breastfed for the initial three days following birth. According to figure $7.19,49$ percent of the newborns in urban areas and only 30 percent in rural parts of Khanewal were medically/physically examined after birth.

Figure 7.19: $\quad$ Newborn feeding and health indicators

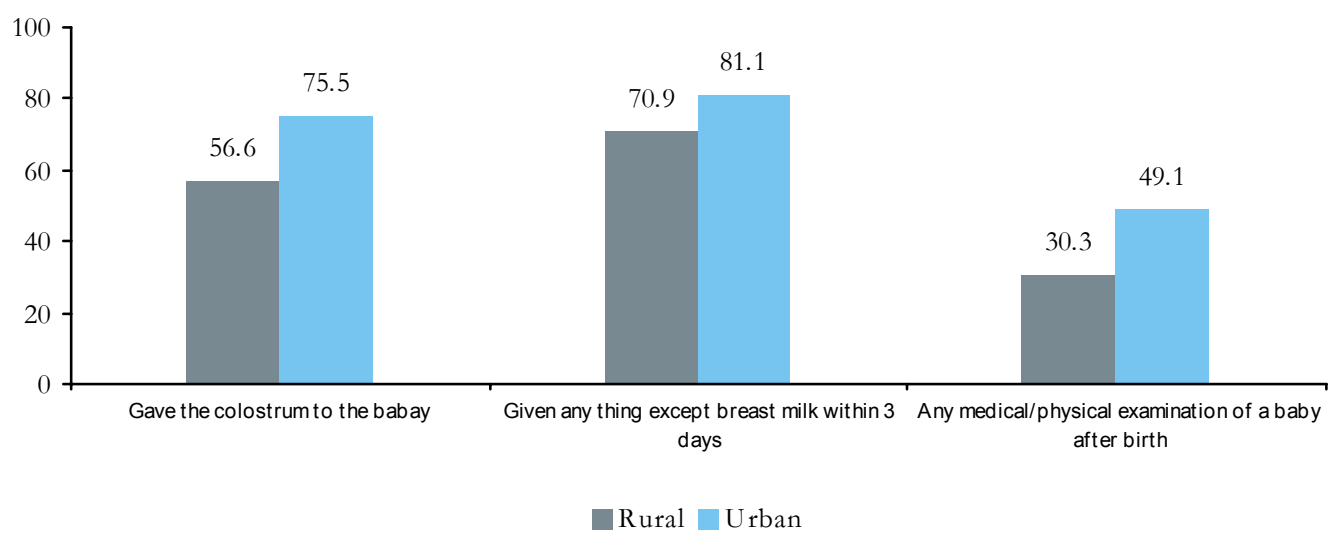




\section{Newborn Medical Check-ups}

Respondents were also asked about the signs and symptoms that appeared in their newborn within an hour of their birth. Some of the commonly reported signs and symptoms by women in urban parts of the district were "weak cry" ( 9.8 percent), "difficulty in breathing" (6.6 percent), "blue skin color" (5 percent), "shivering" and "poor suckling" (1.6 percent). According to figure 7.20, widely reported symptoms in rural areas were "difficulty breathing" (5.2 percent), "weak cry" (3.3 percent) and "shivering" (2.7 percent).

The respondents were also asked to indicate danger signs and symptoms which appeared in their newborns within the first seven days following birth (Figure 7.21).

Figure 7.20: $\quad$ Percentage of newborns with appeared signs/symptoms soon after deliver by place of residence

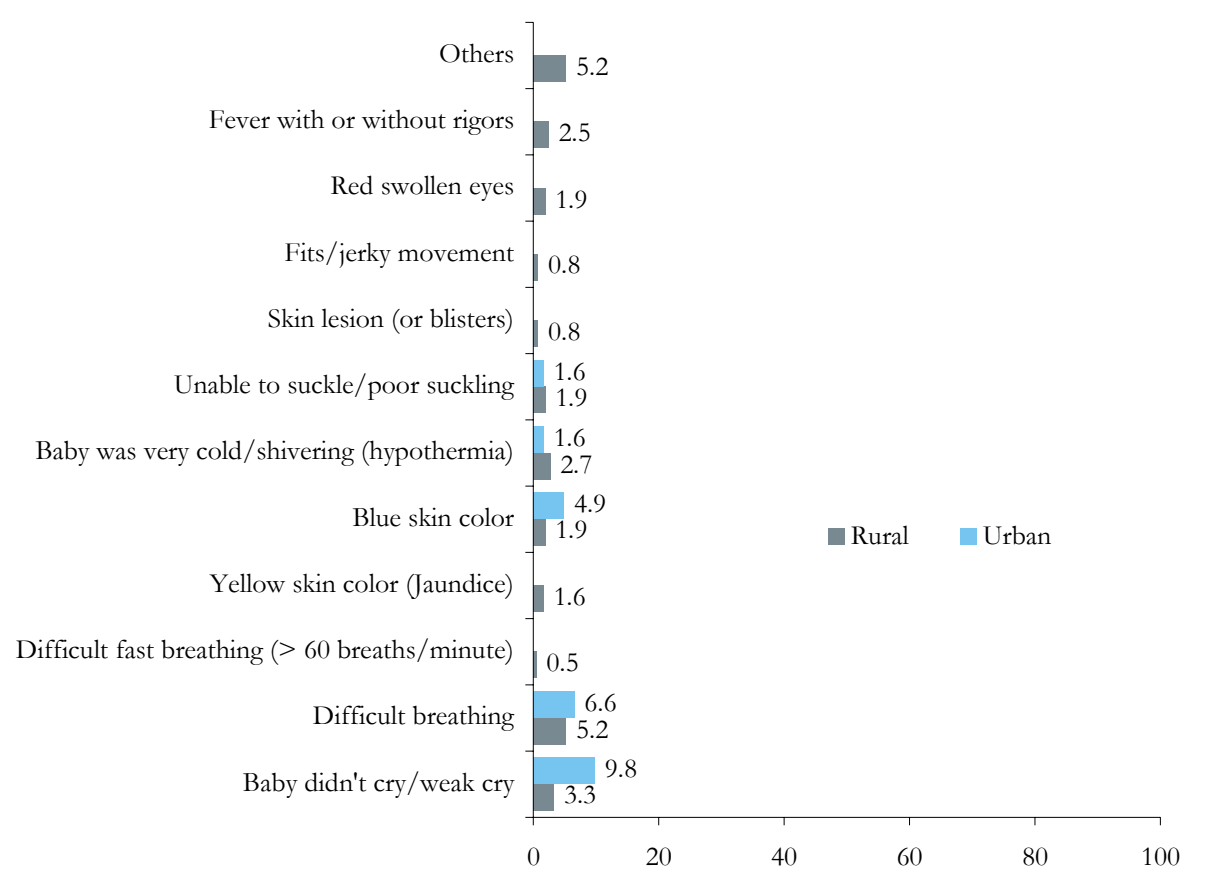


Figure 7.21: $\quad$ Percentage of newborns with appeared signs/symptoms within 7-days after last delivery by place of residence

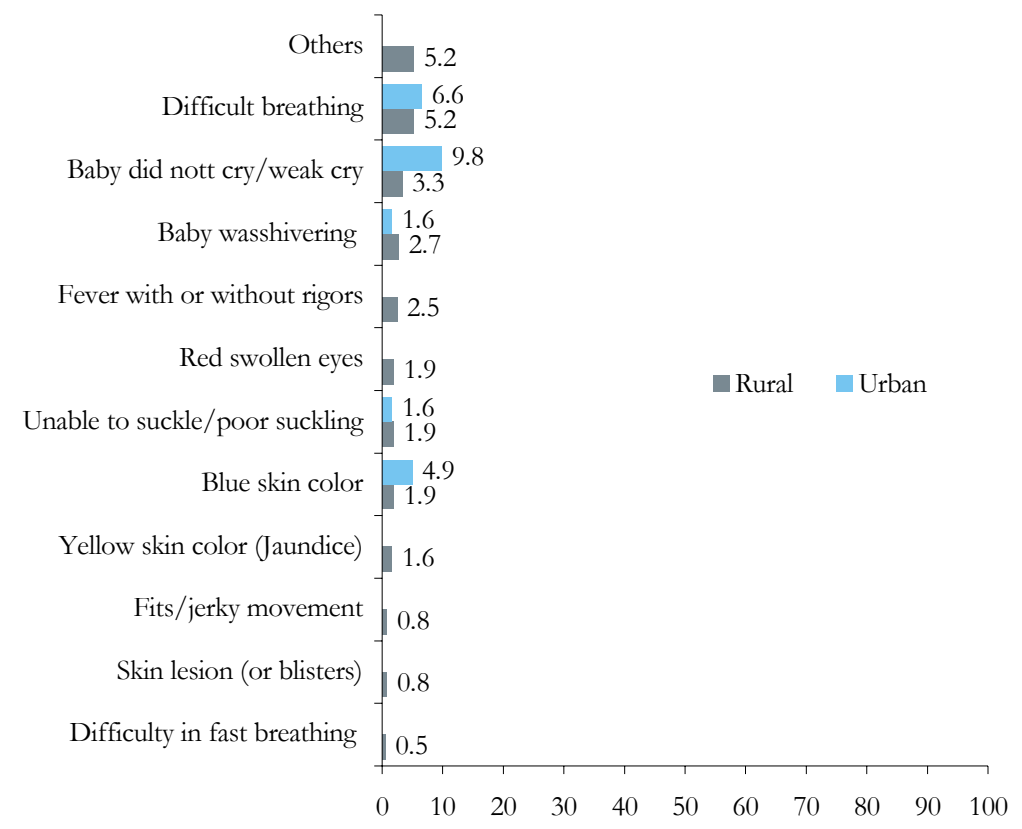

Respondents were asked to indicate the treatment they sought after observing the danger signs in their newborns. Approximately 73 percent of the respondents in urban areas and 41 percent in rural parts of Khanewal reported going to a private hospital or clinic. Shockingly, 20 percent of the rural respondents sought no treatment at all.

Figure 7.22: $\quad$ Percentage of newborn with measures taken to have complications treated by place of residence

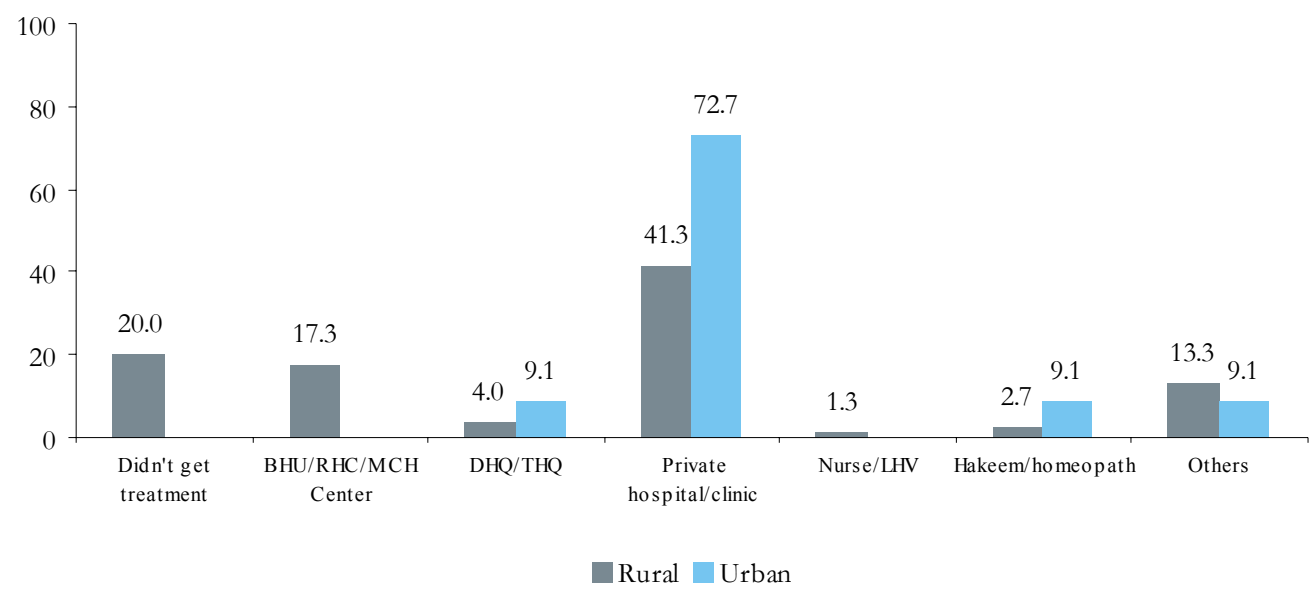


Figure 7.23: $\quad$ Status of last live birth

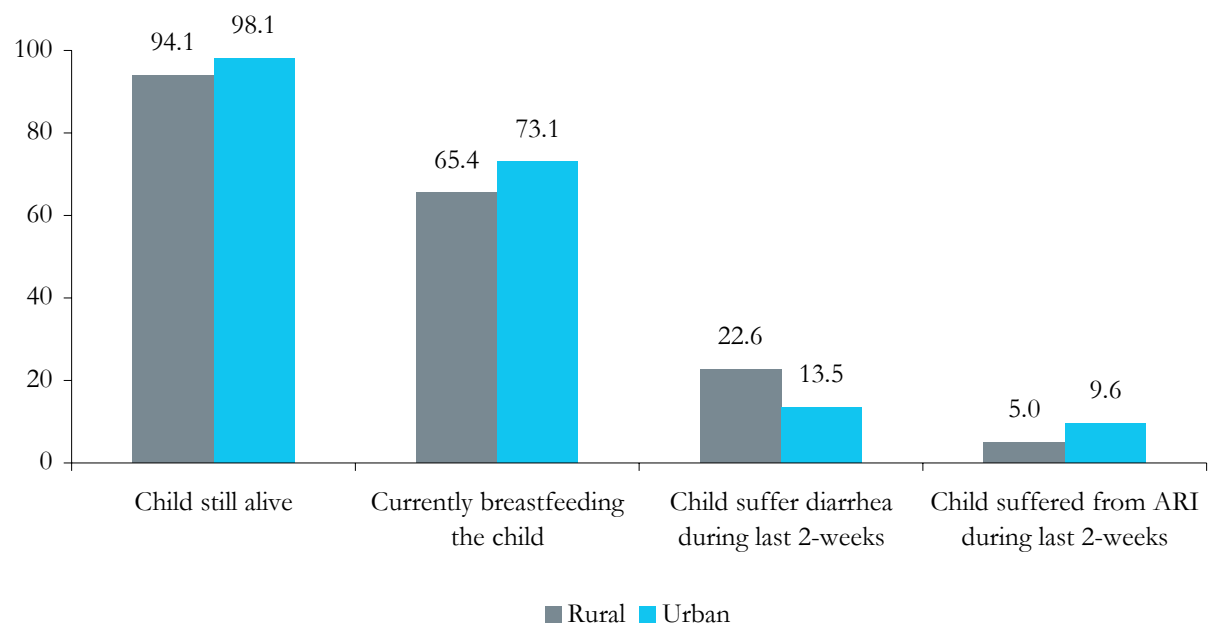

Finally, when respondents were asked to indicate the status of health of their last child, 98 percent in urban areas and 94 percent in rural parts reported that their child was still alive. Another 73 percent and 65 percent of the women in urban and rural Khanewal respectively were breastfeeding their child at the time of the baseline survey. About 13 percent of the respondents in urban areas and 23 percent in rural areas reported that their child suffered from diarrhea during the last two weeks preceding the baseline survey. Acute Respiratory Infection (ARI) was also reported by 5 percent of the respondents in rural areas and almost 10 percent of the respondents in urban parts of the district. 



\section{Chapter \\ 8}

\section{Conclusions}

According to the baseline, not everyone in rural and urban parts of Khanewal district has access to basic necessities like clean drinking water, sanitation facilities and natural gas for cooking. Ownership of various household items including a television, radio, fridge, VCR, iron, air-conditioner, car etc, is more common in urban areas although rural areas are not altogether deprived of such things.

The basic background characteristics of the study population in the district (all currently married women of reproductive age 15-49 years) indicate that almost 41 percent of the population is between 25-34 years of age, and the majority ( 93 percent) married by the age of 24 years. In regards to educational status of currently married women, only 34 percent are literate, out of which only 16 percent have been educated up to the middle level or higher. There is not much difference in the figures of children ever born and mean number of children for rural and urban parts.

The percentage of women who reported having access to media was higher in urban areas (58.4 percent) than rural areas (38 percent). Even though television and radio were reported to have about the same level of influence on the health behaviors of people, 50 percent considered TV to be the most trustworthy source, followed by radio ( 8.5 percent) and newspaper ( 3.1 percent). Out of the total TV viewers, 94.4 percent of women in Khanewal reported watching TV in their homes and 50.2 percent watched it on a daily basis.

A very high percentage in both rural parts (82.4 percent) and urban parts (85.4 percent) of Khanewal indicated the importance of antenatal check-ups during pregnancy. Out of the 82.8 percent of respondents who were in favor of antenatal checkups, the highest percentage (38 percent) believed that a woman should go for check-ups only when needed. About 17.9 percent believed that a woman should seek antenatal care in her third month of pregnancy. Almost three quarters of the women (74.3 percent) in Khanewal recognized the importance of Tetanus Toxoid (TT) shots during pregnancy.

When asked if a woman should receive delivery services from a trained health provider, 85 percent of the respondents in both rural and urban Khanewal responded positively. However, the majority of the respondents in rural (57.6 percent) and urban (59.1 percent) areas said that only some women in their respective communities received delivery services from trained health providers. Only 41 percent in urban and 34 percent in rural considered a hospital the appropriate place for delivery.

It may be noted here that though a very high percentage of women $(85$ percent in both rural and urban areas) in Khanewal want to receive the services of a trained health provider many of them still deliver at home. 
Married women often undervalue the importance of postnatal care. When asked whether a woman needed a postnatal checkup or not, 43 percent in both urban and rural did not consider it important.

Information was gathered on each respondent's last pregnancy, given that it was within the past three years. Respondents were asked several questions regarding their experiences during their last pregnancy including antenatal and delivery care, complications during pregnancy and delivery, postnatal care and problems in accessing health care. According to results, out of the total pregnancies reported, 88.2 percent resulted in live births, 3.5 percent in stillbirths, and 8.3 percent in abortions (both spontaneous and induced). About 75 percent of the spontaneous abortions and all of the induced abortions took place in the first trimester of pregnancy.

A high percentage of respondents (18.6 percent) who had antenatal check-ups went for their first one during the seventh month of pregnancy. Only 4 percent of the respondents in Khanewal had nine antenatal check-ups during their last pregnancy. Approximately 42 percent of the women who had gone for an antenatal visit during their last pregnancy, were accompanied by their husbands followed by 15 percent who were accompanied by their mothers in law.

As in the case of pregnancy, many women are not aware of the complications that may arise during delivery. Only 7.8 percent of the respondents in rural areas and 12.4 percent in urban Khanewal were able to name three or more danger signs during delivery. Deliveries can only be made safe if married women are educated regarding the danger signs during the delivery, therefore enabling them to decide when to seek treatment. Innovative approaches are therefore needed to make these communities more aware of issues regarding maternal and newborn health. According to the findings, heavy vaginal bleeding was the most highly reported danger sign during postpartum complications by 58.8 percent of urban respondents and 39 percent of rural respondents. More than half of urban respondents (54.7 percent) and 27.3 percent of rural respondents reported high fever with or without rigors as a danger sign as well.

Nearly 92 percent of the respondents in rural areas and 91 percent in urban Khanewal indicated that the TBAs who assisted with their deliveries washed their hands and used clean delivery kits as well. Furthermore, approximately 43 percent of the respondents in both urban and rural Khanewal indicated that their TBA used a new blade for cutting the cord. About 10.4 percent of the respondents mentioned suffering excruciating abnormal pain, followed by 8.9 percent who suffered from prolonged/obstructed labor, and 8 percent who had premature rupture of membranes.

According to 66 percent of the respondents, families were the main decision makers when it came to obtaining health care for pregnant women, followed by 30 percent who indicated that the husbands of women made such decisions. Finally, 13 percent cited mothers in law as the main decision maker regarding the health of an expectant mother. However, a comparison between rural and urban parts of the district shows that families play a more dominant role in the decision making process in rural areas.

Of the 85 percent of the respondents who delivered at home, more than three quarters (76 percent) did not have any postnatal check-ups. Out of those who delivered at home and had a postnatal checkup, only 14.6 percent had it on the same day as their delivery. Furthermore, 21 percent of the respondents in both rural and urban parts of Khanewal experienced complications during the postpartum period. About 75 percent of the respondents in urban areas and 56.6 percent in rural parts of Khanewal fed their newborns colostrums. As well, 81 percent and 71 percent of the newborns in 
urban and rural respectively were exclusively breastfed for the initial three days after birth. About 49 percent of the newborns in urban areas and 30 percent in rural areas of Khanewal were medically/physically examined after birth.

The various sections of the survey allow for a comprehensive analysis of all areas concerned with maternal and infant health and well being. The separation of rural and urban areas makes it easier to compare results and analyze the reasons for these differences. The indicators obtained will be used to monitor and evaluate the success of the project upon completion. 


\section{References}

Caldwell, J., Routes to Low Mortality in Poor Countries. Population and Development Review, Vol. 12, No. 2. (Jun., 1986), pp. 171-220.

Federal Bureau of Statistics, "Socio-Economic Indicators at District Level, Punjab," Statistics Division, Government of Pakistan, (2002).

Hollander, D., Antenatal Education Helps Turkish Women Adopt Health-Promoting Behaviour. International Family Planning Perspectives, Vol. 30, No. 1. (Mar., 2004), pp. 45-46.

JHPIEGO/Maternal and Neonatal Health Program, "Monitoring Birth Preparedness and Complication Readiness: Tools and Indicators for Maternal and Newborn Health,” (2004).

Mahmood, Arshad, Determinants of Neonatal and Post-Neonatal Mortality in Pakistan. The Pakistan Development Review, Vol. 41, No. 4, Part II (Winter 2002), pp. 723-744.

Mahmood, Arshad, Socioeconomic Factors, Personal Illness Control and Infant and Child Mortality in Pakistan. Pakistan Population Review, Vol. 3, No. 1 (1992), pp 67-86.

Martin, Linda G.; J. Trussell; Florentina Reyes Salvail; Nasra M. Shah, Co-variates of Child Mortality in the Philippines, Indonesia, and Pakistan: An Analysis Based on Hazard Models. Population Studies, Vol. 37, No. 3. (Nov., 1983), pp. 417-432.

Nawaz, Shuja, The Mass Media and Development in Pakistan. Asian Survey, Vol. 23, No. 8. (Aug., 1983), pp. 934-957.

Ringheim, Karin, When the Client is Male: Client-Provider Interaction from a Gender Perspective, International Family Planning Perspectives, Vol. 28, No. 3 (Sept., 2002), pp. 170-175.

Robbins, P.T., Global Approaches to Development. Sociology of Development, University of London, (2001), pp. 29-37.

Sathar, Zeba; Nigel Crook; Christine Callum; Shahnaz Kazi, Women's Status and Fertility Change in Pakistan. Population and Development Review, Vol. 14, No. 3. (Sep., 1988), pp. $415-$ 432.

Simmons, George B., Family Planning Programs or Development: How Persuasive is the New Wisdom? International Family Planning Perspectives, Vol. 5, No. 3. (Sep., 1979), pp. 101-110.

Syed, Sabiha H., Communications Channels and Family Planning in Pakistan. Studies in Family Planning, Vol. 10, No. 2. (Feb., 1979), pp. 53-60.

www.unesco.org 